Carolina Santos Brandão

Desempenho dos Modelos APT e CAPM no Mercado Acionário Brasileiro

Dissertação de Mestrado

Dissertação apresentada como requisito parcial para obtenção do título de Mestre pelo Programa de PósGraduação em Engenharia de Produção da PUCRio.

Orientador: Prof. Carlos Patricio Samanez 


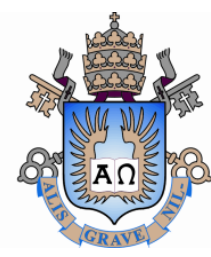

Carolina Santos Brandão

\title{
Desempenho dos Modelos APT e CAPM no Mercado \\ Acionário Brasileiro
}

\begin{abstract}
Dissertação apresentada como requisito parcial para obtenção do título de Mestre pelo Programa de Pós-Graduação em Engenharia de Produção da PUC-Rio. Aprovada pela Comissão Examinadora abaixo assinada.
\end{abstract}

Prof. Carlos Patricio Samanez

Orientador

Departamento de Engenharia Industrial PUC-Rio

Prof. Antônio Carlos Gonçalves Universidade Federal Rural do Rio de Janeiro; UFRRJ

Prof. Letícia de Almeida Costa Departamento de Engenharia Industrial PUC-Rio

Prof. Paulo Henrique Soto Costa Universidade do Estado do Rio de Janeiro; UERJ

Prof. José Eugenio Leal Coordenador(a) Setorial do Centro Técnico Científico - PUC-Rio 
Todos os direitos reservados. É proibida a reprodução total ou parcial do trabalho sem autorização da universidade, da autora e do orientador.

Carolina Santos Brandão

Graduou-se em Ciências Econômicas pela Pontifícia Universidade Católica do Rio de Janeiro em 2003. Completou o CFA Program em 2006. Atuou como relações com investidores, analista de renda variável e private equity.

Ficha Catalográfica

Brandão, Carolina Santos

Desempenho dos modelos APT e CAPM no mercado acionário brasileiro / Carolina Santos Brandão ; orientador: Carlos Patrício Samarez. 2013.

82 f. ; $30 \mathrm{~cm}$

Dissertação (mestrado)-Pontifícia Universidade Católica do Rio de Janeiro, Departamento de Engenharia Industrial, 2013.

Inclui bibliografia

1. Engenharia Industrial - Teses. 2. APT. 3. Modelo de arbitragem. 4. CAPM. 5. Modelo de três fatores de Fama e French. 6. Fama e French. 7. APT unificado ao CAPM. 8. Wei. I. Samarez, Carlos Patrício. II. Pontifícia Universidade Católica do Rio de Janeiro. Departamento de Engenharia Industrial. III. Título. 
Aos meus pais. 


\section{Agradecimentos}

Ao meu marido Marcio pelo apoio.

Aos meus filhos pela motivação e inspiração.

À CAPES e à PUC-Rio pelos auxílios concedidos. 


\section{Resumo}

Santos Brandão, Carolina, Patricio Samanez, Carlos. Desempenho dos Modelos APT e CAPM no Mercado Acionário Brasileiro. Rio de Janeiro, 2013. 82p. Dissertação de Mestrado - Departamento de Engenharia Industrial, Pontifícia Universidade Católica do Rio de Janeiro.

A intenção do presente estudo é avaliar o desempenho do mercado acionário brasileiro, no período pós-estabilização econômica, através da utilização dos modelos financeiros APT e CAPM a fim de verificar qual deles é melhor capaz de retratar o desempenho das ações. O modelo CAPM foi comparado a dois modelos APT distintos: o Modelo de Três Fatores de Fama e French, e o Modelo APT Unificado ao CAPM proposto por John Wei, onde foram utilizados fatores macroeconômicos além do fator de mercado. Em todos os modelos o prêmio de risco se mostrou relevante. O Modelo de Três Fatores apresentou melhor capacidade explicativa em relação ao CAPM. Todavia, este modelo apresentou uma anomalia do mercado brasileiro, tendo as empresas de pequeno porte apresentado retornos menores que as empresas grandes. A utilização deste modelo implicaria na crença que esta anomalia irá perdurar no futuro. No modelo APT Unificado ao CAPM não foi possível rejeitar a hipótese da inexistêcia de prêmio de risco de todos fatores simultaneamente. Além disso, o ganho de poder explicativo do modelo quando comparado ao CAPM foi insignificante.

\section{Palavras-chave}

APT; Modelo de Arbitragem; CAPM; Modelo de Três Fatores de Fama e French; Fama e French, APT Unificado ao CAPM; Wei 


\section{Abstract}

Santos Brandão, Carolina, Patricio Samanez, Carlos (Advisor). Performance of APT and CAPM in the Brazilian Stock Market. Rio de Janeiro, 2013. 82p. MSc. Dissertation - Departamento de Engenharia Industrial, Pontifícia Universidade Católica do Rio de Janeiro.

This study analyses the Brazilian stock market after the stabilization of the local economy using the APT and CAPM models to evaluate which of them better reflect stock performance. The CAPM was compared to two different APT models: Fama and French Three Factor Model, and An Asset Pricing Theory Unifying the CAPM and APT as proposed by John Wei based on macroeconomic factors and the market premium. For all models the market premium was a relevant variable. The Fama and French Three Factor Model was superior in explaining stock returns than the CAPM, although the size factor for the Brazilian market had an anomaly behavior: large companies outperformed small companies. The use of this model implies that this anomaly will continue in the future which is against the risk-return theory. For model Unifying the CAPM and APT it was not possible to reject the hypothesis that all variables are statically different than zero simultaneously. The increase in explaining power of the model was marginal compared to the CAPM.

\section{Keywords}

APT; Arbitrage Pricing Model; CAPM; Fama e French Three Factor Model; Fama e French, Unifying the CAPM and APT; Wei 


\section{Sumário}

1 Introdução

2 Apresentação Teórica e Breve Revisão da Literatura 15

2.1. Capital Asset Pricing Model - CAPM 15

2.2. Arbitrage Pricing Theory - APT 18

2.3. O Modelo de Três Fatores 21

2.4. Modelo APT Unificado ao CAPM 24

3 Metodologia e Coleta de Dados 26

3.1. O Modelo de Três Fatores de Fama e French 26

3.2. Modelo APT Unificado ao CAPM 28

3.3. Métodos Estatísticos 30

3.3.1. Teste $t$

3.3.2. Coeficiente de Determinação $-R^{2}$ e $R^{2}$ ajustado 32

3.3.3. Teste $F \quad 32$

3.3.4. Teste Durbin-Watson 33

3.3.5. Teste Jarque-Bera 34

3.3.6. Teste White 35

3.3.7. Variance Inflation Factor (VIF) 35

4 Resultados Empíricos 36

4.1. O Modelo de Três Fatores de Fama e French 36

4.1.1. Dados e Estatísticas 36

4.1.2. Resultado Modelo de Três Fatores 39

4.1.3. Comparação do Modelo de Três Fatores com o CAPM 42

4.2. Modelo APT Unificado ao CAPM 44

4.2.1. Determinação das Variáveis Independentes do Modelo 44

4.2.2. Dados e Estatísiticas 49

4.2.3. Resultado Modelo APT Unificado ao CAPM 51 
4.2.4. Comparação do Modelo APT Unificado ao CAPM com o CAPM

5 Conclusões e Sugestões para Estudos Futuros

6 Referências Bibliográficas

66

6.1. Citadas

66

6.2. Não Citadas

67

7 Anexos 


\section{Lista de tabelas}

Figura 1 - Tangência entre Curvas de Indiferença e

a Fronteira Eficiente de Markowitz

Figura 2 - Tangência entre a Fronteira Eficiente e a CML

Figura 3 - Tangência entre as Curvas de Indiferença e a CML 16

Figura 4 - Security Market Line (SML) 17

Figura 5 - Critério de Avaliação do Teste t e o P-Valor 32

Figura 6 - Processo de Decisão para o Teste Durbin-Watson 34

Tabela 1 - Número de Empresas por Carteira entre 1995-2012 36

Tabela 2 - Valor de Mercado das Carteiras ( $\mathrm{R} \$$ bilhões) entre 1995-2012 36

Tabela 3 - Participação de Mercado por Carteira entre 1995-2012 37

Tabela 4 - Retorno Médio Mensal por Carteira entre 1995-2012 37

Tabela 5 - Correlação das Carteiras Puras $\quad 37$

Tabela 6 - Correlação dos Fatores do Modelo de 3 Fatores 38

Tabela 7 - Variance Inflation Factor para Modelo de Três Fatores 38

Tabela 8 - Retorno Médio Mensal de cada Fator 39

Tabela 9 - Comparação do Retorno Médio Mensal por Fator Calculado em Outros Estudos $\quad 39$

Tabela 10 - Resultado da Regressão para Modelo de Três Fatores $\quad 40$

Tabela 11 - Teste F para o Modelo de Três Fatores 41

Tabela 12 - Teste Durbin-Watson para Modelo Três Fatores 41

Tabela 13 - Teste Jarque-Bera para Modelo Três Fatores 42

Tabela 14 - Teste White para Modelo Três Fatores 42

Tabela 15 - Resultado da Regressão para Modelo CAPM 43

Tabela 16 - Valores Encontrados pelo Modelo CAPM Menos Valores Encontrados pelo Modelo de Três Fatores 43

Tabela 17 - Teste Durbin-Watson para Modelo CAPM 43

Tabela 18 - Teste Jarque-Bera para Modelo CAPM 44

Tabela 19 - Teste White para Modelo CAPM 44

Tabela 20 - Correlação Cruzada das Carteiras com a Variação 
Cambial

Tabela 21 - Correlação Cruzada das Carteiras com a Variação da Taxa Selic

Tabela 22 - Correlação Cruzada das Carteiras com a Variação do Índice de Produção Industrial Dessazonalizado

Tabela 23 - Correlação Entre as Variáveis Independentes Produção Industrial com Lag+2

Tabela 24 - Correlação Entre as Variáveis Independentes Produção Industrial com Lag+4

Tabela 25 - Correlação Entre as Variáveis Independentes Produção Industrial com Lag-4

Figura 7 - Autocorrelação da Variação do IGP-M

Tabela 26 - Correlação Cruzada das Carteiras com a Variação IGP-M

Tabela 28 - Número Médio de Empresas por Carteira 50

Tabela 29 - Retorno Médio Mensal por Ano por Carteira 1 a 10

Tabela 30 - Variação Mensal Média das Variáveis Explicativas por Ano

Tabela 31 - Variance Inflation Factor para Modelo APT Unificado ao CAPM

Tabela 32 - Resultado das Regressões: $R^{2}$ Ajustado e os Coeficientes por Carteira

Tabela 33 - Resultado das Regressões: P-Valor por Coeficiente por Carteira

Figura 8 - Gráficos dos Coeficientes do Modelo APT Unificado ao CAPM por Carteira

Tabela 34 - Teste F para o Modelo APT Unificado ao CAPM

Tabela 35 - Teste Durbin Watson para Modelo APT Unificado ao CAPM

Tabela 36 - Teste Jarque-Bera para Modelo APT Unificado ao CAPM

Tabela 37 - Teste White para Modelo APT Unificado ao CAPM 56

Tabela 38 - Prêmio de Risco para os Fatores Macroeconômicos 
Tabela 39 - Indicadores da Regressão Cross Section do

Modelo APT Unificado ao CAPM

Tabela 40 - Resultado das Regressões Mínimos Quadrados Ponderados: $R^{2}$ Ajustado e os Coeficientes por Carteira 58

Tabela 41 - Resultado das Regressões Mínimos Quadrados

Ponderados: P-Valor por Coeficiente por Carteira

Tabela 42 - Resultado das Regressões: $R^{2}, R^{2}$ Ajustado, Coeficientes

e P-Valor por Carteira para o Modelo CAPM

Tabela 43 - Comparação dos Modelos CAPM e APT Unificado ao CAPM

Tabela 44 - Teste Durbin Watson para o Modelo CAPM 60

Tabela 45 - Teste Jarque-Bera para Modelo CAPM 61

Tabela 46 - Teste White para Modelo CAPM 62

Tabela 47 - Número de Empresas por Carteira entre 1995-2012 71

Tabela 49 - Participação de Mercado por Carteira entre 1995-2012 72

Tabela 50 - Retorno Médio Mensal por Carteira entre 1995-2012 73

Tabela 51 - Retorno Médio Mensal de cada Fator 74

Tabela 52 - Número Médio de Empresas por Ano por

Carteira 1 a 10

Tabela 53 - Número Médio de Empresas por Ano por Carteira 11 a 20

Tabela 56 - Variação Mensal Média das Variáveis Explicativas por Ano

Tabela 57 - Teste Jarque-Bera para Modelo APT Unificado ao CAPM pelo Método dos Mínimos Quadrados Ponderado

Tabela 58 - Teste White para Modelo APT Unificado ao CAPM pelo Método dos Mínimos Quadrados Ponderado

Tabela 59 - Comparação dos Modelos CAPM e APT Unificado ao CAPM 


\section{1 \\ Introdução}

Este estudo busca analisar o mercado acionário brasileiro, pósestabilização econômica, utilizando modelos amplamente conhecidos e utilizados tanto na área acadêmica como pelos analistas de mercado. O objetivo é verificar qual modelo melhor caracteriza o mercado acionário brasileiro e avaliar sua utilização prática pelos agentes do mercado.

Serão apresentados os modelos Capital Asset Pricing Model (CAPM), Arbitrage Pricing Theory (APT), e os casos particulares do APT: o Modelo de Três Fatores de Fama e French (1993) e o Modelo APT Unificado ao CAPM proposto por John Wei (1988).

O CAPM desenvolvido por Willian Sharpe (1964) e John Lintner (1965), explica o retorno dos ativos considerando apenas sua relação com o risco de mercado, o beta de cada ativo. O modelo tem como premissa simplificações em relação à realidade que geram críticas sobre sua capacidade de refletir o desempenho do mercado. Apesar disso, o modelo é amplamente utilizado pelos analistas de mercado para analisar o potencial de retorno das ações e auxiliar na construção de carteiras de investimento.

O modelo APT desenvolvido por Stephen Ross em 1976 busca explicar o retorno dos ativos considerando a não existência da possibilidade de arbitragem no mercado. O modelo prevê que existem diversas fontes de risco associadas ao retorno das ações, não se limitando ao fator de mercado. Todavia, o modelo não prevê quais seriam esses fatores e nem quantos fatores devem ser utilizados. Em 1988, John Wei propôs a utilização de um modelo APT unificado ao CAPM, considerando a importância do fator de mercado para explicar o retorno das ações.

O modelo de três fatores desenvolvido por Eugene Fama e Kenneth French (1993), busca explicar o retorno dos ativos utilizando não apenas o beta, mas também o tamanho da companhia e a precificação dos seus ativos em relação ao seu valor contábil. O tamanho da companhia é avaliado pelo seu valor de mercado, sendo que empresas de menor porte apresentam maiores riscos aos investidores e, portanto devem apresentar um retorno maior. O outro fator utilizado é a relação do valor patrimonial contábil e seu valor de mercado. 
No desenvolvimento do presente estudo, serão estimados os modelos de Três Fatores de Fama e French e um modelo APT Unificado ao CAPM baseado em fatores macroeconômicos. Ambos terão seus desempenhos comparados ao modelo CAPM.

No próximo capítulo será apresentada a base teórica para o modelo CAPM, para o modelo APT, assim como para os casos particulares do modelo APT: o Modelo de Três Fatores de Fama e French e o Modelo APT Unificado ao CAPM de Wei (1988). Junto com a apresentação dos modelos será feito um breve resumo de estudos relevantes já realizados, principalmente, no mercado acionário brasileiro.

No capítulo 3 será apresentada a metodologia para o desenvolvimento de cada um dos modelos, assim como a base de dados utilizada. Os resultados empíricos serão destacados no capítulo 4.

As conclusões do presente estudo serão expostas no capítulo 5 seguidas por sugestões para futuros estudos.

O último capítulo da dissertação apresenta a referência bibliográfica utilizada para o desenvolvimento deste trabalho. 


\section{2 \\ Apresentação Teórica e Breve Revisão da Literatura}

\subsection{Capital Asset Pricing Model - CAPM}

O Capital Asset Pricing Model foi desenvolvido por Sharpe (1964) e Lintner (1965). Sharpe se baseou na teoria para seleção de carteiras de Markowitz (1952) e no processo de decisão de investimento de Tobin (1958).

Markowitz (1952) propôs que a seleção da carteira de investimento teria como premissa a maximização do retorno para determinado nível de risco através da diversificação, uma análise de média-variância.

A fronteira eficiente de mercado é composta pelas oportunidades de investimento que apresentam o maior nível de retorno dado determinado nível de risco, considerando todos ativos do mercado. A função utilidade do investidor reflete seu nível de aversão a risco. A maximização da utilidade encontra-se no ponto de tangência entre a fronteira eficiente de mercado e curva de indiferença do investidor como pode ser visto na Figura 1.

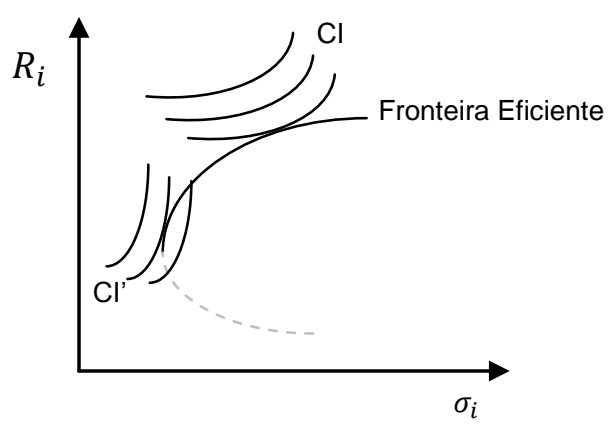

Figura 1 - Tangência entre Curvas de Indiferença e a Fronteira Eficiente de Markowitz

Partindo do modelo de Markowitz, Tobin (1958) considerou a existência de uma taxa livre de risco na qual os investidores poderiam emprestar e tomar empréstimos. Tobin analisou que a decisão de investimento se daria em duas etapas: inicialmente se determina a carteira ótima dos ativos com risco; e posteriormente se decide quanto será investido nesta carteira de ativos com risco e quanto será investido/emprestado na taxa livre de risco de acordo com as curvas de indiferença individuais. 
O CAPM visa estudar o risco sistemático, ou o risco de mercado que não pode ser eliminado pela diversificação dos ativos proposta por Markowitz. O modelo se baseia na maximização da utilidade do individuo considerando a existência do ativo livre de risco.

A reta que tangência a fronteira eficiente de Markowitz passando pela taxa livre de risco $\left(R_{f}\right)$ é a capital market line $(C M L)$. O ponto de tangência representa a carteira de mercado diversificada, onde o risco não sistemático foi totalmente eliminado (ver Figura 2).

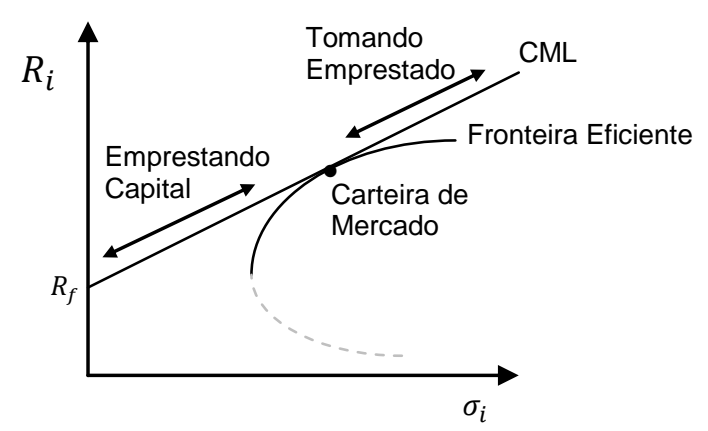

Figura 2 - Tangência entre a Fronteira Eficiente e a CML

Cada investidor irá investir no ponto onde sua curva de utilidade tangência a CML como exposto na Figura 3. Caso este ponto de tangência esteja à esquerda da carteira de mercado o investidor irá investir parte do seu capital na taxa livre de risco, ou emprestar capital. Já se o ponto de tangência estiver à direita da carteira de mercado, o investidor irá tomar um empréstimo a taxa livre de risco.

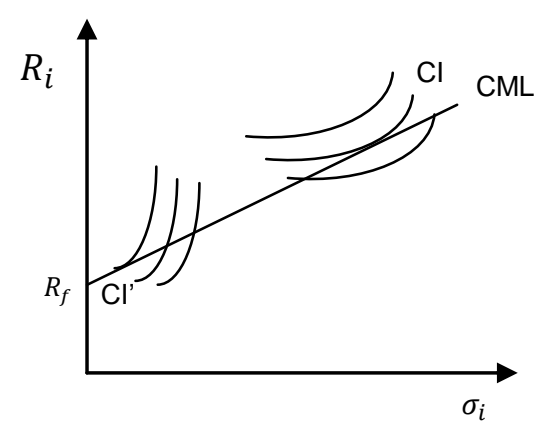

Figura 3 - Tangência entre as Curvas de Indiferença e a CML

As principais premissas do modelo CAPM são:

- O retorno dos ativos segue distribuição normal ou a utilidade é uma função côncava.

- Investidores são avessos ao risco e visam maximizar sua utilidade. 
- Os investidores têm expectativas homogêneas em relação ao retorno esperados, ao desvio padrão e aos coeficientes de correlação dos ativos.

- Existe um ativo sem risco ao qual qualquer indivíduo pode tomar empréstimo ou emprestar capital a esta taxa sem limite para o montante principal.

- O mercado é perfeito: não existem custos de transação, não existe efeito de impostos nos ganhos de capital ou dividendos. A carteira de mercado é eficiente.

- Ativos são infinitamente divisíveis e podem ser negociados em qualquer quantidade. É prevista a possibilidade de venda a descoberto.

- Os investidores são tomadores de preço, ou seja, um investidor não é capaz de alterar o preço dos ativos.

A equação que representa o CAPM é:

$$
E\left(R_{i t}\right)=R_{f}+\left[E\left(R_{m t}\right)-R_{f}\right] * \beta_{i} \text { onde, }
$$

- $\quad R_{i t}=$ retorno do ativo $i$ no instante $t$.

- $R_{f}=$ retorno do ativo sem risco.

- $R_{m t}=$ retorno da carteira de mercado no instante $t$.

- $\left[E\left(R_{m t}\right)-R_{f}\right]=$ prêmio de risco do mercado.

- $\quad \beta_{i}=$ beta do ativo $i$.

O beta representa o risco sistemático do mercado que não pode ser eliminado pela diversificação dos ativos.

$$
\beta_{i}=\frac{\operatorname{Cov}\left(R_{i,} R_{m}\right)}{\sigma_{m}^{2}}
$$

A security market line (SML), apresentada na Figura 4, analisa o retorno esperado dos ativos com base no risco sistemático que não pode ser diversificado, o beta. O CAPM prevê que a relação risco retorno deve ser avaliada com base apenas no risco sistemático. Não haverá retorno sobre o risco que pode ser eliminado através da diversificação dos ativos.

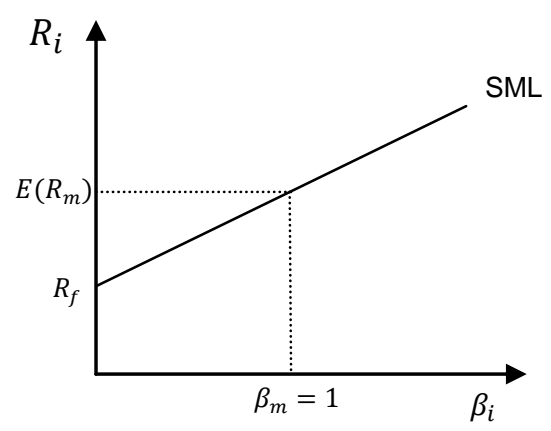

Figura 4 - Security Market Line (SML) 
As principais críticas ao CAPM são em relação às premissas de normalidade da distribuição dos retornos dos ativos e da função utilidade dos investidores. Os críticos do modelo CAPM apontam que estas restrições não são realistas. Além disso, argumentam que o modelo nunca poderá ser testado por, na prática, não existir uma carteira de mercado eficiente.

\subsection{Arbitrage Pricing Theory - APT}

O modelo Arbitrage Pricing Theory (APT) foi desenvolvido por Stephen Ross em 1976 propondo uma alternativa a análise de média-variância utilizada pelo modelo CAPM. As principais críticas ao CAPM se baseiam nas premissas de que o retorno dos ativos segue uma distribuição normal ou que a função utilidade dos investidores é quadrática, ambas muito restritivas e pouco realistas.

O modelo APT prevê que o retorno dos ativos possa ser explicado pela combinação linear de $k$ fatores e não apenas um como previsto pelo CAPM, sendo representado pela equação:

$$
\tilde{R}_{i}=E\left(\tilde{R}_{i}\right)+b_{i 1} * \tilde{F}_{1}+\ldots+b_{i k} * \tilde{F}_{k}+\tilde{\varepsilon}_{i},
$$

Onde:

- $\quad \tilde{R}_{i}=$ retorno aleatório do ativo $i$.

- $E\left(\widetilde{R}_{i}\right)=$ retorno esperado do ativo $i$.

- $\quad b_{i k}=$ coeficiente de sensibilidade do ativo $i$ ao fator explicativo $k$.

- $\tilde{F}_{k}=$ fator explicativo de média zero para o retorno de todos ativos.

- $\tilde{\varepsilon}_{i}=$ resíduo da regressão do ativo $i$.

As premissas do APT são:

- O mercado é perfeitamente competitivo e não existem custos de transação.

- Os investidores têm expectativas homogêneas em relação ao retorno dos ativos explicado pelo modelo de $\mathrm{k}$ fatores.

- Número de ativos $\mathrm{n}$ deve ser muito superior ao número de fatores $\mathrm{k}$.

- $\quad$ O erro $\tilde{\varepsilon}_{i}$ deve ser o risco não sistemático do ativo $i$.

- Os erros $\tilde{\varepsilon}_{i}$ devem ser independentes dos fatores $\tilde{F}_{k}$.

- Os erros $\tilde{\varepsilon}_{i}$ devem ser independentes entre si.

O modelo APT se baseia na teoria de que em equilíbrio não existe possibilidade de arbitragem no mercado, ou seja, não é possível obter retorno positivo sem a utilização de riqueza e sem incorrer em risco.

Para se criar uma carteira sem a utilização de riqueza é necessário que se faça a venda descoberta de algum ativo. Matematicamente pode-se escrever a variação de riqueza nula como: 


$$
\sum_{i=1}^{n} w_{i}=0, \text { onde } w_{i} \text { representa a riqueza }
$$

O retorno adicional da carteira com $n$ ativos é:

$$
\begin{gathered}
\tilde{R}_{p}=\sum_{i=1}^{n} w_{i} * \tilde{R}_{i} \\
=\sum_{i=1}^{n} w_{i} * E\left(\tilde{R}_{i}\right)+\sum_{i=1}^{n} w_{i} * b_{i 1} * \tilde{F}_{1}+\ldots+\sum_{i=1}^{n} w_{i} * b_{i k} * \tilde{F}_{k}+\sum_{i=1}^{n} w_{i} * \tilde{\varepsilon}_{i}
\end{gathered}
$$

Para se eliminar o risco sistemático e não sistemático é necessário:

- Escolher pequenas variações na riqueza e diversificar os investimentos em muitos ativos:

$$
w_{i} \approx 1 / n \text {, sendo } n \text { um número grande. }
$$

- Escolher a variação da riqueza $w_{i}$ de forma que a soma do risco sistemático $b_{k}$ seja zero para cada fator.

$$
\sum_{i=1}^{n} w_{i} * b_{i k}=0 \text { para cada fator }
$$

A diversificação sem custos de transação permite eliminar o risco não sistemático determinado pelo termo do resíduo. Como os resíduos são independentes, com o aumento do número de ativos, a média ponderada do erro pela variação na riqueza tende a zero.

$$
\sum_{i=1}^{n} w_{i} * \tilde{\varepsilon}_{i}=0
$$

Assim, o retorno da carteira se dá pela média ponderada do retorno esperado de cada ativo.

$$
\tilde{R}_{p}=\sum_{i=1}^{n} w_{i} * E\left(\tilde{R}_{i}\right)
$$

Em equilíbrio, uma carteira sem utilização de riqueza e sem incorrer em risco só pode ter retorno igual a zero.

$$
\sum_{i=1}^{n} w_{i} * E\left(\tilde{R}_{i}\right)=0
$$


Algebricamente tem-se como consequência que o retorno esperado pode ser escrito como uma combinação linear de uma constante e dos coeficientes:

$$
\begin{gathered}
E\left(\tilde{R}_{i}\right)=\lambda_{0}+\lambda_{1} * b_{i 1}+\ldots+\lambda_{k} * b_{i k} \\
\lambda_{0}=R_{f}
\end{gathered}
$$

No caso de apenas um fator explicativo, tem-se a equação de uma reta:

$$
E\left(\tilde{R}_{i}\right)=R_{f}+\lambda_{k} * b_{i k}
$$

Em equilíbrio, pode-se entender $\lambda_{k}$ como um prêmio de risco:

$$
\lambda_{k}=\bar{\delta}_{k}-R_{f}
$$

Onde $\bar{\delta}_{k}$ é o retorno esperado de uma carteira com sensibiliadade igual a 1 para o fator $k$ e zero para os demais fatores.

Generalizando, o modelo APT pode ser reescrito como:

$$
E\left(\tilde{R}_{i}\right)-R_{f}=\left[\bar{\delta}_{1}-R_{f}\right] * b_{i 1}+\ldots+\left[\bar{\delta}_{k}-R_{f}\right] * b_{i k}
$$

As principais críticas ao modelo APT é que este não é capaz de determinar quais são os fatores que conseguem explicar o retorno dos ativos e nem quantos fatores são necessários.

Para testar empiricamente o modelo APT, Roll e Ross (1980) propuseram estimar estatisticamente quantos fatores seriam necessários para explicar 0 retorno das ações no mercado norte americano entre 1962 e 1972. Os autores encontraram que seriam necessários pelo menos três fatores e possivelmente quatro. Contudo nada se pode dizer a respeito de quais são estes fatores. Todavia, é interessante observar que Dhrymes, Friend e Gultekin (1982), encontraram evidências que o número de fatores necessários aumenta de acordo com o número de ativos sendo avaliados.

Estudo semelhante realizado para o mercado brasileiro, Mello (1999) estima que são necessários seis fatores explicativos para se explicar o retorno das ações no período entre janeiro de 1989 e agosto de 1995, sendo que existe $40 \%$ de chance de que mais de seis fatores sejam necessários. O autor estimou a correlação dos fatores encontrados com o índice lbovespa e encontrou uma correlação de 0,88 do primeiro fator com o índice.

Outra forma de se estimar o modelo APT é através da utilização de fatores pré-determinados. Estes fatores podem ser relacionados aos ativos como, por exemplo, indicadores de rentabilidade da empresa, dividendos pagos e tamanho da empresa ou fatores macroeconômicos como inflação, produção industrial e variação na curva de juros. 
O Modelo de Três Fatores de Fama e French (1993) é um caso particular do APT.

\subsection{O Modelo de Três Fatores}

O modelo de três fatores foi proposto por Fama e French em 1993, buscando obter uma melhor explicação do risco sistemático dos ativos, não se limitando apenas ao seu beta.

Os autores partiram da observação de que, no mercado norte americano, a relação positiva entre o beta e o retorno médio das ações não permanecia verdadeira para o período entre 1963-1990, e a relação era fraca entre o período 1941-1990 com base no retorno das ações da NYSE (New York Stock Exchange).

Estudos anteriores destacavam importantes relações entre o retorno das ações com outras variáveis como tamanho da empresa (Banz, 1981), alavancagem (Bhandari, 1988), o indicador lucro/preço (Basu, 1983) e o indicador valor patrimonial/valor de mercado (Stattman, 1980; e Rosenberg, Reid e Lanstein, 1985).

Com esse panorama, os autores publicaram, em 1992, um estudo no qual buscavam avaliar a existência de correlação entre o retorno das ações e os indicadores: tamanho, alavancagem, lucro/preço e valor patrimonial/valor de mercado. Foram incluídas na amostra apenas empresas não financeiras, devido ao elevado grau de alavancagem característico das empresas deste setor.

A conclusão deste estudo foi que a combinação do indicador de tamanho da empresa e do valor patrimonial / valor de mercado contribuíam para melhor explicar o retorno das ações. Estes dois indicadores seriam capazes de absorver a contribuição que a alavancagem e o indicador lucro / preço traziam para explicar o retorno das ações no período de 1963-1990.

No ano seguinte os autores publicaram outro artigo no qual apresentaram o que veio a ser conhecido com o Modelo de Três Fatores da Fama e French.

Foram utilizados dados para o período de 1963-1991, tomando como base junho de cada ano. Novamente foram excluídas as empresas do setor financeiro. Visando isolar o efeito de cada variável explicativa, as empresas foram separadas em carteiras de investimentos de acordo com suas respectivas características. 
Para a variável tamanho da empresa, elas foram classificadas como grandes (big) ou pequenas (small) com base na mediana das ações negociadas na NYSE em junho de cada ano. A amostra também incluiu as empresas negociadas na Amex (American Stock Exchagen) e NASDAQ Stock Market.

A variável valor patrimonial / valor de mercado (VP/VM) da companhia foi calculado utilizando o valor patrimonial contábil do ano fiscal $t$ - 1 dividido pelo valor de mercado em dezembro do ano $t$-1. Empresas com valor patrimonial negativo foram excluídas da amostra. As empresas foram divididas em 3 grupos de acordo com o valor do indicador: as $30 \%$ baixo (low), $40 \%$ médio (medium) e as $30 \%$ de alto (high).

A decisão de dividir a amostra em dois grupos com base no tamanho e em três grupos com base no valor patrimonial / valor de mercado (VP?VM)baseouse no estudo de 1992 que indicava que o indicador apresentava maior poder explicativo em relação ao retorno das ações.

Assim, as empresas foram divididas em 6 carteiras, sendo elas:

- $\mathrm{S} / \mathrm{L}=$ empresas pequenas (small) com baixo (low) VP/VM.

- $\mathrm{S} / \mathrm{M}=$ empresas pequenas (small) com médio (medium) VP/VM.

- $\mathrm{S} / \mathrm{H}=$ empresas pequenas (small) com alto (high) VP/VM.

- $\mathrm{B} / \mathrm{L}=$ empresas grandes (big) com baixo (low) VP/VM.

- $\mathrm{B} / \mathrm{M}=$ empresas grandes (big) com médio (medium) VP/VM.

- $\mathrm{B} / \mathrm{H}=$ empresas grandes (big) com alto (high) VP/VM.

O retorno das carteiras foi calculado com base no retorno mensal ponderado de cada ação entre julho do ano $t$ e junho de $t+1$. Em junho de cada ano eram recalculados os indicadores para fazer nova divisão das carteiras. Optou-se pelo uso da média ponderada visando minimizar a variância e a melhor refletir as oportunidades de investimento existentes.

Para calcular o retorno das carteiras com empresas de pequeno porte foi utilizada a média aritmética simples entre as três carteiras contendo empresas pequenas. O mesmo é feito para as empresas de grande porte e para as carteiras divididas de acordo com VP/VM.

- Retorno das empresas pequenas (small) $=(S / L+S / M+S / H) / 3$

- Retorno das empresas grandes $(b i g)=(B / L+B / M+B / H) / 3$

- Retorno das empresas com baixo VP/VM (low) $=(S / L+B / L) / 2$

- Retorno das empresas com médio VP/VM (medium) $=(S / M+$ $B / M) / 2$

- Retorno das empresas com alto VP/VM (high) $=(S / H+B / H) / 2$ 
Para a variável do retorno de mercado, os autores utilizaram todas as empresas da amostra, calculando o retorno ponderado de acordo com o valor de mercado das companhias.

Visando minimizar a correlação entre as variáveis explicativas do modelo, os autores propõem calcular o excesso de retorno das empresas pequenas sobre as empresas grandes (small minus big, ou SMB), e o excesso de retorno das empresas com alto VP/VM (high minus low, ou HML).

$$
\begin{aligned}
& S M B=(S / L+S / M+S / H) / 3-(B / L+B / M+B / H) / 3 \\
& H M L=(S / H+B / H) / 2-(S / L+B / L) / 2
\end{aligned}
$$

O terceiro fator do modelo é o prêmio de risco do mercado, ou o retorno do mercado menos a taxa livre de risco. A carteira de mercado foi calculada utilizando as ações que compõe as carteiras de investimentos do modelo com base na média ponderado dos seus retornos.

Assim temos o modelo de três fatores:

$$
R_{i t}-R_{f t}=\alpha_{i t}+\beta_{i t} *\left(R_{m t}-R_{f t}\right)+s_{i t} * S M B_{t}+h_{i t} * H M L_{t}+\varepsilon_{i t},
$$

onde:

- $R_{i t}=$ retorno do ativo $i$ no instante $t$.

- $R_{f t}=$ retorno do ativo livre de risco no instante $t$.

- $R_{m t}=$ retorno da carteira de mercado no instante $t$.

- $S M B_{t}=$ retorno da carteira small minus big no instante $t$.

- $H M L_{t}=$ retorno da carteira high minus low no instante $t$.

- $\alpha_{i t}, \beta_{i t}, s_{i t}, h_{i t}=$ variáveis a serem estimadas pelo modelo através das regressões $i$.

- $\varepsilon_{i t}=$ resíduo da regressão.

No estudo os autores encontraram que as empresas do maior quintil do valor de mercado, apresentaram sensibilidade negativa ao fator SMB, todos os demais quintis apresentaram sensibilidade positiva ao fator. Quanto menor o tamanho da empresa, maior o a sensibilidade ao fator SMB.

Em relação ao fator $\mathrm{HML}$, as empresas do menor quintil do indicador VP/VM apresentaram sensibilidades negativas. Os demais grupos apresentaram uma variação positiva ao indicador, sendo que quanto maior o VP/VM, maior a sensibilidade ao HML.

O fator prêmio de risco se mostrou significativo e muito próximo de um para todas as carteiras, enquanto o intercepto se aproxima de zero, evidenciando que os três fatores são capazes de capturar grande parte da variação no retorno das carteiras. $O R^{2}$ das carteiras foi superior a 0,83 em todas as regressões, sendo superior a 0,9 na maioria dos casos. 
Os autores concluem que o modelo de três fatores contribui para a explicação do retorno das ações no mercado norte americano entre 1963-1990.

Estudos realizados para o mercado brasileiro apresentam resultados bastante discrepantes. Segundo Mello (1999), para o período entre janeiro 1989 e agosto de 1995, o modelo de três fatores não foi representativo para o mercado brasileiro. O autor encontrou que em $65 \%$ das carteiras observadas o fator SMB não foi estatisticamente diferente de zero, e em $70 \%$ dos casos para o fator HML.

Málaga e Securato (2004) estudaram o mercado brasileiro no período entre janeiro 1995 e junho 2003. Encontraram que o retorno médio das empresas de pequeno porte não supera o retorno das empresas grandes, como seria de se esperar. O prêmio médio do fator SMB foi de $-0,32 \%$ ao mês. Apesar da falta de justificativa teórica para o efeito tamanho, o modelo de três fatores se mostrou superior ao CAPM ao explicar o retorno das ações. O fator SMB se mostrou significante para sete das nove carteiras e o fator HML foi significante para seis carteiras.

Mussa (2007) analisou dados para o período de junho 1995 a junho 2007 no mercado brasileiro. Assim como Málaga, Mussa não encontrou prêmio de risco para as empresas de menor porte no Brasil (prêmio médio de 0,04\% ao mês). O autor encontrou que a sensibilidade ao fator SMB foi significante apenas para seis das doze carteiras, e ao fator HML foi significante em $83 \%$ dos casos. O fator tamanho foi capaz de explicar melhor o retorno das empresas pequenas enquanto o fator VP/VM foi capaz de explicar melhor o retorno das carteiras com alto índice. O autor conclui que o modelo de três fatores é superior ao CAPM para estimar o retorno das ações.

\subsection{Modelo APT Unificado ao CAPM}

Wei (1988) realizou um estudo comparando e integrando os modelos APT e CAPM. Neste estudo o autor inclui o fator de mercado ao modelo APT conseguindo obter um melhor poder explicado dos retornos.

Como o modelo APT não indica quantos fatores devem ser utilizados Wei testou o impacto da exclusão de alguns fatores. Quando todos os fatores são excluídos o modelo se resume ao CAPM.

A relevância do fator de mercado depende do número de fatores omitidos do modelo, se tornando mais importante à medida que o número de fatores explicativos se reduz. 
Schor, Bonomo e Pereira (1998) realizaram um estudo utilizando o fator de mercado juntamente com fatores macroeconômicos para explicar o retorno das ações do mercado brasileiro para o período entre 1987 e 1997. A variável de mercado se mostrou significante para todas as carteiras do estudo enquanto apenas algumas das variáveis macroeconômicas apresentaram poder explicativo. 


\section{3 \\ Metodologia e Coleta de Dados}

Os dados utilizados para o desenvolvimento desta dissertação foram extraídos do Sistema Economática, Bloomberg, Banco Central, IBGE e Ipeadata.

Para o processamento estatístico utilizou-se o software E-Views 7 Student Edition.

\subsection{O Modelo de Três Fatores de Fama e French}

Os dados utilizados para criação do modelo foram extraídos do Sistema Economática. Foram usados dados para o período entre janeiro 1995 e dezembro de 2012.

As empresas do setor financeiro foram excluídas do estudo, assim como feito por Fama e French (1993), em função das características particulares do setor em relação ao seu nível de alavancagem. Todas as demais companhias listadas no Bovespa foram incluídas desde que apresentassem:

- Valor patrimonial positivo no período anterior a formação das carteiras.

- Valor de mercado para o período e o período anterior ao da formação das carteiras, com tolerância de até 22 dias para trás.

- Retorno, com base na cotação de fechamento, do semestre calculado pelo Economática, com tolerância de até quatro dias para trás tanto para a data inicial como para a data final. A taxa apresentada é ao mês.

O valor de mercado foi calculado com base no preço das ações ON e PN. Caso umas das classes de ação não apresentasse cotação para o período, considerando a tolerância, foi utilizada a ação mais líquida para o cálculo do valor de mercado.

Para o cálculo do retorno foram considerados o pagamento de proventos e dividendos no período.

A taxa livre de risco utilizada foi a caderneta de poupança.

Diferente do modelo original, optou-se por realizar a avaliação da performance e o rebalanceamento das carteiras semestralmente, e não 
anualmente, a fim de obter um maior número de observações. Como o mercado brasileiro apresenta uma volatilidade superior ao mercado americano, é razoável supor que os gestores de investimento façam o rebalanceamento de suas carteiras com uma frequência maior no Brasil.

A metodologia para a formação das carteiras seguiu a do modelo original utilizada por Fama e French (1993). Para a formação das carteiras e seu rebalanceamento, em cada período dividiu-se as empresas de acordo com o seu tamanho e o índice de (VP/VM).

A classificação das ações em relação ao tamanho das empresas foi feita com base na mediana do valor de mercado da amostra, dividindo o grupo em empresas pequenas (small) e empresas grandes (big). O valor de mercado do fim do período foi utilizado no cálculo, ou seja, para as carteiras do primeiro semestre utilizou-se o valor de mercado do final de junho, e para as carteiras do segundo semestre, o valor de mercado de dezembro.

Para a classificação de acordo com o indicador do valor patrimonial/valor de mercado (VP/VM) foi feita a divisão em três grupos: 30\% mais baixos (low), $40 \%$ com valores intermediários / médios (medium) e os $30 \%$ com indicadores altos (high). $\mathrm{O}$ indicador foi calculado com base nos dados do semestre imediatamente anterior, ou seja:

- $1^{\text {o }}$ semestre ano $t$ : valor patrimonial dezembro $(\mathrm{t}-1) /$ valor de mercado dezembro $_{(\mathrm{t}-1)}$.

- $\quad 2^{\circ}$ semestre ano $t$ : valor patrimonial $j u n h o_{(\mathrm{t})} /$ valor de mercado junho ${ }_{(\mathrm{t})}$.

Assim a amostra fica subdividida em seis diferentes carteiras de investimento: low/small (L/S), low/big (L/B), medium/small (M/S), medium/big $(\mathrm{M} / \mathrm{B})$, high/small $(\mathrm{H} / \mathrm{S})$ e high/big $(\mathrm{H} / \mathrm{B})$. O retorno das carteiras foi ponderado com base no valor de mercado de cada empresa.

O retorno do mercado foi calculado utilizando o retorno ponderado pelo valor de mercado de todas as ações da amostra, conforme realizado no modelo original de Fama e French. A poupança foi utilizada como a taxa livre de risco do mercado para cálculo do fator do prêmio de risco.

O fator small minus big (SMB) foi calculado usando a média aritmética do retorno das carteiras das empresas pequenas menos a média aritmética do retorno das carteiras das empresas grandes:

$$
S M B=(L / S+M / S+H / S) / 3-(L / B+M / B+H / B) / 3 .
$$


O fator high minus low (HML) foi calculado usando a média aritmética do retorno das carteiras das empresas com alto indicador VP/VM menos a média aritmética do retorno das carteiras das empresas com baixo indicador:

$$
H M L=(H / S+H / B) / 2-(L / S+L / B) / 2 \text {. }
$$

Assim o modelo de três fatores foi estimado:

$R_{i t}-R_{f t}=\alpha_{i t}+\beta_{i t} *\left(R_{m t}-R_{f t}\right)+s_{i t} * S M B_{t}+h_{i t} * H M L_{t}+\varepsilon_{i t}$, onde:

- $\quad R_{i t}=$ retorno do ativo $i$ no instante $t$.

- $R_{f t}=$ retorno do ativo livre de risco no instante $t$.

- $R_{m t}=$ retorno da carteira de mercado no instante $t$.

- $S M B_{t}=$ retorno da carteira small minus big no instante $t$.

- $H M L_{t}=$ retorno da carteira high minus low no instante $t$.

- $\alpha_{i t}, \beta_{i t}, s_{i t}, h_{i t}=$ variáveis a serem estimadas pelo modelo através das regressões $i$.

- $\varepsilon_{i t}=$ resíduo da regressão .

\subsection{Modelo APT Unificado ao CAPM}

Os dados utilizados para o desenvolvimento deste modelo foram extraídos do sistema Bloomberg, do site do Banco Central Brasileiro, do site do IBGE, do site Ipeadata e do sistema Economática.

Foram usados dados para as companhias de dezembro 1994 a dezembro de 2012, sendo a base de dados com periodicidade mensal extraída do Bloomberg. Calculou-se o retorno mensal com a cotação de fechamento de cada mês. Para os meses em que não houve cotação o valor foi deixado em branco.

As empresas incluídas na amostra totalizaram 142. Foram excluídas empresas com menos de 2 anos de histórico, assim como empresas que não apresentassem cotação de fechamento em pelo menos $10 \%$ dos meses em análise (após o início de negociação de cada companhia na bolsa).

Vale notar que no período em questão houve um aumento significativo de empresas com presença em bolsa, e, portanto, na amostra há inclusão de novas empresas à medida que ocorreram as aberturas de capital.

As empresas foram separadas em 20 carteiras diferentes de acordo com seus respectivos betas. As carteiras 1 a 19 possuem até 7 empresas e a carteira 20 até 9 empresas. Como na amostra existem muitas empresas que realizaram abertura de capital no período, algumas carteiras não têm dados no início da série. 
O índice lbovespa foi utilizado como a carteira de mercado e para a taxa livre de risco utilizou-se o retorno da caderneta de poupança.

Os dados macroeconômicos utilizados foram: variação cambial, variação na taxa de juros, a variação no índice de produção industrial e a inflação. A escolha das variáveis macroeconômicas teve como premissa inicial serem indicadores relevantes amplamente acompanhadas pelos agentes de mercado. Diversas outras variáveis foram testadas, assim como diferente número total de fatores. A combinação indicada foi a que apresentou o melhor resultado para o modelo.

Para o cálculo da variação cambial foi utilizada a cotação de venda (R\$/US\$) de fechamento de cada mês.

A variação na taxa de juros considerou a variação mês a mês da taxa Selic definida pelo Banco Central.

A variação mês a mês da produção industrial foi feita com base no índice com ajuste sazonal medido pelo IBGE.

O índice de inflação utilizado foi o IGP-M calculado pela Fundação Getúlio Vargas.

Para a criação do modelo APT Unificado ao CAPM é necessária inicialmente realizar a regressão do prêmio de mercado do modelo CAPM tendo como variáveis explicativas os fatores macroeconômicos. Assim, com os dados organizados realizou-se primeiro uma regressão linear da série temporal do prêmio de risco de mercado:

$$
\begin{aligned}
R_{m t}-R_{f t}= & \alpha_{1}+\alpha_{2} * \operatorname{Câmbio}_{(t+1)}+\alpha_{3} * \operatorname{Selic}_{(t+1)}+\alpha_{4} * \operatorname{PIM}_{(t+4)}+\alpha_{5} \\
& * I G P-M_{(t-4)}+\varepsilon_{t}
\end{aligned}
$$

Onde,

- $\quad R_{m t}=$ retorno da carteira de mercado no mês $t$.

- $R_{f t}=$ retorno da taxa livre de risco no mês $t$.

- $\operatorname{Câmbio}_{(t+1)}=$ variação cambial no mês $(t+1)$.

- $\operatorname{Selic}_{(t+1)}=$ variação da taxa Selic no mês $(t+1)$.

- $\operatorname{PIM}_{(t+4)}=$ variação da produção industrial no mês $(t+4)$.

- $\quad I G P-M_{(t-4)}=$ variação da inflação no mês $(t-4)$.

- $\alpha_{1}, \alpha_{2}, \alpha_{3}, \alpha_{4}, \alpha_{5}=$ coeficientes a serem estimados

- $\varepsilon_{t}=$ resíduo no mês $t$. Este fator será referido como ResidIbov ${ }_{t}$.

Com o resíduo desta regressão fez-se uma nova regressão linear de série temporal buscando explicar o retorno das carteiras: 
$R_{i t}=\beta_{1 i}+\beta_{2 i} * \operatorname{Câmbio}_{(t+1)}+\beta_{3 i} * \operatorname{Selic}_{(t+1)}+\beta_{4 i} * \operatorname{PIM}_{(t+4)}+\beta_{5 i} *$
$I G P-M_{(t-4)}+\beta_{6 i} * \operatorname{ResidIbov}_{t}+\varepsilon_{i t}^{\prime}$

Onde,

- $R_{i t}=$ retorno por carteira $i$ no mês $t$.

- $\operatorname{Câmbio}_{(t+1)}=$ variação cambial no mês $(t+1)$.

- $\operatorname{Selic}_{(t+1)}=$ variação da taxa Selic no mês $(t+1)$.

- $\quad \operatorname{PIM}_{(t+4)}=$ variação da produção industrial no mês $(t+4)$.

- $\quad I G P-M_{(t-4)}=$ variação da inflação no mês $(t-4)$.

- $\quad$ ResidIbov $v_{t}$ resíduo da regressão do prêmio de risco do mercado no mês $t\left(o u \varepsilon_{t}\right)$.

- $\beta_{1 i}, \beta_{2 i}, \beta_{3 i}, \beta_{4 i}, \beta_{5 i}$ e $\beta_{6 i}=$ coeficientes a serem estimados.

- $\varepsilon_{i t}^{\prime}=$ resíduo no mês $t$.

Com os coeficientes estimados pelas regressões anteriores é feito análise cross sectional dos dados:

$\bar{R}_{l}-R_{f}=\lambda_{1}+\lambda_{2} * \hat{\beta}_{2 i}+\lambda_{3} * \hat{\beta}_{3 i}+\lambda_{4} * \hat{\beta}_{4 i}+\lambda_{5} * \hat{\beta}_{5 i}+\lambda_{6} * \hat{\beta}_{6 i}+\varepsilon_{i}^{\prime \prime}$

Onde,

- $\quad \bar{R}_{l}=$ retorno médio da carteira $i$ no período.

- $R_{f}=$ retorno da taxa livre de risco.

- $\hat{\beta}_{2 i} \hat{\beta}_{3 i}, \hat{\beta}_{4 i}, \hat{\beta}_{5 i}$ e $\hat{\beta}_{6 i}=$ coeficientes estimados pelas regressões da série temporal.

- $\lambda_{1}, \lambda_{2}, \lambda_{3}, \lambda_{4}, \lambda_{5}$ e $\lambda_{6}=$ coeficientes a serem estimados pela regressão.

- $\varepsilon_{i}^{\prime \prime}=$ resíduo da regressão por carteira $i$.

\subsection{Métodos Estatísticos}

Os modelos deste estudo foram estimados através de regressões lineares simples e múltiplas pelo método dos mínimos quadrados ordinários. Utilizou-se o pacote estatístico E-Views 7 Student Edition.

O método dos mínimos quadrados ordinários baseia-se na minimização do quadrado dos erros da regressão linear. O modelo têm as seguintes premissas:

- Existe uma relação linear entre as variáveis.

- Os valores da variável independente são fixos, ou seja, não estocásticos.

- O valor esperado do erro é zero. 
- Homoscedasticidade - a variância do erro é constante.

- Os resíduos não são auto correlacionados.

- A covariância entre as variáveis explicativas e o erro é zero.

- O número de observações deve ser maior que o número de parâmetros a serem estimados.

- O valor das variáveis independentes deve oscilar, não pode ser fixo.

- O modelo deve ser corretamente especificado.

- Não existe multicolinearidade perfeita entre as variáveis explicativas.

\subsubsection{Teste $t$}

Para testar a significância dos coeficientes estimados é utilizado o teste t, onde compara se o valor estimado é igual a um determinado valor, ou a hipótese nula. A estatística $t$ calculada é comparada ao $t$ crítico $\left(t_{\alpha, v}\right)$, ao nível de significância de interesse $(\alpha)$, de acordo com o graud de liberdade $(v)$ para se aceitar ou rejeitar a hipótese de igualdade.

$$
t=\frac{\hat{\beta}_{2}-\beta_{2}}{\operatorname{se}\left(\hat{\beta}_{2}\right)} \text { onde, }
$$

- $\hat{\beta}_{2}=$ coeficiente a ser testatdo.

- $\beta_{2}=$ valor para o qual quer se testar a hipótese nula.

- $\operatorname{se}\left(\hat{\beta}_{2}\right)=$ desvio padrão de $\hat{\beta}_{2}$.

A hipótese do teste é:

- $\mathrm{H}_{0}: \hat{\beta}_{2}=\beta_{2}$

- $\mathrm{H}_{\mathrm{a}}: \hat{\beta}_{2} \neq \beta_{2}$

Para avaliar a relevância do coeficiente, pode-se utilizar também o p-valor, estatística apresentada por todos os pacotes estatísticos. O p-valor indica o valor exato de significância do coeficiente, ou o menor nível ao que se pode rejeitar a hipótese nula. É a área das extremidades além do valor da estatística $t$ calculada. A Figura 5 destaca o critério para aceitação ou rejeição da hipótese nula e a região representada pelo $p$-valor.

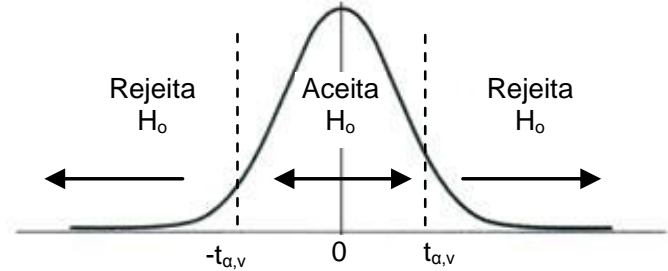

$t_{a, v}=$ valor da tabela da Distribuição $t$

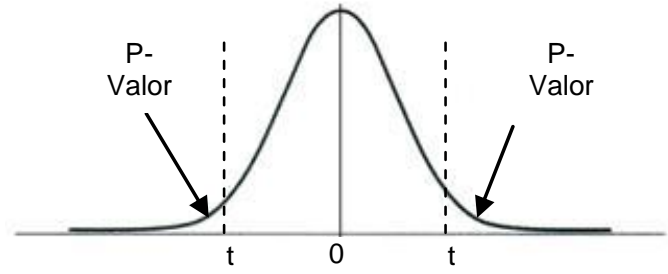

$t$ = estatística $t$ calculadat 
Figura 5 - Critério de Avaliação do Teste t e o P-Valor

\subsubsection{Coeficiente de Determinação $-R^{2}$ e $R^{2}$ ajustado}

O coeficiente de determinação, ou $R^{2}$, serve para avaliar quão bem especificada está a regressão. O valor pode variar entre 0 e 1. Quando mais perto de 1, mais o modelo terá conseguido explicar a variável dependente. Este coeficiente é calculado avaliando os erros da regressão em relação aos valores observados.

$$
\begin{gathered}
R^{2}=\frac{E S S}{T S S} \text { ou } \\
R^{2}=1-\frac{R S S}{T S S} \quad \text { onde, }
\end{gathered}
$$

- $\quad E S S=$ Explained sum of squares ou soma dos quadrados da regressão ou $\Sigma \hat{y}_{i}^{2}$.

- $\quad R S S=$ Residual sum of squares ou soma dos quadrados dos resíduos ou $\Sigma \hat{u}_{i}^{2}$.

- $\quad T S S=$ Total sum of squares ou soma dos quadrados total ou $\Sigma y_{i}^{2}$.

O coeficiente de correlação ajustado, $R^{2}$ ajustado, é utilizado para avaliar os modelos com mais de uma variável explicativa. O aumento do número de variáveis irá sempre aumentar 0 valor de $R^{2}$, sendo portanto necessário um ajuste para o número de parâmetros a fim de verificar se a adição de novas variáveis está contribuindo significativamente para a explicação da variável dependente.

$$
\bar{R}^{2}=1-\frac{\sum \hat{u}_{i}^{2} /(n-k)}{\Sigma y_{i}^{2} /(n-1)} \text { onde, }
$$

- $\hat{u}=$ resíduo da regressão.

- $n=$ número de observações.

- $\quad k$ = número de parâmetros estimados.

- $y=$ valor da variável dependente.

\subsubsection{Teste $F$}

O teste $\mathrm{F}$ é utilizado para testar a hipótese nula de todos os coeficientes estimados serem iguais a zero simultaneamente a determinado nível de significância. A estatística de teste pode ser calculada pela seguinte fórmula: 


$$
F=\frac{E S S /(k-1)}{R S S /(n-k)} \text { onde, }
$$

- $\quad E S S=$ Explained sum of squares ou soma dos quadrados da regressão ou $\Sigma \hat{y}_{i}^{2}$.

- $\quad R S S=$ Residual sum of squares ou soma dos quadrados dos resíduos ou $\Sigma \hat{u}_{i}^{2}$.

- $n=$ número de observações.

- $\quad k=$ número de parâmetros estimados.

A hipótese do teste é:

- $\mathrm{H}_{0}: \hat{\beta}_{1}=\hat{\beta}_{2}=\cdots=\hat{\beta}_{n}=0$

- $\mathrm{H}_{\mathrm{a}}$ : Pelo menos um dos parâmentros é diferente de zero.

\subsubsection{Teste Durbin-Watson}

O teste Durbin-Watson é utilizado para testar se os resíduos da regressão são autocorrelacionados visando avaliar a qualidade da regressão estimada. Como apresentando anteriormente, uma das premissas do método dos mínimos quadrados ordinários é que os resíduos não sejam autocorrelacionados.

As premissas para utilização deste teste são:

- A regressão estimada possui intercepto.

- As variáveis independentes não são estocásticas.

- $\mathrm{O} \mathrm{u}_{\mathrm{t}}$ é gerado pelo processo auto regressivo de primeira ordem, e não detecta autocorrelação de outra ordem.

- O erro tem distribuição normal.

- A regressão estimada não possui valores defasados da variável dependente como variável explicativa.

- A série é completa, não há observações sem dados.

A estatística a ser calculada para o teste é:

$$
d=\frac{\sum_{\mathrm{t}=2\left(\widehat{\mathrm{u}}_{\mathrm{t}}-\widehat{\mathrm{u}}_{\mathrm{t}-1}\right)^{2}}^{\mathrm{t}=\mathrm{t}}}{\sum_{\mathrm{t}=1}^{\mathrm{t}=\mathrm{n}} \widehat{\mathrm{u}}^{2}}
$$

Este valor deverá ser comparado ao valor crítico da tabela de teste DurbinWatson. A conclusão a do teste depende dos valores do limite inferior e limite superior como pode ser visto na figura abaixo ${ }^{1}$.

A hipótese do teste é:

- $\mathrm{H}_{\mathrm{o}}$ : Não existe autocorrelação

\footnotetext{
${ }^{1}$ GUJARATI, D. N., Basic Econometrics, p.469
} 
- $\mathrm{H}_{\mathrm{a}}$ : Autocorrelação positiva

- $\mathrm{H}_{0}^{*}$ : Não existe autocorrelação

- $\mathrm{H}_{\mathrm{a}}^{*}$ : Autocorrelação negativa

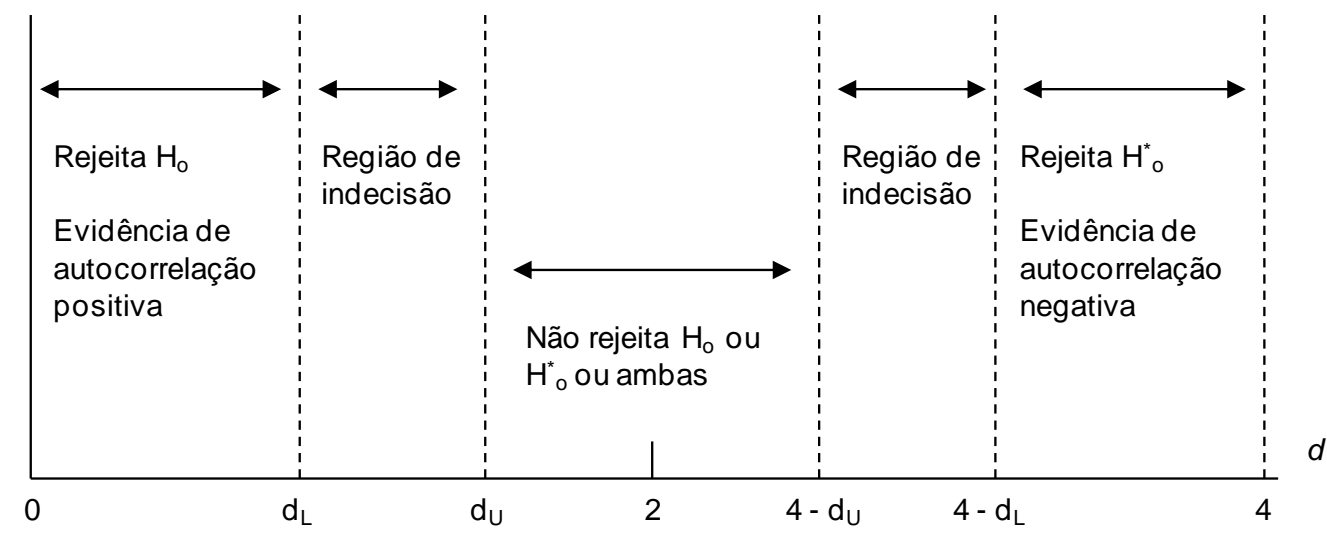

$\mathrm{H}_{0}$ : Não há autocorrelação positiva

$\mathrm{H}^{*}$ : Não há autocorrelação negativa

Figura 6 - Processo de Decisão para o Teste Durbin-Watson

Os limites $d_{L}$ e $d_{U}$ são o limite inferior (lower) e o limite superior (upper) indicados na tabela estatística do teste Durbin-Watson, com base no número de observações da amostra e do número de variáveis explicativas (sem o intercepto) da regressão.

\subsubsection{Teste Jarque-Bera}

O teste Jarque-Bera avalia se uma série apresenta distribuição normal. Este teste é apropriado para amostras com grande número de observações. A estatística de teste é:

$$
J B=n *\left[\frac{S^{2}}{6}+\frac{(K-3)^{2}}{24}\right], \text { onde }
$$

- $n$ = número de observações

- $S=$ Coeficiente de assimetria (skewness)

- $K=$ Coeficiente de curtose (kurtosis)

A hipótese nula do teste é que os dados possuem distribuição normal. A estatística $J B$ apresenta uma distribuição qui-quadrada com dois graus de liberdade.

A hipótese do teste é:

- $\mathrm{H}_{\mathrm{o}}$ : Distribuição normal

- $\mathrm{H}_{\mathrm{a}}$ : Não segue distribuição normal 


\subsubsection{Teste White}

O teste White serve para avaliar se a variância dos resíduos da equação são constantes.

A estatística de teste é calculada realizando uma regressão para do quadrado dos resíduos com as variáveis explicativas originais, o quadrado destas variáveis e o produto cruzado das variáveis explicativas. Usando um modelo com 2 variáveis explicativas temos:

$$
\begin{gathered}
Y_{i}=\beta_{1}+\beta_{2} * X_{2 i}+\beta_{3} * X_{3 i}+\beta_{3} * X_{3 i}+u_{i} \\
\hat{u}_{i}^{2}=\alpha_{1}+\alpha_{2} * X_{2 i}+\alpha_{3} * X_{3 i}+\alpha_{4} * X_{2 i}^{2}+\alpha_{5} * X_{3 i}^{2}+\alpha_{6} * X_{2 i} * X_{3 i}+v_{i}
\end{gathered}
$$

$O R^{2}$ da regressão do quadrado do resíduo é então utilizado para calcular a estatística de teste que, para amostras grandes, segue uma distribuição quiquadrada, com os graus de liberdade igual ao número de parâmentros excluindo o interecepto.

$$
n * R^{2}
$$

A hipótese nula do teste é que não existe heterodedasticidade. Se o valor da calculado estatística for acima do valor critíco da tabela qui-quadrado no nível de significância escolhido os resíduos a variância dos resíduos não é constante.

A hipótese do teste é:

- $\mathrm{H}_{0}$ : Homocedasticidade

- $\mathrm{H}_{\mathrm{a}}$ : Heterocedasticidade

\subsubsection{Variance Inflation Factor (VIF)}

O indicador variance inflation factor ou VIF é usado para avaliar se a variância dos coeficientes é inflada pela presença de multicolinearidade das variáveis.

$$
V I F_{i}=\frac{1}{\left(1-R_{i}^{2}\right)}
$$

Como regra de bolso, valores acima de 4 ou 5 sugerem problemas de multicolinearidade. 


\section{Resultados Empíricos}

\subsection{O Modelo de Três Fatores de Fama e French}

Inicialmente serão apresentadas algumas informações sobre a amostra utilizada e posteriormente serão apresentados os resultados do modelo.

\subsubsection{Dados e Estatísticas}

O número médio de empresas por semestre foi de 247 (ver Tabela 1), sendo que as carteiras low/small e high/big possuem o menor número de empresas representativas, 22 e 18 respectivamente. A carteira que apresentou o maior número médio de empresas foi high/small com 56 , seguida pelas carteiras medium/big (53) e low/big (52).

\begin{tabular}{|rrrrrrrr|} 
& $\begin{array}{l}\text { Low / } \\
\text { Small }\end{array}$ & $\begin{array}{r}\text { Low / } \\
\text { Big }\end{array}$ & $\begin{array}{r}\text { Medium } \\
\text { / Small }\end{array}$ & $\begin{array}{r}\text { Medium } \\
\text { / Big }\end{array}$ & $\begin{array}{r}\text { High / } \\
\text { Small }\end{array}$ & $\begin{array}{r}\text { High / } \\
\text { Big }\end{array}$ & $\begin{array}{r}\text { Total } \\
\text { Amostra }\end{array}$ \\
\hline Média & 22 & 52 & 46 & 53 & 56 & 18 & 247 \\
\hline
\end{tabular}

Tabela 1 - Número de Empresas por Carteira entre 1995-2012²

As carteiras compostas pelas empresas de grande porte representam a maior capitalização de mercado, cerca de $R \$ 1.300$ bilhões na média do período, atingindo $96,6 \%$ do total (Tabela 2). A maior carteira em termos financeiros é a low/big com valor médio de $\mathrm{R} \$ 625$ bilhões (média de $\mathrm{R} \$ 11,9$ bilhões por empresa), e a menor carteira é a low/small com apenas $\mathrm{R} \$ 11,5$ bilhões (tamanho médio de $\mathrm{R} \$ 0,5$ bilhão por empresa), como pode ser visto na Tabela 2.

\begin{tabular}{|lrrrrrrr|} 
& $\begin{array}{r}\text { Low / } \\
\text { Small }\end{array}$ & $\begin{array}{r}\text { Low / } \\
\text { Big }\end{array}$ & $\begin{array}{r}\text { Medium } \\
\text { / Small }\end{array}$ & $\begin{array}{r}\text { Medium } \\
\text { / Big }\end{array}$ & $\begin{array}{r}\text { High / } \\
\text { Small }\end{array}$ & $\begin{array}{r}\text { High / } \\
\text { Big }\end{array}$ & Mercado \\
\hline Média & 11,5 & 625,1 & 19,1 & 556,5 & 15,1 & 135,3 & $1.362,4$ \\
Valor por & 0,5 & 11,9 & 0,4 & 10,6 & 0,3 & 7,4 & 5,7 \\
Empresa & & & &
\end{tabular}

Tabela 2 - Valor de Mercado das Carteiras (R $\$$ bilhões) entre 1995-2012 3

\footnotetext{
2 Tabela compela no anexo.

3 Tabela compela no anexo.
} 
$\mathrm{Na}$ Tabela 3 é apresentada a participação percentual de cada carteira em termos do valor de mercado das empresas por semestre.

\begin{tabular}{|c|c|c|c|c|c|c|}
\hline & $\begin{array}{l}\text { Low / } \\
\text { Small }\end{array}$ & Low / Big & $\begin{array}{r}\text { Medium / } \\
\text { Small }\end{array}$ & $\begin{array}{r}\text { Medium / } \\
\text { Big }\end{array}$ & $\begin{array}{l}\text { High / } \\
\text { Small }\end{array}$ & $\begin{array}{r}\text { High / } \\
\text { Big }\end{array}$ \\
\hline Média & $0,8 \%$ & $49,0 \%$ & $1,5 \%$ & $36,5 \%$ & $1,1 \%$ & $11,0 \%$ \\
\hline
\end{tabular}

Tabela 3 - Participação de Mercado por Carteira entre 1995-2012

O retorno médio por carteira, por semestre, encontra-se na Tabela 4. Cabe destacar o retorno médio negativo $(-0,2 \%)$ da carteira low/small e o baixo retorno $(0,8 \%)$ da carteira medium/small. Quando realizado um teste de hipótese para verificar se os retornos destas carteiras são iguais a zero, em ambos os casos, não se consegue rejeitar a hipótese nula a 10\%.

\begin{tabular}{|lrrrrrrrr|}
\hline & $\begin{array}{r}\text { Low / } \\
\text { Small }\end{array}$ & $\begin{array}{r}\text { Low / } \\
\text { Big }\end{array}$ & $\begin{array}{r}\text { Mediu } \\
\text { m / } \\
\text { Small }\end{array}$ & $\begin{array}{r}\text { Mediu } \\
\mathbf{m} / \text { Big }\end{array}$ & $\begin{array}{r}\text { High / } \\
\text { Small }\end{array}$ & $\begin{array}{r}\text { High / } \\
\text { Big }\end{array}$ & $\begin{array}{r}\text { Merca } \\
\text { do }\end{array}$ & $\begin{array}{r}\text { Poupa } \\
\text { nça }\end{array}$ \\
\hline $\begin{array}{l}\text { Média } \\
-0,2 \%\end{array}$ & $1,9 \%$ & $0,8 \%$ & $2,3 \%$ & $2,6 \%$ & $2,0 \%$ & $2,0 \%$ & $0,9 \%$ \\
\hline $\begin{array}{l}\text { Desvio } \\
\text { Padrão }\end{array}$ & $4,5 \%$ & $4,0 \%$ & $4,1 \%$ & $4,1 \%$ & $4,1 \%$ & $4,1 \%$ & $4,0 \%$ & $0,6 \%$ \\
\hline $\begin{array}{l}\text { Estatís } \\
\text { tica t }\end{array}$ & $-0,32$ & 2,86 & 1,19 & 3,33 & 3,76 & 2,89 & 2,93 & 9,61 \\
\hline $\begin{array}{l}t \text { crítico } \\
5 \%\end{array}$ & 2,03 & - & - & - & - & - & - & - \\
\hline $\begin{array}{l}t \text { crítico } \\
10 \%\end{array}$ & 1,69 & - & - & - & - & - & - & - \\
\hline
\end{tabular}

Tabela 4 - Retorno Médio Mensal por Carteira entre 1995-2012 ${ }^{5}$

A correlação entre o retorno das carteiras e do mercado é muito elevada, sendo maior para a carteira de grandes empresas $(0,99)$ seguida das carteiras com indicador VP/VM médio $(0,96)$. Esta elevada correlação é natural em função da metodologia utilizada para criação da carteira de mercado. A correlação entre o retorno de todas as carteiras também é muito elevado como apresentado na Tabela 5 a seguir.

\begin{tabular}{|lcccccc|}
\hline Small & Small & Big & High & Medium & Low & Mercado \\
\hline Big & 1,00 & - & - & - & - & - \\
\hline High & 0,80 & 1,00 & - & - & - & - \\
\hline Medium & 0,86 & 0,94 & 1,00 & - & - & - \\
\hline Low & 0,92 & 0,95 & 0,91 & 1,00 & - & - \\
\hline Mercado & 0,96 & 0,85 & 0,83 & 0,93 & 1,00 & - \\
\hline
\end{tabular}

Tabela 5 - Correlação das Carteiras Puras

A preocupação com a alta correlação entre as variáveis, que pode ocasionar problemas de multicolinearidade para a regressão linear, levou Fama

\footnotetext{
${ }^{4}$ Tabela compela no anexo.

5 Tabela compela no anexo.
} 
e French a optarem pela utilização dos fatores small minus big e high minus low. $\mathrm{Na}$ Tabela 6 é apresentada a correlação entre variáveis independentes utilizadas no modelo.

Nota-se a significativa redução na correlação entre as variáveis. Não se pode negar a hipótese de correlação nula entre o prêmio de mercado e as demais carteiras, ao nível de $5 \%$. Todavia, a correlação entre os fatores SMB e HML se mostrou relevante em -0,49. No trabalho de Fama e French sobre o mercado norte americano, este valor ficou reduzido a apenas $-0,08$.

\begin{tabular}{|l|ccc|ccc|}
\hline & \multicolumn{3}{|c|}{ Correlação } & \multicolumn{3}{c|}{ Estatística t } \\
\hline $\mathbf{R}_{\mathbf{m}}-\mathbf{R}_{\mathbf{f}}$ & $\mathbf{R}_{\mathbf{m}}-\mathbf{R}_{\mathbf{f}}$ & $\mathbf{S M B}$ & $\mathbf{H M L}$ & $\mathbf{R}_{\mathbf{m}}-\mathbf{R}_{\mathbf{f}}$ & $\mathbf{S M B}$ & $\mathbf{H M L}$ \\
\hline $\mathbf{S M B}$ & $-0,14$ & - & - & - & - & - \\
\hline $\mathbf{H M L}$ & $-0,07$ & $-0,49$ & 1,00 & $-0,43$ & $-3,31$ & - \\
\hline
\end{tabular}

Tabela 6 - Correlação dos Fatores do Modelo de 3 Fatores

Outros estudos para o mercado brasileiro também encontraram uma correlação entre os fatores. Junior (2003) encontrou -0,16 de correlação entre as carteiras SMB e HML, Mussa (2007) -0,26 e Málaga e Securato (2004) de apenas $-0,07$. Cabe ressaltar que estes autores encontraram correlação elevada entre outros fatores, como: Junior (2003) calculou em 0,39 a correlação entre prêmio de mercado e HML, Mussa (2007) de -0,61 para a correlação prêmio de mercado e SMB e Málaga e Securato (2004) de -0,48 para a correlação prêmio de mercado e SMB.

Visando checar se a dependência entre as variáveis poderia acarretar problemas de multicolinearidade foi calculado o variance inflation factor (VIP). Como os valores ficaram próximos de um a multicolinearidade não parece ser um problema no modelo apesar da correlação encontrada entre os fatores SMB e HML.

\begin{tabular}{|cc|}
\hline & VIF \\
\hline $\mathbf{R}_{\mathbf{m}}-\mathbf{R}_{\mathbf{f}}$ & 1,05 \\
\hline $\mathbf{S M B}$ & 1,38 \\
\hline $\mathbf{H M L}$ & 1,36 \\
\hline
\end{tabular}

Tabela 7 - Variance Inflation Factor para Modelo de Três Fatores

A Tabela 8 a seguir mostra os valores das variáveis independentes para cada semestre e sua média do período. Para o prêmio de risco calculou-se um retorno médio de $1,1 \%$ ao mês. 
Para a estratégia small minus big encontrou-se um prêmio negativo de $-1,0 \%$, indicando que as empresas menores não apresentam retornos acima das grandes empresas no Brasil. Este fator é contra intuitivo e não corresponde às expectativas de maior risco e maior retorno. Uma maior valorização das grandes empresas no país pode estar relacionada a uma maior liquidez destas companhias - um possível prêmio de liquidez, porém isso não será foco do presente estudo. Apesar desta anomalia, o estudo prosseguiu conforme modelado por Fama e French.

O fator HML apresentou um retorno médio mensal de 1,5\% no período.

\begin{tabular}{|c|c|c|c|}
\hline & & SMB & HML \\
\hline Média & $1,1 \%$ & $-1,0 \%$ & $1,5 \%$ \\
\hline Desvio Padrão & $4,1 \%$ & $2,5 \%$ & $2,3 \%$ \\
\hline Estatística t & 1,56 & $-2,45$ & 3,81 \\
\hline t crítico 5\% & 2,03 & - & - \\
\hline t crítico $10 \%$ & 1,69 & - & - \\
\hline
\end{tabular}

Tabela 8 - Retorno Médio Mensal de cada Fator ${ }^{6}$

$\mathrm{Na}$ Tabela 9 a seguir pode-se comparar o retorno médio mensal para cada fator encontrado em outros estudos para o mercado brasileiro, e do modelo original de Fama e French.

\begin{tabular}{|lcrr|}
\hline & $\mathbf{R}_{\mathrm{m}}-\mathbf{R}_{\mathrm{f}}$ & SMB & HML \\
\hline Brasil & & & \\
\hline Junior (2003) & $1,7 \%$ & $1,3 \%$ & $1,0 \%$ \\
\hline Mussa (2007) & $1,6 \%$ & $-0,1 \%$ & $1,6 \%$ \\
\hline Málaga e Securato (2004) & $1,1 \%$ & $-0,3 \%$ & $0,6 \%$ \\
\hline Presente Estudo & $1,1 \%$ & $-1,0 \%$ & $1,5 \%$ \\
\hline EUA & & & \\
\hline Fama e French (1993) & $0,4 \%$ & $0,3 \%$ & $0,4 \%$ \\
\hline
\end{tabular}

Tabela 9 - Comparação do Retorno Médio Mensal por Fator Calculado em Outros Estudos

\subsubsection{Resultado Modelo de Três Fatores}

Com base nos dados apresentados anteriormente foram calculadas as regressões lineares pelo método dos mínimos quadrados ordinários.

Todas as regressões apresentaram um poder explicativo elevado. O menor valor do $\mathrm{R}^{2}$ ajustado encontrado foi de 0,86 para a carteira high/big.

\footnotetext{
${ }^{6}$ Tabela compela no anexo.
} 
O intercepto de todas as regressões apresentou-se muito próximo de zero indicando que os fatores do modelo conseguiram explicar grande parte da variação da variável dependente.

O beta de mercado ficou entre 0,90 e 0,97 sendo estatisticamente significativo para todas as carteiras. Fama e French também observaram que 0 valor do beta tende a se aproximar de 1 e diminui sua variabilidade com a inclusão dos novos fatores.

Em relação ao fator $\mathrm{SMB}$, duas das seis carteiras não apresentaram coeficiente com valor significativo a 5\% (low/big e high/big), e uma apresentou o coeficiente negativo (medium/big). Nas carteiras com empresas de pequeno porte o coeficiente variou entre 0,95 e 1,00. Assim, pode-se notar que o fator tamanho foi mais importante para ajudar a explicar o retorno das carteiras das empresas de pequeno porte.

Para o fator $\mathrm{HML}$, apenas uma carteira não teve 0 coeficiente estatisticamente diferente de zero (medium/big) ao nível de $5 \%$. O valor do coeficiente aumenta de acordo com o valor do indicador VP/VM. Nas carteiras com baixo VP/VM o coeficiente se mostrou negativo entre $-0,40$ e $-0,16$, nas carteiras com indicador médio o valor varia entre $-0,07$ e 0,26 , e nas carteiras de alto VP/VM o coeficiente foi positivo entre 0,68 e 0,77.

\begin{tabular}{|c|c|c|c|c|c|c|c|c|c|c|}
\hline Carteira & $\mathrm{R}^{2}$ & $\begin{array}{c}R^{2} \\
\text { Ajus } \\
\text { tado }\end{array}$ & $\alpha$ & $\begin{array}{l}\text { p- } \\
\text { valor } \\
\alpha\end{array}$ & $\beta$ & $\begin{array}{c}\text { p- } \\
\text { valor } \\
\beta\end{array}$ & $\mathbf{s}$ & $\begin{array}{c}\text { p- } \\
\text { valor } \\
s\end{array}$ & h & $\begin{array}{c}\text { p- } \\
\text { valor } \\
h\end{array}$ \\
\hline Low/Small & 0,93 & 0,93 & $-0,01$ & 0,04 & 0,91 & 0,00 & 0,95 & 0,00 & $-0,40$ & 0,00 \\
\hline Low/Big & 0,95 & 0,95 & 0,00 & 0,12 & 0,97 & 0,00 & 0,10 & 0,18 & $-0,16$ & 0,05 \\
\hline Medium/Small & 0,91 & 0,90 & 0,00 & 0,10 & 0,96 & 0,00 & 1,00 & 0,00 & 0,26 & 0,03 \\
\hline Medium/Big & 0,95 & 0,94 & 0,00 & 0,27 & 0,97 & 0,00 & $-0,24$ & 0,01 & $-0,07$ & 0,44 \\
\hline High/Small & 0,96 & 0,95 & 0,01 & 0,00 & 0,97 & 0,00 & 0,99 & 0,00 & 0,68 & 0,00 \\
\hline High/Big & 0,87 & 0,86 & $-0,01$ & 0,01 & 0,90 & 0,00 & 0,07 & 0,58 & 0,77 & 0,00 \\
\hline
\end{tabular}

Tabela 10 - Resultado da Regressão para Modelo de Três Fatores

Utilizando a estatística $F$ para testar se todos os coeficientes são diferentes de zero conjuntamente, pode-se rejeitar a hipótese nula a 5\% (Tabela 11).

$\mathrm{H}_{0}: \beta=s=h=0$

$\mathrm{H}_{\mathrm{a}}$ : Pelo menos um dos coeficientes é diferente de zero

\begin{tabular}{|lcc|}
\hline Carteira & Estatística F & p-valor \\
\hline Low/Small & 147,25 & 0,00 \\
\hline Low/Big & 214,74 & 0,00 \\
\hline Medium/Small & 111,51 & 0,00 \\
\hline
\end{tabular}




\begin{tabular}{|lcc|}
\hline Medium/Big & 196,43 & 0,00 \\
\hline High/Small & 245,58 & 0,00 \\
\hline High/Big & 70,34 & 0,00 \\
\hline
\end{tabular}

Tabela 11 - Teste F para o Modelo de Três Fatores

Para verificar a autocorrelação dos resíduos e avaliar a qualidade da regressão foi realizado o teste de Durbin-Watson ao nível de significância de 5\%. Como se pode ver na Tabela 12 não foi encontrado autocorrelação para nenhuma das equações.

A hipótese do teste é:

- $\mathrm{H}_{0}$ : Não existe autocorrelação

- $\mathrm{H}_{\mathrm{a}}$ : Autocorrelação positiva

- $\mathrm{H}_{\circ}^{*}$ : Não existe autocorrelação

- $\mathrm{H}_{\mathrm{a}}^{*}$ : Autocorrelação negativa

\begin{tabular}{|lcc|}
\hline & Estatística DW & \multicolumn{1}{c|}{ Resultado } \\
\hline Low/Small & 1,97 & Não tem autocorrelação \\
\hline Low/Big & 1,72 & Não tem autocorrelação \\
\hline Medium/Small & 1,67 & Não tem autocorrelação \\
\hline Medium/Big & 2,12 & Não tem autocorrelação \\
\hline High/Small & 1,54 & Inconclusivo \\
\hline High/Big & 1,86 & Não tem autocorrelação \\
\hline
\end{tabular}

Tabela 12 - Teste Durbin-Watson para Modelo Três Fatores

Para avaliar se os resíduos seguem uma distribuição normal foi realizado o teste Jarque-Bera. Na Tabela 13 mostra-se a estatística JB calculada e a probabilidade desta estatística exceder o valor da tabela (caso em que se rejeitaria a hipótese nula). A hipóstese nula é que a série tem uma distribuição normal. Assim, ao nível de 5\% aceita-se a hipótese nula que os resíduos seguem distribuição normal para todas as regressões do modelo. Cabe destacar que o teste serve para amostras grandes, não sendo possível garantir que as 36 observações desta amostra são suficientemente grande.

A hipótese do teste é:

- $\mathrm{H}_{0}$ : Distribuição normal

- $\mathrm{H}_{\mathrm{a}}$ : Não segue distribuição normal

\begin{tabular}{|lcc|} 
& Estatística JB & Probabilidade \\
\hline Low/Small & 3,38 & 0,18 \\
\hline Low/Big & 0,25 & 0,88 \\
\hline Medium/Small & 1,88 & 0,39 \\
\hline Medium/Big & 0,67 & 0,72 \\
\hline High/Small & 0,17 & 0,92 \\
\hline
\end{tabular}




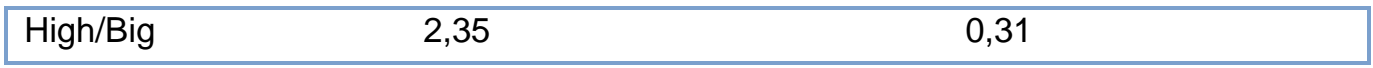

Tabela 13 - Teste Jarque-Bera para Modelo Três Fatores

Foi realizado o Teste White para avaliar se os resíduos são homocedásticos. Na Tabela 14 a estatística White calculada e a probabilidade desta estatística exceder o valor da tabela (caso em que se rejeitaria a hipótese nula) estão apresentados. A hipótese nula é que não existe heterocedasticidade. Ao nível de $5 \%$ aceita-se a hipótese nula para 5 regressões, a outra regressão pode-se aceitar a hipótese nula ao nível de 1\%.

Cabe destacar que o teste serve para amostras grandes, não sendo possível garantir que as 36 observações desta amostra são suficientemente grande.

A hipótese do teste é:

- $\mathrm{H}_{\mathrm{o}}$ : Homocedasticidade

- $\mathrm{H}_{\mathrm{a}}$ : Heterocedasticidade

\begin{tabular}{|lcc|}
\hline & $\mathbf{n}^{*} \mathbf{R}^{2}$ & Probabilidade Qui-Quadrado \\
\hline Low/Small & 7,8 & 0,55 \\
\hline Low/Big & 16,4 & 0,06 \\
\hline Medium/Small & 17,4 & 0,04 \\
\hline Medium/Big & 14,4 & 0,11 \\
\hline High/Small & 15,3 & 0,08 \\
\hline High/Big & 9,4 & 0,41 \\
\hline
\end{tabular}

Tabela 14 - Teste White para Modelo Três Fatores

\subsubsection{Comparação do Modelo de Três Fatores com o CAPM}

Utilizando a mesma base de dados estimou-se o modelo CAPM. Os valores encontrados para $\mathrm{R}^{2}$ ajustado foram inferiores, para todas as carteiras, aos encontrados no Modelo de Três Fatores (ver Tabela 15 e Tabela 16). Destaca-se que as carteiras das empresas de pequeno porte apresentaram as maiores reduções no seu poder explicativo. Isso era esperado em função dos valores e relevância dos coeficientes SMB calculados no modelo de três fatores previamente apresentados na Tabela 10.

\begin{tabular}{|l|cc|cc|cc|}
\hline Carteira & $\mathbf{R}^{2}$ & $\begin{array}{c}\mathbf{R}^{2} \\
\text { Ajustado }\end{array}$ & $\boldsymbol{\alpha}$ & $\mathbf{p}$-valor $\boldsymbol{\alpha}$ & $\boldsymbol{\beta}$ & $\mathbf{p}$-valor $\boldsymbol{\beta}$ \\
\hline Low/Small & 0,55 & 0,54 & $-0,02$ & 0,00 & 0,85 & 0,00 \\
\hline Low/Big & 0,94 & 0,93 & 0,00 & 0,89 & 0,97 & 0,00 \\
\hline $\begin{array}{l}\text { Medium/Sma } \\
\text { II }\end{array}$ & 0,66 & 0,65 & $-0,01$ & 0,03 & 0,87 & 0,00 \\
\hline Medium/Big & 0,93 & 0,93 & 0,00 & 0,08 & 0,99 & 0,00 \\
\hline
\end{tabular}




\begin{tabular}{|l|ll|ll|ll|}
\hline High/Small & 0,71 & 0,71 & 0,01 & 0,06 & 0,87 & 0,00 \\
\hline High/Big & 0,71 & 0,70 & 0,00 & 0,66 & 0,87 & 0,00 \\
\hline
\end{tabular}

Tabela 15 - Resultado da Regressão para Modelo CAPM

\begin{tabular}{|l|cc|c|}
\hline Carteira & $\mathbf{R}^{2}$ & $\mathbf{R}^{2}$ Ajustado & $\boldsymbol{\beta}$ \\
\hline Low/Small & $-0,38$ & $-0,39$ & $-0,06$ \\
\hline Low/Big & $-0,02$ & $-0,01$ & 0,00 \\
\hline Medium/Small & $-0,25$ & $-0,25$ & $-0,09$ \\
\hline Medium/Big & $-0,02$ & $-0,01$ & 0,02 \\
\hline High/Small & $-0,24$ & $-0,25$ & $-0,11$ \\
\hline High/Big & $-0,16$ & $-0,15$ & $-0,04$ \\
\hline
\end{tabular}

Tabela 16 - Valores Encontrados pelo Modelo CAPM Menos Valores Encontrados pelo Modelo de Três Fatores

O valor do beta se reduziu para a maioria das carteiras, e apresentou um aumento de sua variabilidade, ficando entre 0,85 e 0,99. O beta se mostrou significante para todas as carteiras do modelo CAPM.

O teste de Durbin-Watson para o modelo CAPM indica uma autocorrelação positiva dos resíduos para a carteira low/small ao nível de significância de 5\% como apresentado na Tabela 17.

A hipótese do teste é:

- $\mathrm{H}_{0}$ : Não existe autocorrelação

- $\mathrm{H}_{\mathrm{a}}$ : Autocorrelação positiva

- $\mathrm{H}_{0}^{*}$ : Não existe autocorrelação

- $\mathrm{H}_{\mathrm{a}}^{*}$ : Autocorrelação negativa

\begin{tabular}{|lcc|}
\hline & Estatistica DW & \multicolumn{1}{c|}{ Resultado } \\
\hline Low/Small & 1,24 & Autocorrelação Positiva \\
\hline Low/Big & 1,47 & Inconclusivo \\
\hline Medium/Small & 1,48 & Inconclusivo \\
\hline Medium/Big & 1,95 & Não tem autocorrelação \\
\hline High/Small & 1,87 & Não tem autocorrelação \\
\hline High/Big & 2,36 & Não tem autocorrelação \\
\hline
\end{tabular}

Tabela 17 - Teste Durbin-Watson para Modelo CAPM

O teste Jarque-Bera indicou que 5 regressões apresentam distribuição normal ao nível de 5\%, e uma ao nível de 1\%, como pode ser visto na Tabela 18. Mais uma vez ressalta-se que o teste serve para amostras grandes, não sendo possível garantir que as 36 observações desta amostra são suficientemente grande.

A hipótese do teste é:

- $\mathrm{H}_{0}$ : Distribuição normal

- $\mathrm{H}_{\mathrm{a}}$ : Não segue distribuição normal 


\begin{tabular}{|lcc|}
\hline & Estatística JB & Probabilidade \\
\hline Low/Small & 1,60 & 0,45 \\
\hline Low/Big & 0,94 & 0,62 \\
\hline Medium/Small & 9,47 & 0,01 \\
\hline Medium/Big & 2,01 & 0,37 \\
\hline High/Small & 1,03 & 0,60 \\
\hline High/Big & 3,97 & 0,14 \\
\hline
\end{tabular}

Tabela 18 - Teste Jarque-Bera para Modelo CAPM

O Teste White indicou que os resíduos são homocedásticos, com as estatísticas de teste e a probabilidade destas estatísticas excederem o valor da tabela (caso em que se rejeitaria a hipótese nula) estão apresentados na Tabela 19. Como já mencionado o teste serve para amostras grandes, não sendo possível garantir que as 36 observações desta amostra são suficientemente grande.

A hipótese do teste é:

- $\mathrm{H}_{0}$ : Homocedasticidade

- $\mathrm{H}_{\mathrm{a}}$ : Heterocedasticidade

\begin{tabular}{|lcc|} 
& $\mathrm{n}^{*} \mathbf{R}^{2}$ & Probabilidade Qui-Quadrado \\
\hline Low/Small & 1,68 & 0,43 \\
\hline Low/Big & 0,26 & 0,88 \\
\hline Medium/Small & 2,45 & 0,29 \\
\hline Medium/Big & 4,42 & 0,11 \\
\hline High/Small & 2,08 & 0,35 \\
\hline High/Big & 0,11 & 0,95 \\
\hline
\end{tabular}

Tabela 19 - Teste White para Modelo CAPM

\subsection{Modelo APT Unificado ao CAPM}

Inicialmente será explicado o critério para a determinação das variáveis independentes do modelo, seguido pela apresentação de alguns dados e estatísticas sobre a amostra utilizada. Finalmente será apresentado o resultado do modelo.

\subsubsection{Determinação das Variáveis Independentes do Modelo}

Para conseguir melhor especificar o modelo foram calculadas as correlações cruzadas entre as vinte carteiras (variáveis dependentes) e as 
variáveis macroeconômicas (variáveis independentes) previamente escolhidas a fim de encontrar o momento temporal que melhor retrata a relação entre as variáveis.

Nas Tabela 20, Tabela 21, Tabela 22, Tabela 23 e Tabela 26 a seguir estão apresentados os valores encontrados. Em negrito estão destacados o maior valor absoluto para a correlação de cada carteira com o fator em análise.

Para a variação cambial (R\$/US\$) o mês seguinte foi o que mostrou maior impacto em 13 das 20 carteiras. Quando o real se deprecia (variação positiva do câmbio) as ações apresentam um resultado negativo. $O$ fato da variação do mês seguinte impactar o retorno das ações no mês atual parece refletir as mudanças de expectativas dos agentes do mercado antes mesmo do fato gerador.

\begin{tabular}{|c|c|c|c|c|c|c|c|c|c|c|c|}
\hline & -5 & -4 & -3 & -2 & -1 & 0 & 1 & 2 & 3 & 4 & 5 \\
\hline Cart 1 & 0,03 & $-0,01$ & $-0,01$ & 0,13 & 0,15 & $-0,26$ & $-0,22$ & $-0,01$ & 0,03 & $-0,03$ & $-0,14$ \\
\hline Cart 2 & $-0,01$ & 0,08 & 0,05 & 0,03 & 0,04 & 0,02 & $-0,12$ & $-0,10$ & $-0,05$ & 0,06 & $-0,03$ \\
\hline Cart 3 & 0,08 & 0,07 & 0,00 & 0,03 & 0,04 & $-0,04$ & $-0,15$ & $-0,13$ & 0,04 & 0,04 & $-0,16$ \\
\hline Cart 4 & $-0,02$ & 0,04 & 0,05 & 0,01 & 0,02 & $-0,11$ & $-0,21$ & $-0,12$ & 0,03 & 0,04 & $-0,08$ \\
\hline Cart 5 & 0,04 & 0,08 & 0,01 & 0,00 & 0,00 & $-0,11$ & $-0,11$ & $-0,06$ & $-0,03$ & $-0,09$ & $-0,16$ \\
\hline Cart 6 & 0,02 & $-0,02$ & $-0,03$ & 0,06 & $-0,05$ & $-0,18$ & $-0,22$ & $-0,18$ & $-0,08$ & 0,00 & $-0,04$ \\
\hline Cart 7 & 0,01 & 0,02 & 0,02 & 0,13 & 0,03 & $-0,25$ & $-0,37$ & $-0,09$ & 0,04 & 0,03 & $-0,11$ \\
\hline Cart 8 & $-0,06$ & $-0,04$ & 0,03 & $-0,02$ & $-0,04$ & $-0,06$ & $-0,18$ & $-0,13$ & $-0,05$ & $-0,11$ & $-0,18$ \\
\hline Cart 9 & 0,05 & 0,06 & 0,02 & 0,12 & 0,01 & $-0,12$ & $-0,20$ & $-0,12$ & $-0,12$ & $-0,10$ & $-0,13$ \\
\hline Cart 10 & $-0,03$ & 0,01 & 0,01 & 0,10 & 0,11 & $-0,27$ & $-0,41$ & $-0,08$ & 0,05 & 0,06 & $-0,09$ \\
\hline Cart 11 & $-0,03$ & $-0,03$ & $-0,01$ & 0,09 & 0,01 & $-0,29$ & $-0,38$ & $-0,09$ & 0,06 & $-0,02$ & $-0,23$ \\
\hline Cart 12 & $-0,02$ & 0,02 & 0,03 & 0,12 & 0,07 & $-0,13$ & $-0,34$ & $-0,11$ & $-0,01$ & 0,12 & $-0,07$ \\
\hline Cart 13 & $-0,07$ & 0,01 & 0,02 & 0,06 & 0,02 & $-0,13$ & $-0,31$ & $-0,08$ & $-0,02$ & 0,11 & $-0,04$ \\
\hline Cart 14 & $-0,03$ & 0,07 & 0,03 & 0,08 & 0,01 & $-0,33$ & $-0,40$ & $-0,14$ & 0,00 & 0,00 & $-0,12$ \\
\hline Cart 15 & 0,02 & 0,06 & $-0,01$ & 0,09 & 0,13 & $-0,21$ & $-0,37$ & $-0,16$ & $-0,01$ & 0,03 & $-0,12$ \\
\hline Cart 16 & 0,04 & 0,05 & 0,01 & 0,18 & 0,15 & $-0,15$ & $-0,30$ & $-0,12$ & $-0,01$ & 0,05 & $-0,06$ \\
\hline Cart 17 & $-0,02$ & $-0,03$ & 0,00 & $-0,07$ & 0,07 & $-0,08$ & $-0,21$ & 0,05 & 0,10 & $-0,02$ & $-0,03$ \\
\hline Cart 18 & 0,18 & 0,15 & $-0,03$ & $-0,03$ & $-0,10$ & $-0,35$ & $-0,32$ & $-0,22$ & $-0,12$ & $-0,08$ & $-0,08$ \\
\hline Cart 19 & 0,16 & 0,13 & $-0,03$ & $-0,07$ & $-0,17$ & $-0,53$ & $-0,43$ & $-0,28$ & $-0,16$ & $-0,14$ & 0,04 \\
\hline Cart 20 & 0,15 & 0,06 & 0,02 & 0,01 & $-0,19$ & $-0,50$ & $-0,49$ & $-0,34$ & $-0,12$ & $-0,09$ & $-0,07$ \\
\hline
\end{tabular}

Tabela 20 - Correlação Cruzada das Carteiras com a Variação Cambial

Em relação à variação na taxa Selic determinada pelo Banco Central, o mês seguinte também foi o que apresentou maior representatividade para 15 das 20 carteiras analisadas. Quando se espera um aumento na taxa de juros no mês seguinte observa-se uma redução no retorno das ações no mês atual.

\begin{tabular}{|lcc|ccc|c|ccccc|}
\hline & $\mathbf{- 5}$ & $\mathbf{- 4}$ & $\mathbf{- 3}$ & $\mathbf{- 2}$ & $\mathbf{- 1}$ & $\mathbf{0}$ & $\mathbf{1}$ & $\mathbf{2}$ & $\mathbf{3}$ & $\mathbf{4}$ & $\mathbf{5}$ \\
\hline Cart 1 & $-0,06$ & $-0,08$ & $\mathbf{0 , 0 2}$ & $-0,05$ & $\mathbf{0 , 0 0}$ & $\mathbf{0 , 1 3}$ & $\mathbf{- 0 , 4 1}$ & $-0,07$ & 0,03 & $-0,01$ & $-0,03$ \\
\hline Cart 2 & $-0,08$ & 0,04 & $\mathbf{0 , 1 3}$ & $-0,13$ & 0,10 & $-0,02$ & $-0,09$ & 0,03 & $-0,10$ & 0,06 & 0,03 \\
\hline Cart 3 & $-0,07$ & $\mathbf{0 , 0 9}$ & $\mathbf{0 , 0 4}$ & $-0,09$ & 0,08 & $-0,05$ & $\mathbf{- 0 , 2 8}$ & 0,04 & $-0,13$ & 0,04 & $-0,09$ \\
\hline Cart 4 & 0,01 & $-0,02$ & 0,06 & $-0,06$ & $-0,02$ & $-0,04$ & $\mathbf{- 0 , 2 7}$ & $-0,05$ & $-0,01$ & $-0,02$ & 0,07 \\
\hline Cart 5 & $\mathbf{0 , 0 2}$ & $\mathbf{0 , 2 5}$ & $\mathbf{0 , 0 6}$ & $-0,10$ & 0,01 & $-0,11$ & $\mathbf{- 0 , 3 0}$ & 0,07 & $-0,13$ & 0,07 & $-0,10$ \\
\hline
\end{tabular}




\begin{tabular}{|lccccc|c|ccccc|}
\hline Cart 6 & $-0,01$ & 0,12 & $-0,04$ & $-0,06$ & 0,15 & $-0,10$ & $\mathbf{- 0 , 2 0}$ & $-0,08$ & $-0,07$ & 0,05 & $-0,03$ \\
\hline Cart 7 & 0,04 & 0,08 & $-0,02$ & $-0,06$ & 0,03 & 0,07 & $\mathbf{- 0 , 2 9}$ & $-0,06$ & $-0,10$ & 0,04 & 0,04 \\
\hline Cart 8 & 0,01 & 0,14 & $-0,03$ & $-0,05$ & 0,04 & 0,00 & $\mathbf{- 0 , 2 0}$ & 0,05 & $-0,11$ & 0,06 & $-0,08$ \\
\hline Cart 9 & $-0,02$ & 0,16 & 0,05 & $-0,11$ & 0,04 & $-0,11$ & $\mathbf{- 0 , 2 3}$ & 0,02 & $-0,03$ & 0,01 & 0,02 \\
\hline Cart 10 & 0,01 & 0,00 & $-0,01$ & $-0,11$ & 0,13 & 0,08 & $\mathbf{- 0 , 3 3}$ & $-0,11$ & $-0,04$ & 0,08 & 0,01 \\
\hline Cart 11 & 0,04 & 0,10 & $-0,08$ & $-0,09$ & 0,12 & $-0,04$ & $\mathbf{- 0 , 2 0}$ & $-0,13$ & 0,03 & 0,09 & 0,09 \\
\hline Cart 12 & $-0,05$ & 0,06 & $-0,03$ & $-0,04$ & 0,12 & 0,15 & $\mathbf{- 0 , 2 1}$ & $-0,10$ & $-0,14$ & 0,05 & $-0,05$ \\
\hline Cart 13 & $-0,07$ & 0,07 & 0,00 & $-0,06$ & 0,10 & 0,14 & $\mathbf{- 0 , 2 1}$ & $-0,06$ & $-0,12$ & 0,02 & $-0,04$ \\
\hline Cart 14 & $-0,01$ & $-0,02$ & 0,07 & $-0,06$ & 0,06 & $-0,02$ & $\mathbf{- 0 , 2 3}$ & $-0,07$ & $-0,05$ & 0,13 & $-0,01$ \\
\hline Cart 15 & 0,04 & 0,02 & $-0,11$ & $-0,10$ & 0,19 & 0,09 & $\mathbf{- 0 , 3 1}$ & $-0,16$ & $-0,04$ & 0,04 & 0,03 \\
\hline Cart 16 & $-0,02$ & 0,05 & $-0,04$ & $-0,12$ & 0,12 & 0,05 & $\mathbf{- 0 , 3 6}$ & 0,02 & $-0,08$ & 0,08 & 0,03 \\
\hline Cart 17 & $-0,02$ & $-0,17$ & 0,17 & $-0,20$ & 0,09 & $-0,01$ & $-0,08$ & 0,03 & $-0,19$ & 0,32 & $-\mathbf{0 , 3 6}$ \\
\hline Cart 18 & $-0,06$ & 0,13 & $-0,02$ & $\mathbf{- 0 , 1 5}$ & $-0,06$ & $-0,12$ & $-0,09$ & $-0,06$ & $-0,06$ & $-0,11$ & 0,10 \\
\hline Cart 19 & $-0,12$ & $-0,01$ & $-0,16$ & $-0,10$ & $-0,03$ & $-0,14$ & $-0,12$ & 0,04 & 0,01 & $-0,05$ & $\mathbf{0 , 1 7}$ \\
\hline Cart 20 & $-0,10$ & $-0,03$ & $-0,02$ & $\mathbf{- 0 , 2 1}$ & 0,06 & $-0,10$ & $-0,12$ & $-0,10$ & 0,07 & $-0,01$ & $-0,05$ \\
\hline
\end{tabular}

Tabela 21 - Correlação Cruzada das Carteiras com a Variação da Taxa Selic

$\mathrm{Na}$ Tabela 22 mostra-se a correlação cruzada entre as carteiras e a variação da produção industrial mensal dessazonalizada medida pelo IBGE. Como nas tabelas anteriores o valor em negrito é o maior número em valor absoluto da relação de cada carteira com a variável independente. O número em negrito e itálico representa o segundo maior número em valor absoluto.

A correlação das carteiras com a produção industrial dois períodos a frente foi a que se mostrou mais significativo para o maior número de carteiras (14 das 20 carteiras). O segundo maior valor absoluto observado para a variável se mostrou para os períodos -4 e +4 , ambos com 6 carteiras cada.

\begin{tabular}{|lccccccccccc|}
\hline & $-\mathbf{5}$ & $-\mathbf{4}$ & $\mathbf{- 3}$ & $\mathbf{- 2}$ & $-\mathbf{1}$ & $\mathbf{0}$ & $\mathbf{1}$ & $\mathbf{2}$ & $\mathbf{3}$ & $\mathbf{4}$ & $\mathbf{5}$ \\
\hline Cart 1 & $-0,05$ & $-0,02$ & $-0,09$ & 0,03 & 0,00 & 0,03 & 0,05 & $\mathbf{0 , 1 9}$ & 0,07 & $\mathbf{0 , 1 6}$ & $-0,01$ \\
\hline Cart 2 & 0,01 & $-0,08$ & $-0,02$ & 0,02 & 0,03 & 0,02 & 0,04 & 0,07 & $\mathbf{0 , 1 4}$ & $\mathbf{0 , 1 4}$ & $-0,11$ \\
\hline Cart 3 & $-0,06$ & $\mathbf{- 0 , 1 4}$ & $-0,06$ & 0,02 & 0,03 & 0,04 & 0,01 & $\mathbf{0 , 2 1}$ & 0,01 & 0,11 & 0,01 \\
\hline Cart 4 & $-0,08$ & $\mathbf{- 0 , 1 2}$ & 0,00 & 0,10 & 0,03 & 0,11 & 0,13 & 0,10 & $\mathbf{0 , 2 0}$ & 0,11 & 0,07 \\
\hline Cart 5 & $-0,10$ & $-0,12$ & $-0,06$ & 0,09 & 0,10 & 0,03 & 0,08 & $\mathbf{0 , 2 1}$ & $\mathbf{0 , 1 2}$ & 0,11 & 0,04 \\
\hline Cart 6 & $\mathbf{- 0 , 1 3}$ & $-0,13$ & 0,02 & 0,09 & 0,01 & 0,07 & 0,11 & $\mathbf{0 , 2 3}$ & 0,09 & 0,13 & $-0,03$ \\
\hline Cart 7 & $-0,15$ & $-0,10$ & $-0,06$ & 0,06 & 0,08 & 0,01 & 0,09 & $\mathbf{0 , 1 7}$ & 0,12 & $\mathbf{0 , 1 5}$ & 0,03 \\
\hline Cart 8 & $-0,06$ & $-0,08$ & $-0,05$ & 0,06 & 0,11 & $-0,07$ & 0,00 & $\mathbf{0 , 1 9}$ & 0,03 & $\mathbf{0 , 1 2}$ & 0,00 \\
\hline Cart 9 & $-0,15$ & $-0,10$ & $-0,04$ & $\mathbf{0 , 1 9}$ & 0,01 & 0,12 & 0,11 & $\mathbf{0 , 2 6}$ & 0,15 & 0,17 & 0,02 \\
\hline Cart 10 & $-0,06$ & $\mathbf{- 0 , 1 6}$ & $-0,04$ & 0,14 & 0,05 & 0,03 & 0,06 & $\mathbf{0 , 2 5}$ & 0,05 & 0,13 & 0,00 \\
\hline Cart 11 & $-0,11$ & $\mathbf{- 0 , 1 9}$ & $-0,01$ & 0,10 & 0,09 & 0,05 & 0,06 & $\mathbf{0 , 2 1}$ & 0,07 & 0,05 & $-0,04$ \\
\hline Cart 12 & $-0,12$ & $\mathbf{- 0 , 1 3}$ & $-0,06$ & 0,09 & 0,03 & 0,04 & $-0,02$ & $\mathbf{0 , 1 7}$ & 0,04 & 0,10 & 0,05 \\
\hline Cart 13 & $-\mathbf{- 0 , 1 2}$ & $-0,10$ & 0,00 & 0,10 & 0,03 & 0,11 & 0,03 & $\mathbf{0 , 1 2}$ & 0,04 & 0,02 & 0,06 \\
\hline Cart 14 & $-0,10$ & $\mathbf{- 0 , 1 1}$ & $-0,04$ & 0,08 & 0,10 & 0,09 & 0,11 & $\mathbf{0 , 1 8}$ & 0,08 & 0,09 & 0,07 \\
\hline Cart 15 & $-0,02$ & $-0,15$ & 0,02 & 0,11 & 0,01 & $-0,01$ & 0,08 & $\mathbf{0 , 2 9}$ & 0,05 & $\mathbf{0 , 1 9}$ & $-0,02$ \\
\hline Cart 16 & $-0,11$ & $-0,13$ & $-0,04$ & $\mathbf{0 , 1 3}$ & 0,04 & 0,06 & 0,13 & $\mathbf{0 , 2 4}$ & 0,09 & 0,08 & 0,02 \\
\hline Cart 17 & 0,00 & $-0,09$ & $-0,09$ & 0,06 & $-0,12$ & $\mathbf{0 , 2 2}$ & 0,03 & $\mathbf{0 , 1 9}$ & $-0,04$ & 0,16 & $-0,04$ \\
\hline Cart 18 & $\mathbf{- 0 , 2 0}$ & $-0,09$ & $-0,03$ & 0,11 & 0,02 & 0,10 & 0,02 & 0,11 & 0,10 & $\mathbf{0 , 1 5}$ & 0,12 \\
\hline Cart 19 & $-0,29$ & $-0,21$ & $-0,01$ & 0,11 & 0,04 & 0,10 & $\mathbf{0 , 3 7}$ & $\mathbf{0 , 4 6}$ & 0,23 & 0,14 & 0,12 \\
\hline Cart 20 & $-0,30$ & $-0,27$ & $-0,01$ & 0,11 & 0,02 & 0,05 & $\mathbf{0 , 3 5}$ & $\mathbf{0 , 3 6}$ & 0,25 & 0,12 & 0,11 \\
\hline
\end{tabular}


Tabela 22 - Correlação Cruzada das Carteiras com a Variação do Índice de Produção Industrial Dessazonalizado

Optou-se por usar como variável explicativa a produção industrial de quatro períodos à frente. Essa decisão teve como base a correlação entre as variáveis independentes do modelo que estão apresentadas na Tabela 23, Tabela 24 e Tabela 25.

A produção industrial quatro períodos a frente foi o fator que apresentou menor correlação com as outras variáveis. Apesar da correlação para a produção industrial dois períodos à frente e de quatro períodos para trás não terem sido alarmantes, o coeficiente destas variáveis se mostraram consideravelmente menos significativos e impactaram a qualidade final do modelo.

\begin{tabular}{|lccccc|}
\hline $\begin{array}{c}\text { Câmbio } \\
(+1)\end{array}$ & Selic (+1) & PIM (+2) & IGP-M (-4) & $\begin{array}{c}\text { Resíduo } \\
\text { lbovespa }\end{array}$ \\
\hline Câmbio (+1) & 1,00 & - & - & - & - \\
\hline Selic (+1) & 0,10 & 1,00 & - & - & - \\
\hline PIM (+2) & $-0,19$ & $-0,17$ & 1,00 & - & - \\
\hline IGP-M (-4) & $-0,10$ & 0,05 & $-0,13$ & 1,00 & - \\
\hline $\begin{array}{l}\text { Resíduo } \\
\text { Ibovespa }\end{array}$ & 0,00 & 0,00 & 0,00 & 0,00 & 1,00 \\
\hline
\end{tabular}

Tabela 23 - Correlação Entre as Variáveis Independentes - Produção Industrial com Lag+2

\begin{tabular}{|lccccc|}
\hline $\begin{array}{c}\text { Câmbio } \\
(+1)\end{array}$ & Selic (+1) & PIM (+4) & IGP-M (-4) & $\begin{array}{c}\text { Resíduo } \\
\text { lbovespa }\end{array}$ \\
\hline Câmbio (+1) & 1,00 & - & - & - & - \\
\hline Selic (+1) & 0,10 & 1,00 & - & - & - \\
\hline PIM (+4) & $-0,02$ & 0,07 & 1,00 & - & - \\
\hline IGP-M (-4) & $-0,10$ & 0,04 & 0,02 & 1,00 & - \\
\hline $\begin{array}{l}\text { Resíduo } \\
\text { Ibovespa }\end{array}$ & 0,00 & 0,00 & 0,00 & 0,00 & 1,00 \\
\hline
\end{tabular}

Tabela 24 - Correlação Entre as Variáveis Independentes - Produção Industrial com Lag+4

\begin{tabular}{|lccccc|}
\hline $\begin{array}{c}\text { Câmbio } \\
(+1)\end{array}$ & Selic (+1) & PIM (-4) & IGP-M (-4) & $\begin{array}{c}\text { Resíduo } \\
\text { lbovespa }\end{array}$ \\
\hline Câmbio (+1) & 1,00 & - & - & - & - \\
\hline Selic (+1) & 0,10 & 1,00 & - & - & - \\
\hline PIM (-4) & 0,02 & 0,12 & 1,00 & - & - \\
\hline IGP-M (-4) & $-0,10$ & 0,05 & 0,02 & 1,00 & - \\
\hline $\begin{array}{l}\text { Resíduo } \\
\text { Ibovespa }\end{array}$ & 0,00 & 0,00 & 0,00 & 0,00 & 1,00 \\
\hline
\end{tabular}

Tabela 25 - Correlação Entre as Variáveis Independentes - Produção Industrial com Lag-4 
Para a variável de inflação, observa-se que a inflação de quatro meses para trás foi a que se mostrou mais representativa. Isso implicaria que o retorno das ações levaria quatro meses para refletir a variação da inflação, o que parece contra intuitivo. Pode também refletir uma possível mudança na tendência da inflação que levaria mais tempo a ser percebido pelos agentes do mercado. É interessante destacar que a série apresenta autocorrelação significativa para os períodos 1 a 5 destacados na Figura 7.

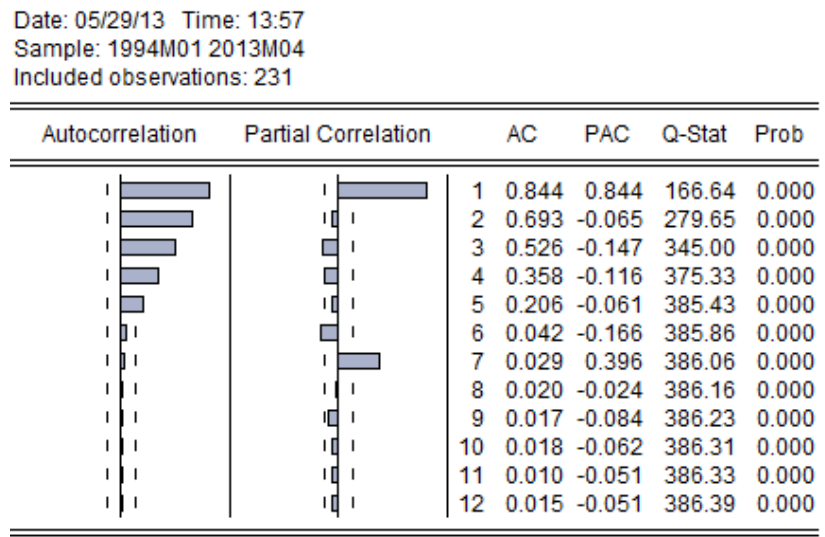

Figura 7 - Autocorrelação da Variação do IGP-M

As carteiras apresentaram uma sensibilidade menor às variações deste indicador conforme pode ser percebido pelo valor absoluto da correlação e pela significância do coeficiente da regressão que será apresentado mais a frente.

\begin{tabular}{|c|c|c|c|c|c|c|c|c|c|c|c|}
\hline & -5 & -4 & -3 & -2 & -1 & & 1 & 2 & 3 & 4 & 5 \\
\hline Cart 1 & 0,02 & 0,01 & $-0,07$ & 0,00 & 0,09 & 0,10 & $-0,04$ & $-0,05$ & 0,02 & & 0,00 \\
\hline Cart 2 & 06 &, 12 & 0,08 &, 08 & & 03 & &, 00 & & & $-0,02$ \\
\hline Cart 3 & 02 &, 03 & 0,04 & $-0,03$ & & & & , & $-0,09$ & $-0,03$ & $-0,03$ \\
\hline Cart 4 & 5 & & $-0,08$ & $-0,06$ & & & & & & & \\
\hline Cart 5 & 03 & 02 & ,01 & $-0,03$ & & & & & & & $-0,06$ \\
\hline Cart 6 & 0,05 & $-0,02$ & $-0,04$ & $-0,03$ & & & & $-0,06$ & 0,09 & $-0,07$ & $-0,02$ \\
\hline Cart 7 & 08 & $-0,06$ & $-0,09$ & $-0,06$ & & & $-0,01$ & $-0,13$ & $-0,07$ & 0,00 & $-0,01$ \\
\hline Cart 8 & 06 & -( & 0,00 & $-0,01$ & & & & $-0,07$ & 3 & $-0,11$ & $-0,13$ \\
\hline Cart 9 &, 04 & $-0,07$ & $-0,04$ & $-0,02$ & & & & 0,0 & & 0, & 0,01 \\
\hline Cart 10 & $-0,03$ & $-0,14$ & $-0,07$ & $-0,06$ & & 07 & $-0,07$ & $-0,09$ & $-0,03$ & 0,01 & 0,01 \\
\hline Cart 11 & 0,04 & $-0,07$ & $-0,08$ & 0,00 & & & & -0 & -0 , & 0 & $-0,05$ \\
\hline Cart 12 & 0,03 & $-0,13$ & $-0,07$ & $-0,06$ & & & $-0,0$ & $-0,0$ & -0 , & $-0,02$ & $-0,03$ \\
\hline Cart 13 & $-0,02$ & $-0,17$ & $-0,09$ & $-0,07$ & & & 0,00 & $-0,07$ & $-0,07$ & $-0,02$ & $-0,01$ \\
\hline Cart 14 & 0,00 & $-0,08$ & $-0,04$ & 0,05 & & & -0 & $-0,12$ & $-0,09$ & $-0,03$ & $-0,04$ \\
\hline Cart 15 & $-0,03$ & $-0,12$ & $-0,05$ & $-0,04$ & & & & -0, & -0 , & 0, & $-0,05$ \\
\hline Cart 16 & $-0,01$ & -0 & $-0,06$ & $-0,01$ & & & & -0 & -0 , & 0, & 0,03 \\
\hline Cart 17 & $-0,08$ & $-0,05$ & $-0,08$ & $-0,09$ & & 0 & & $-0,05$ & $-0,03$ & $-0,03$ & 0,01 \\
\hline Cart 18 & 0,09 & 0,05 & $-0,06$ & $-0,08$ & $-0,03$ & 0,0 & $-0,06$ & $-0,20$ & $-0,27$ & $-0,22$ & $-0,13$ \\
\hline Cart 19 & $-0,18$ & $-0,34$ & $-0,39$ & $-0,24$ & -0 , & $-0,2$ & -0 & $-0,04$ & 0,02 & $-0,09$ & 0,13 \\
\hline Cart 20 & $-0,10$ & $-0,3$ & $-0,41$ & $-0,20$ & $-0,22$ & -0 , & -0 & $-0,0$ & -0 & $-0,11$ & 0,07 \\
\hline
\end{tabular}

Tabela 26 - Correlação Cruzada das Carteiras com a Variação IGP-M 


\subsubsection{Dados e Estatísiticas}

$\mathrm{Na}$ amostra do estudo foram consideradas um total de 142 empresas. Todavia, nem todas as empresas apresentaram cotações para todos os meses analisados. Houve casos em que a empresa não apresentou negociação no mês, assim com empresas que realizaram a abertura de capital durante o período estudado e só passaram a integrar a base de dados a partir desta data.

A divisão das carteiras foi feita com base no beta das empresas. As empresas da carteira 1 apresentam os menores betas e as empresas da carteira 20 os maiores. $O$ beta médio de cada carteira está apresentando na Tabela 27.

\begin{tabular}{|lc|}
\hline Cart 1 & $\beta$ Médio \\
\hline Cart 2 & 0,32 \\
\hline Cart 3 & 0,49 \\
\hline Cart 4 & 0,57 \\
\hline Cart 5 & 0,65 \\
\hline Cart 6 & 0,69 \\
\hline Cart 7 & 0,74 \\
\hline Cart 8 & 0,80 \\
\hline Cart 9 & 0,82 \\
\hline Cart 10 & 0,86 \\
\hline Cart 11 & 0,89 \\
\hline Cart 12 & 0,92 \\
\hline Cart 13 & 0,96 \\
\hline Cart 14 & 0,99 \\
\hline Cart 15 & 1,03 \\
\hline Cart 16 & 1,08 \\
\hline Cart 17 & 1,13 \\
\hline Cart 18 & 1,18 \\
\hline Cart 19 & 1,32 \\
\hline Cart 20 & 1,50 \\
\hline Tabela 27 Beta Medi & 1,88 \\
\hline
\end{tabular}

Tabela 27 - Beta Médio por Carteira

A Tabela 28 mostra a média anual do total de empreses que compuseram cada carteira. As carteiras 19 e 20 só tiveram representatividade a partir de 2006 e 2005 respectivamente. O período de 2005 a 2008 foi marcado pela abertura de capital de diversas empresas no mercado brasileiro, a partir do qual tivemos um aumento na representatividade da nossa amostra.

\begin{tabular}{|lc|}
\hline & Média de Empresas \\
\hline Cart 1 & 4 \\
\hline Cart 2 & 4 \\
\hline Cart 3 & 4 \\
\hline Cart 4 & 4 \\
\hline Cart 5 & 5 \\
\hline
\end{tabular}




\begin{tabular}{|l|l|}
\hline Cart 6 & 4 \\
\hline Cart 7 & 4 \\
\hline Cart 8 & 6 \\
\hline Cart 9 & 5 \\
\hline Cart 10 & 4 \\
\hline Cart 11 & 5 \\
\hline Cart 12 & 3 \\
\hline Cart 13 & 3 \\
\hline Cart 14 & 4 \\
\hline Cart 15 & 3 \\
\hline Cart 16 & 4 \\
\hline Cart 17 & 3 \\
\hline Cart 18 & 3 \\
\hline Cart 19 & 2 \\
\hline Cart 20 & 3 \\
\hline
\end{tabular}

Tabela 28 - Número Médio de Empresas por Carteira ${ }^{7}$

Os retornos médios mensais por ano para cada carteira estão apresentados na Tabela 29. Para as carteiras que tiveram representatividade desde 1995 , o retorno médio do período oscilou entre $1,2 \%$ ao mês e 3,0\% ao mês.

Como as carteiras foram agrupadas de acordo com o beta, pode-se notar uma tendência de aumento do desvio padrão das carteiras. A carteira 1 foi a que apresentou o menor desvio padrão enquanto a carteira 18 o maior.

\begin{tabular}{|lll|}
\hline & Média & Desvio Padrão \\
\hline Cart 1 & $2,5 \%$ & $7,1 \%$ \\
\hline Cart 2 & $1,5 \%$ & $7,8 \%$ \\
\hline Cart 3 & $2,2 \%$ & $8,0 \%$ \\
\hline Cart 4 & $1,7 \%$ & $8,2 \%$ \\
\hline Cart 5 & $2,0 \%$ & $8,5 \%$ \\
\hline Cart 6 & $2,1 \%$ & $8,7 \%$ \\
\hline Cart 7 & $1,7 \%$ & $9,8 \%$ \\
\hline Cart 8 & $3,0 \%$ & $14,0 \%$ \\
\hline Cart 9 & $2,0 \%$ & $9,8 \%$ \\
\hline Cart 10 & $1,7 \%$ & $10,0 \%$ \\
\hline Cart 11 & $1,6 \%$ & $10,8 \%$ \\
\hline Cart 12 & $1,2 \%$ & $12,7 \%$ \\
\hline Cart 13 & $1,5 \%$ & $13,6 \%$ \\
\hline Cart 14 & $2,4 \%$ & $11,9 \%$ \\
\hline Cart 15 & $2,3 \%$ & $11,7 \%$ \\
\hline Cart 16 & $2,7 \%$ & $12,5 \%$ \\
\hline Cart 17 & $3,0 \%$ & $16,7 \%$ \\
\hline Cart 18 & $1,3 \%$ & $21,2 \%$ \\
\hline Cart 19 & $0,5 \%$ & $12,6 \%$ \\
\hline Cart 20 & $3,2 \%$ & $15,9 \%$ \\
\hline
\end{tabular}

${ }^{7}$ Tabela compela no anexo. 
Tabela 29 - Retorno Médio Mensal por Ano por Carteira 1 a $10^{8}$

De maneira semelhante, na Tabela 30 está exposto a variação mensal das variáveis explicativas do modelo. O retorno médio mensal do Ibovespa no período foi de $1,7 \%$ e da poupança de $0,9 \%$ ao mês.

\begin{tabular}{|lcccccc|}
\hline & Câmbio & Selic & PIM & IGP-M & Ibovespa & Poupança \\
\hline Média & $0,5 \%$ & $-0,2 \%$ & $0,1 \%$ & $0,7 \%$ & $1,7 \%$ & $0,9 \%$ \\
\hline Desvio & $4,3 \%$ & $3,5 \%$ & $2,1 \%$ & $6,7 \%$ & $9,1 \%$ & $0,6 \%$ \\
Padrão & & & & & & \\
\hline
\end{tabular}

Tabela 30 - Variação Mensal Média das Variáveis Explicativas por Ano ${ }^{9}$

O variance inflation factor foi calculado apenas para verificação (Tabela 31). Conforme esperado, dado a baixa correlação entre as variáveis explicativas previamente apresentadas, os valores mostraram-se baixos e bastante próximos de um.

\begin{tabular}{|c|c|}
\hline & VIF \\
\hline Câmbio (+1) & 1,03 \\
\hline Selic (+1) & 1,02 \\
\hline PIM (+4) & 1,00 \\
\hline IGPM (-4) & 1,02 \\
\hline Resíduo Ibovespa & 1,00 \\
\hline
\end{tabular}

Tabela 31 - Variance Inflation Factor para Modelo APT Unificado ao CAPM

\subsubsection{Resultado Modelo APT Unificado ao CAPM}

Com os dados apresentados foram estimadas 20 regressões lineares pelo método dos mínimos quadrados ordinários. Os resultados das regressões estão apresentados na Tabela 32 e na Tabela 33.

\begin{tabular}{|l|cc|cccccc|}
\hline & $\mathbf{R}^{2}$ & $\begin{array}{c}\mathbf{R}^{2} \\
\text { Ajustado }\end{array}$ & $\beta_{1}$ & $\begin{array}{c}\beta_{2} \\
\text { Câmbio } \\
(+1)\end{array}$ & $\begin{array}{c}\beta_{3 \text { Selic }} \\
(+1)\end{array}$ & $\begin{array}{c}\beta_{4 \text { PIM }} \\
(+4)\end{array}$ & $\begin{array}{c}\beta_{5 \text { IGP-M }} \\
(-4)\end{array}$ & $\begin{array}{c}\beta_{6} \\
\text { Residuo } \\
\text { lbovespa }\end{array}$ \\
\hline Cart 1 & 0,35 & 0,34 & 0,02 & $-0,27$ & $-0,90$ & 0,59 & 0,02 & 0,34 \\
\hline Cart 2 & 0,36 & 0,34 & 0,03 & $-0,23$ & $-0,18$ & 0,53 & $-1,48$ & 0,53 \\
\hline Cart 3 & 0,54 & 0,53 & 0,03 & $-0,23$ & $-0,63$ & 0,62 & $-0,65$ & 0,66 \\
\hline Cart 4 & 0,46 & 0,45 & 0,03 & $-0,37$ & $-0,60$ & 0,55 & $-1,08$ & 0,61 \\
\hline Cart 5 & 0,57 & 0,56 & 0,02 & $-0,14$ & $-0,75$ & 0,62 & $-0,03$ & 0,72 \\
\hline Cart 6 & 0,56 & 0,55 & 0,03 & $-0,42$ & $-0,48$ & 0,58 & $-0,58$ & 0,75 \\
\hline Cart 7 & 0,57 & 0,56 & 0,03 & $-0,77$ & $-0,74$ & 0,94 & $-1,19$ & 0,72 \\
\hline Cart 8 & 0,31 & 0,30 & 0,04 & $-0,52$ & $-0,77$ & 0,83 & $-1,09$ & 0,85 \\
\hline Cart 9 & 0,58 & 0,57 & 0,03 & $-0,43$ & $-0,62$ & 0,89 & $-1,20$ & 0,83 \\
\hline
\end{tabular}

\footnotetext{
${ }^{8}$ Tabela compela no anexo.

${ }^{9}$ Tabela compela no anexo.
} 


\begin{tabular}{|l|ll|llllll|}
\hline Cart 10 & 0,69 & 0,68 & 0,03 & $-0,90$ & $-0,85$ & 0,85 & $-2,22$ & 0,78 \\
\hline Cart 11 & 0,59 & 0,58 & 0,03 & $-0,91$ & $-0,50$ & 0,41 & $-1,38$ & 0,87 \\
\hline Cart 12 & 0,56 & 0,55 & 0,04 & $-0,98$ & $-0,67$ & 0,64 & $-2,75$ & 0,98 \\
\hline Cart 13 & 0,54 & 0,52 & 0,04 & $-0,97$ & $-0,68$ & 0,34 & $-3,42$ & 1,03 \\
\hline Cart 14 & 0,60 & 0,59 & 0,04 & $-1,06$ & $-0,67$ & 0,73 & $-1,85$ & 0,92 \\
\hline Cart 15 & 0,73 & 0,72 & 0,04 & $-0,96$ & $-0,97$ & 1,17 & $-2,54$ & 0,97 \\
\hline Cart 16 & 0,68 & 0,67 & 0,05 & $-0,81$ & $-1,21$ & 0,81 & $-2,51$ & 1,04 \\
\hline Cart 17 & 0,47 & 0,45 & 0,04 & $-0,70$ & $-1,15$ & 1,62 & $-2,55$ & 1,42 \\
\hline Cart 18 & 0,35 & 0,33 & 0,02 & $-1,28$ & $-0,83$ & 1,48 & $-0,15$ & 1,49 \\
\hline Cart 19 & 0,54 & 0,51 & 0,04 & $-1,02$ & $-2,10$ & 0,91 & $-4,45$ & 1,23 \\
\hline Cart 20 & 0,63 & 0,61 & 0,07 & $-1,53$ & $-1,71$ & 0,96 & $-5,92$ & 1,60 \\
\hline
\end{tabular}

Tabela 32 - Resultado das Regressões: $R^{2}$ Ajustado e os Coeficientes por Carteira

\begin{tabular}{|lcccccc|}
\hline P-Valor & $\beta_{1}$ & $\begin{array}{c}\beta_{2} \text { Câmbio } \\
(+1)\end{array}$ & $\beta_{3}$ Sellic (+1) & $\beta_{4 \text { PIM (+4) }}$ & $\beta_{5 \text { IGP-M (-4) }}$ & $\begin{array}{c}\beta_{6 \text { Residuo }} \\
\text { lbovespa }\end{array}$ \\
\hline Cart 1 & 0,00 & 0,00 & 0,00 & 0,01 & 0,97 & 0,00 \\
\hline Cart 2 & 0,00 & 0,02 & 0,16 & 0,01 & 0,00 & 0,00 \\
\hline Cart 3 & 0,00 & 0,01 & 0,00 & 0,00 & 0,15 & 0,00 \\
\hline Cart 4 & 0,00 & 0,00 & 0,00 & 0,01 & 0,03 & 0,00 \\
\hline Cart 5 & 0,00 & 0,12 & 0,00 & 0,00 & 0,94 & 0,00 \\
\hline Cart 6 & 0,00 & 0,00 & 0,00 & 0,00 & 0,22 & 0,00 \\
\hline Cart 7 & 0,00 & 0,00 & 0,00 & 0,00 & 0,03 & 0,00 \\
\hline Cart 8 & 0,00 & 0,01 & 0,00 & 0,03 & 0,25 & 0,00 \\
\hline Cart 9 & 0,00 & 0,00 & 0,00 & 0,00 & 0,02 & 0,00 \\
\hline Cart 10 & 0,00 & 0,00 & 0,00 & 0,00 & 0,00 & 0,00 \\
\hline Cart 11 & 0,00 & 0,00 & 0,00 & 0,10 & 0,02 & 0,00 \\
\hline Cart 12 & 0,00 & 0,00 & 0,00 & 0,02 & 0,00 & 0,00 \\
\hline Cart 13 & 0,00 & 0,00 & 0,00 & 0,30 & 0,00 & 0,00 \\
\hline Cart 14 & 0,00 & 0,00 & 0,00 & 0,01 & 0,00 & 0,00 \\
\hline Cart 15 & 0,00 & 0,00 & 0,00 & 0,00 & 0,00 & 0,00 \\
\hline Cart 16 & 0,00 & 0,00 & 0,00 & 0,00 & 0,00 & 0,00 \\
\hline Cart 17 & 0,00 & 0,00 & 0,00 & 0,00 & 0,02 & 0,00 \\
\hline Cart 18 & 0,34 & 0,00 & 0,11 & 0,04 & 0,92 & 0,00 \\
\hline Cart 19 & 0,01 & 0,00 & 0,01 & 0,06 & 0,02 & 0,00 \\
\hline Cart 20 & 0,00 & 0,00 & 0,03 & 0,07 & 0,00 & 0,00 \\
\hline
\end{tabular}

Tabela 33 - Resultado das Regressões: P-Valor por Coeficiente por Carteira

O coeficiente de determinação ajustado variou entre 0,34 e 0,72. Como era de se esperar, as carteiras com os betas mais próximos de um apresentaram um poder explicativo maior.

A variável câmbio apresentou sinal negativo para todas as carteiras, ou seja, quando o real se deprecia (variação positiva do câmbio) as ações apresentam um resultado negativo. Apenas para a carteira 5 o coeficiente não se mostrou significativo ao nível de 5\%.

A variação na taxa Selic também apresentou coeficiente negativo para todas as carteiras, condizente com o esperado, e não se mostrou 
estatisticamente diferente de zero apenas para duas carteiras (carteiras 2 e 18) ao nível de $5 \%$.

Todas as carteiras apresentaram coeficiente positivo para a variação mensal da produção industrial, como seria de se esperar com base na teoria econômica, sendo que 4 não foram estatisticamente significativas a $5 \%$. Cabe destacar que ao nível de $10 \%$ apenas 1 carteira não se mostra estatisticamente significativa.

A variável inflação foi a que apresentou pior nível de significância, não sendo estatisticamente relevante para 6 das 20 carteiras a $5 \%$, das quais 3 carteiras não apresentaram significância quase nenhuma. $O$ coeficiente se mostrou negativo em 19 carteiras.

A componente do mercado se mostrou positiva e significativa para todas as carteiras.

Cabe destacar que as carteiras de maior beta tendem a serem mais sensíveis aos indicadores estimados. Nos gráficos da Figura 8 pode-se observar os coeficientes estimados para cada carteira.
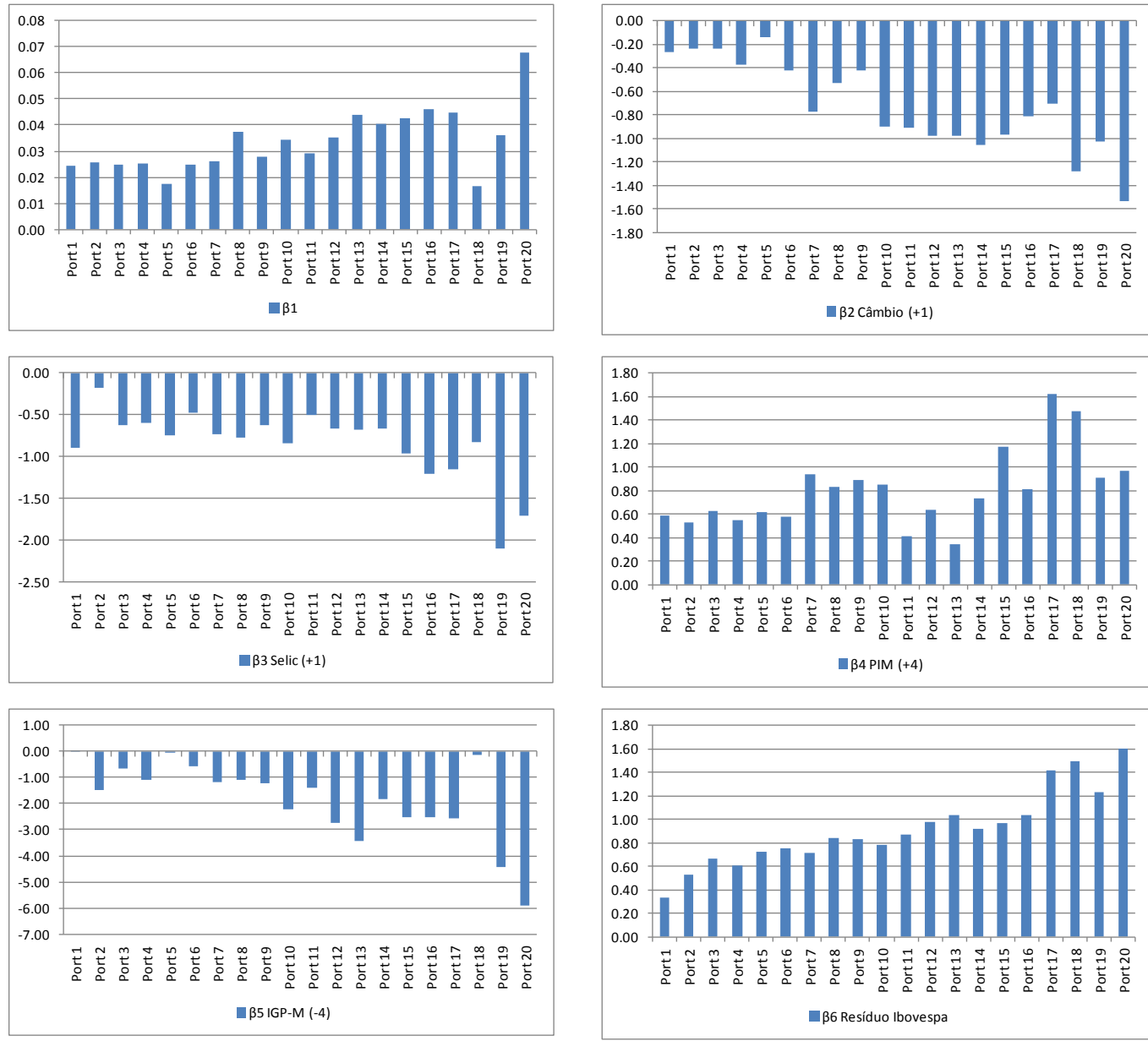

Figura 8 - Gráficos dos Coeficientes do Modelo APT Unificado ao CAPM por Carteira 
A fim de testar se todos os coeficientes são iguais a zero simultaneamente para cada carteira, foi realizado o teste F. Como apresentado na tabela abaixo, em nenhuma das carteiras pode-se aceitar a hipótese nula.

\begin{tabular}{|lcc|} 
& Estatistica F & p-valor \\
\hline Cart 1 & 20,77 & 0,00 \\
\hline Cart 2 & 22,97 & 0,00 \\
\hline Cart 3 & 48,69 & 0,00 \\
\hline Cart 4 & 35,19 & 0,00 \\
\hline Cart 5 & 54,34 & 0,00 \\
\hline Cart 6 & 53,49 & 0,00 \\
\hline Cart 7 & 55,54 & 0,00 \\
\hline Cart 8 & 18,92 & 0,00 \\
\hline Cart 9 & 58,15 & 0,00 \\
\hline Cart 10 & 92,36 & 0,00 \\
\hline Cart 11 & 59,05 & 0,00 \\
\hline Cart 12 & 52,26 & 0,00 \\
\hline Cart 13 & 47,68 & 0,00 \\
\hline Cart 14 & 60,97 & 0,00 \\
\hline Cart 15 & 111,51 & 0,00 \\
\hline Cart 16 & 86,86 & 0,00 \\
\hline Cart 17 & 28,85 & 0,00 \\
\hline Cart 18 & 18,14 & 0,00 \\
\hline Cart 19 & 17,32 & 0,00 \\
\hline Cart 20 & 27,52 & 0,00 \\
\hline
\end{tabular}

Tabela 34 - Teste F para o Modelo APT Unificado ao CAPM

Efetuou-se o teste de Durbin-Watson para checar a presença de autocorrelação dos resíduos das regressões do modelo. Cada destacar que neste modelo não foi possível realizar o teste Durbin-Watson nos resíduos das carteiras 1, 4 e 18, uma vez que estas não apresentaram uma séria completa de observações (sem dados faltando).

A hipótese do teste é:

- $\mathrm{H}_{0}$ : Não existe autocorrelação

- $\mathrm{H}_{\mathrm{a}}$ : Autocorrelação positiva

- $\mathrm{H}_{0}^{*}$ : Não existe autocorrelação

- $\mathrm{H}_{\mathrm{a}}^{*}$ : Autocorrelação negativa

Pode-se ver na Tabela 35 que 2 carteiras apresentaram autocorrelação positiva dos resíduos e duas apresentaram autocorrelação negativa.

\begin{tabular}{|lccc|} 
& $\begin{array}{c}\text { Estatística } \\
\text { DW }\end{array}$ & $\begin{array}{c}\text { № } \\
\text { Observações }\end{array}$ & Resultado \\
\hline Cart 1 & - & - & - \\
\hline Cart 2 & 2,22 & 214 & Inconclusivo \\
\hline Cart 3 & 2,16 & 213 & Não tem autocorrelação \\
\hline Cart 4 & - & - & - \\
\hline
\end{tabular}




\begin{tabular}{|lccc|}
\hline Cart 5 & 1,74 & 213 & Inconclusivo \\
\hline Cart 6 & 2,14 & 214 & Não tem autocorrelação \\
\hline Cart 7 & 1,68 & 213 & Autocorrelação Positiva \\
\hline Cart 8 & 2,21 & 214 & Inconclusivo \\
\hline Cart 9 & 1,66 & 214 & Autocorrelação Positiva \\
\hline Cart 10 & 2,15 & 213 & Não tem autocorrelação \\
\hline Cart 11 & 1,92 & 213 & Não tem autocorrelação \\
\hline Cart 12 & 1,99 & 214 & Não tem autocorrelação \\
\hline Cart 13 & 2,04 & 213 & Não tem autocorrelação \\
\hline Cart 14 & 1,88 & 213 & Não tem autocorrelação \\
\hline Cart 15 & 2,29 & 214 & Autocorrelação Negativa \\
\hline Cart 16 & 1,73 & 213 & Inconclusivo \\
\hline Cart 17 & 2,38 & 169 & Autocorrelação Negativa \\
\hline Cart 18 & - & - & Não tem autocorrelação \\
\hline Cart 19 & 2,12 & 80 & Não tem autocorrelação \\
\hline Cart 20 & 2,08 & 87 & \\
\hline
\end{tabular}

Tabela 35 - Teste Durbin Watson para Modelo APT Unificado ao CAPM

O teste Jarque-Bera indicou que 5 regressões (das 20) apresentam distribuição normal ao nível de 5\%, como pode ser visto na Tabela 36 . Ressaltase que o teste serve para amostras grandes, não sendo possível garantir que as observações das amostras são suficientemente grande.

A hipótese do teste é:

- $\mathrm{H}_{\mathrm{o}}$ : Distribuição normal

- $\mathrm{H}_{\mathrm{a}}$ : Não segue distribuição normal

\begin{tabular}{|lccc|}
\hline & Estatística JB & Probabilidade & № Observações \\
\hline Cart 1 & 122 & 0,00 & 195 \\
\hline Cart 2 & 3 & 0,22 & 214 \\
\hline Cart 3 & 6 & 0,05 & 213 \\
\hline Cart 4 & 5 & 0,09 & 211 \\
\hline Cart 5 & 63 & 0,00 & 213 \\
\hline Cart 6 & 73 & 0,00 & 214 \\
\hline Cart 7 & 2 & 0,42 & 213 \\
\hline Cart 8 & 18.471 & 0,00 & 214 \\
\hline Cart 9 & 17 & 0,00 & 214 \\
\hline Cart 10 & 11 & 0,00 & 213 \\
\hline Cart 11 & 118 & 0,00 & 213 \\
\hline Cart 12 & 143 & 0,00 & 214 \\
\hline Cart 13 & 129 & 0,00 & 213 \\
\hline Cart 14 & 31 & 0,00 & 213 \\
\hline Cart 15 & 5 & 0,09 & 214 \\
\hline Cart 16 & 747 & 0,00 & 213 \\
\hline Cart 17 & 1.530 & 0,00 & 169 \\
\hline Cart 18 & 802 & 0,00 & 176 \\
\hline & & & \\
\hline
\end{tabular}




\begin{tabular}{|lccc|}
\hline Cart 19 & 8 & 0,02 & 80 \\
\hline Cart 20 & 24 & 0,00 & 87 \\
\hline
\end{tabular}

Tabela 36 - Teste Jarque-Bera para Modelo APT Unificado ao CAPM

O Teste White indicou que os resíduos são homocedásticos para 8 regressões, ao nível de $5 \%$, com as estatísticas de teste e a probabilidade destas estatísticas excederem o valor da tabela (caso em que se rejeitaria a hipótese nula) estão apresentados na Tabela 37. O teste serve para amostras grandes, não sendo possível garantir que as observações das amostras são suficientemente grande.

A hipótese do teste é:

- $\mathrm{H}_{\mathrm{o}}$ : Homocedasticidade

- $\mathrm{H}_{\mathrm{a}}$ : Heterocedasticidade

\begin{tabular}{|lccc|}
\hline & White & Probabilidade & № Observações \\
\hline Cart 1 & 39,1 & 0,01 & 195 \\
\hline Cart 2 & 28,0 & 0,11 & 214 \\
\hline Cart 3 & 39,2 & 0,01 & 213 \\
\hline Cart 4 & 15,8 & 0,73 & 211 \\
\hline Cart 5 & 29,4 & 0,08 & 213 \\
\hline Cart 6 & 24,8 & 0,22 & 214 \\
\hline Cart 7 & 39,1 & 0,01 & 213 \\
\hline Cart 8 & 2,0 & 1,00 & 214 \\
\hline Cart 9 & 44,8 & 0,00 & 214 \\
\hline Cart 10 & 90,4 & 0,00 & 213 \\
\hline Cart 11 & 70,3 & 0,00 & 213 \\
\hline Cart 12 & 13,1 & 0,88 & 214 \\
\hline Cart 13 & 12,4 & 0,90 & 213 \\
\hline Cart 14 & 45,0 & 0,00 & 213 \\
\hline Cart 15 & 72,5 & 0,00 & 214 \\
\hline Cart 16 & 160,6 & 0,00 & 213 \\
\hline Cart 17 & 60,3 & 0,00 & 169 \\
\hline Cart 18 & 54,5 & 0,00 & 176 \\
\hline Cart 19 & 25,3 & 0,19 & 80 \\
\hline Cart 20 & 41,2 & 0,00 & 87 \\
\hline
\end{tabular}

Tabela 37 - Teste White para Modelo APT Unificado ao CAPM

Ao realizar a regressão cross sectional dos coeficientes das carteiras nenhum deles apresentou um prêmio de risco estatisticamente significante (Tabela 38). No teste $F$ (Tabela 39) não se pode rejeitar a hipótese nula de que todos os coeficientes são simultaneamente nulos. 


\begin{tabular}{|lll|}
\hline $\boldsymbol{\lambda}_{1}$ & 0,01 & 0,16 \\
\hline $\boldsymbol{\lambda}_{2}$ & 0,01 & 0,45 \\
\hline $\boldsymbol{\lambda}_{3}$ & 0,00 & 0,76 \\
\hline $\boldsymbol{\lambda}_{4}$ & 0,01 & 0,42 \\
\hline $\boldsymbol{\lambda}_{5}$ & 0,00 & 0,57 \\
\hline $\boldsymbol{\lambda}_{6}$ & 0,00 & 0,91 \\
\hline
\end{tabular}

Tabela 38 - Prêmio de Risco para os Fatores Macroeconômicos

\begin{tabular}{|lc|}
\hline $\mathbf{R}^{2}$ & Indicadores \\
\hline $\mathbf{R}^{2}$ Ajustado & 0,10 \\
\hline Estatística $\mathbf{F}$ & $-0,22$ \\
\hline $\mathbf{p}$-valor & 0,32 \\
\hline Durbin- & 0,89 \\
Watson & 2,17 (inconclusivo) \\
\hline
\end{tabular}

Tabela 39 - Indicadores da Regressão Cross Section do Modelo APT Unificado ao CAPM

No estudo realizado por Schor, Bonomo e Pereira (1998) os autores também não encontraram valores estatisticamente diferente de zero para todos os prêmios de risco dos fatores macroeconômicos estimados conjuntamente (risco de crédito, inflação inesperada, taxa real de juros, produção industrial, CDB-CDI e carteira de mercado).

Como muitas regressões não apresentaram resíduos com distribuição normal e apresentaram heterocedasticidade foram realizadas novas regressões utilizando mínimos quadrados ponderados (pelo inverso do desvio padrão da variável resíduo ibovespa) visando obter resultados melhores. Esta varíavel apresenta uma variância significativa e que possivelmente está relacionada a variabilidade das demais carteiras. O resultado pode ser visto na Tabela 40, e o p-valor dos coeficientes na Tabela 41. Observa-se que o coeficiente de determinação aumentou significativamente em relação aos anteriormente calculados. Todavia, o resíduo das regressões continuou não apresentando distribuição normal e com heterocedasticidade como pode ver visto na Tabela 57 e na Tabela 58 do anexo.

\begin{tabular}{|lcccccccc|} 
& $\mathbf{R}^{2}$ & $\begin{array}{c}\mathbf{R}^{2} \\
\text { Ajustado }\end{array}$ & $\boldsymbol{\beta}_{1}$ & $\begin{array}{c}\boldsymbol{\beta}_{2} \\
\text { Câmbio (+1) }\end{array}$ & $\begin{array}{c}\boldsymbol{\beta}_{3} \\
\text { Selic (+1) }\end{array}$ & $\begin{array}{c}\boldsymbol{\beta}_{4} \\
\text { PIM (+4) }\end{array}$ & $\begin{array}{c}\boldsymbol{\beta}_{5} \\
\text { IGP-M (- } \\
4)\end{array}$ & $\begin{array}{c}\boldsymbol{\beta}_{6 \text { Residuo }} \\
\text { Ibovespa }\end{array}$ \\
\hline Cart 1 & 0,75 & 0,74 & 0,02 & $-0,73$ & $-1,41$ & 0,52 & $-0,61$ & 0,41 \\
\hline Cart 2 & 0,74 & 0,73 & 0,02 & 0,13 & $-0,14$ & 0,73 & $-1,44$ & 0,51 \\
\hline Cart 3 & 0,89 & 0,88 & 0,02 & 0,00 & $-0,73$ & 0,71 & $-0,41$ & 0,76 \\
\hline Cart 4 & 0,78 & 0,78 & 0,02 & $-0,50$ & $-0,72$ & 0,52 & $-0,76$ & 0,62 \\
\hline Cart 5 & 0,92 & 0,92 & 0,01 & 0,22 & $-0,58$ & 0,61 & $-0,53$ & 0,79 \\
\hline
\end{tabular}




\begin{tabular}{|lllllllll|}
\hline Cart 6 & 0,89 & 0,89 & 0,02 & 0,01 & $-0,34$ & 0,82 & $-0,46$ & 0,81 \\
\hline Cart 7 & 0,79 & 0,79 & 0,03 & $-0,88$ & $-0,70$ & 1,35 & $-1,31$ & 0,73 \\
\hline Cart 8 & 0,80 & 0,79 & 0,05 & $-0,23$ & $-0,69$ & 0,88 & $-2,28$ & 0,92 \\
\hline Cart 9 & 0,91 & 0,91 & 0,01 & 0,12 & $-0,64$ & 1,12 & $-0,59$ & 0,81 \\
\hline Cart 10 & 0,83 & 0,83 & 0,03 & $-1,28$ & $-0,97$ & 1,15 & $-2,93$ & 0,71 \\
\hline Cart 11 & 0,80 & 0,80 & 0,03 & $-1,65$ & $-0,75$ & 0,42 & $-1,26$ & 0,77 \\
\hline Cart 12 & 0,84 & 0,84 & 0,03 & $-0,96$ & $-1,04$ & 0,68 & $-1,99$ & 1,05 \\
\hline Cart 13 & 0,83 & 0,82 & 0,03 & $-0,78$ & $-1,05$ & 0,59 & $-2,11$ & 1,09 \\
\hline Cart 14 & 0,76 & 0,75 & 0,05 & $-1,36$ & $-0,76$ & 0,53 & $-2,75$ & 0,91 \\
\hline Cart 15 & 0,89 & 0,89 & 0,04 & $-1,37$ & $-1,03$ & 1,21 & $-2,73$ & 1,01 \\
\hline Cart 16 & 0,93 & 0,93 & 0,03 & $-0,40$ & $-0,97$ & 1,11 & $-2,56$ & 1,09 \\
\hline Cart 17 & 0,69 & 0,68 & 0,11 & $-0,89$ & $-1,54$ & 1,63 & $-7,44$ & 1,61 \\
\hline Cart 18 & 0,55 & 0,54 & 0,03 & $-1,87$ & $-1,60$ & 2,37 & 4,65 & 1,94 \\
\hline Cart 19 & 0,84 & 0,83 & 0,05 & $-0,75$ & $-2,54$ & 1,28 & $-5,35$ & 1,45 \\
\hline Cart 20 & 0,88 & 0,88 & 0,08 & $-1,58$ & $-2,06$ & 1,13 & $-6,79$ & 1,56 \\
\hline
\end{tabular}

Tabela 40 - Resultado das Regressões Mínimos Quadrados Ponderados: $R^{2}$ Ajustado e os Coeficientes por Carteira

\begin{tabular}{|c|c|c|c|c|c|c|}
\hline & $\beta_{1}$ & $\begin{array}{c}\boldsymbol{\beta}_{2} \\
\text { Câmbio (+1) }\end{array}$ & $\begin{array}{c}\beta_{3} \\
\text { Selic }(+1)\end{array}$ & $\begin{array}{c}\boldsymbol{\beta}_{4} \\
\operatorname{PIM}(+4)\end{array}$ & $\begin{array}{c}\beta_{5} \\
\text { IGP-M (-4) }\end{array}$ & $\boldsymbol{\beta}_{6}$ Resíduo lbovespa \\
\hline Cart 1 & 0,01 & 0,00 & 0,00 & 0,02 & 0,28 & 0,00 \\
\hline Cart 2 & 0,00 & 0,04 & 0,11 & 0,00 & 0,01 & 0,00 \\
\hline Cart 3 & 0,00 & 0,95 & 0,00 & 0,00 & 0,38 & 0,00 \\
\hline Cart 4 & 0,01 & 0,00 & 0,00 & 0,01 & 0,13 & 0,00 \\
\hline Cart 5 & 0,04 & 0,00 & 0,00 & 0,00 & 0,20 & 0,00 \\
\hline Cart 6 & 0,01 & 0,82 & 0,00 & 0,00 & 0,34 & 0,00 \\
\hline Cart 7 & 0,00 & 0,00 & 0,00 & 0,00 & 0,03 & 0,00 \\
\hline Cart 8 & 0,00 & 0,01 & 0,00 & 0,00 & 0,00 & 0,00 \\
\hline Cart 9 & 0,02 & 0,02 & 0,00 & 0,00 & 0,20 & 0,00 \\
\hline Cart 10 & 0,00 & 0,00 & 0,00 & 0,00 & 0,00 & 0,00 \\
\hline Cart 11 & 0,00 & 0,00 & 0,00 & 0,09 & 0,06 & 0,00 \\
\hline Cart 12 & 0,00 & 0,00 & 0,00 & 0,01 & 0,01 & 0,00 \\
\hline Cart 13 & 0,00 & 0,00 & 0,00 & 0,04 & 0,01 & 0,00 \\
\hline Cart 14 & 0,00 & 0,00 & 0,00 & 0,08 & 0,00 & 0,00 \\
\hline Cart 15 & 0,00 & 0,00 & 0,00 & 0,00 & 0,00 & 0,00 \\
\hline Cart 16 & 0,00 & 0,00 & 0,00 & 0,00 & 0,00 & 0,00 \\
\hline Cart 17 & 0,00 & 0,00 & 0,00 & 0,01 & 0,00 & 0,00 \\
\hline Cart 18 & 0,39 & 0,00 & 0,00 & 0,01 & 0,04 & 0,00 \\
\hline Cart 19 & 0,00 & 0,04 & 0,00 & 0,01 & 0,00 & 0,00 \\
\hline Cart 20 & 0,00 & 0,00 & 0,01 & 0,02 & 0,00 & 0,00 \\
\hline
\end{tabular}

Tabela 41 - Resultado das Regressões Mínimos Quadrados Ponderados: P-Valor por Coeficiente por Carteira 


\subsubsection{Comparação do Modelo APT Unificado ao CAPM com o CAPM}

Para efeito de comparação foi estimado o modelo CAPM com a mesma base de dados utilizada para a criação do modelo APT unificado ao CAPM.

O valor do coeficiente de determinação ajustado apresentou pequena redução no seu poder explicativo, variando entre $0,26-0,70$. A redução média no poder explicativo das 20 carteiras foi de apenas -0,01 (ver Tabela 42 e Tabela 43) quando comparado as regressões por mínimos quadrados ordinários.

\begin{tabular}{|l|cccc|cc|}
\hline & $\mathbf{R}^{2}$ & $\begin{array}{c}\mathbf{R}^{2} \\
\text { Ajustado }\end{array}$ & $\boldsymbol{\beta}_{1}$ & $\mathbf{p}$-valor & $\boldsymbol{\beta}_{2}$ & p-valor \\
\hline Cart 1 & 0,27 & 0,26 & 0,02 & 0,00 & 0,41 & 0,00 \\
\hline Cart 2 & 0,33 & 0,33 & 0,01 & 0,01 & 0,50 & 0,00 \\
\hline Cart 3 & 0,52 & 0,52 & 0,02 & 0,00 & 0,64 & 0,00 \\
\hline Cart 4 & 0,46 & 0,45 & 0,01 & 0,00 & 0,62 & 0,00 \\
\hline Cart 5 & 0,53 & 0,53 & 0,01 & 0,00 & 0,68 & 0,00 \\
\hline Cart 6 & 0,56 & 0,56 & 0,02 & 0,00 & 0,72 & 0,00 \\
\hline Cart 7 & 0,55 & 0,55 & 0,01 & 0,02 & 0,80 & 0,00 \\
\hline Cart 8 & 0,31 & 0,31 & 0,02 & 0,00 & 0,86 & 0,00 \\
\hline Cart 9 & 0,58 & 0,58 & 0,01 & 0,00 & 0,82 & 0,00 \\
\hline Cart 10 & 0,65 & 0,65 & 0,01 & 0,02 & 0,89 & 0,00 \\
\hline Cart 11 & 0,57 & 0,57 & 0,01 & 0,07 & 0,90 & 0,00 \\
\hline Cart 12 & 0,54 & 0,54 & 0,00 & 0,50 & 1,04 & 0,00 \\
\hline Cart 13 & 0,51 & 0,51 & 0,01 & 0,32 & 1,08 & 0,00 \\
\hline Cart 14 & 0,57 & 0,57 & 0,02 & 0,00 & 1,00 & 0,00 \\
\hline Cart 15 & 0,70 & 0,70 & 0,01 & 0,00 & 1,08 & 0,00 \\
\hline Cart 16 & 0,65 & 0,65 & 0,02 & 0,00 & 1,12 & 0,00 \\
\hline Cart 17 & 0,46 & 0,46 & 0,02 & 0,08 & 1,38 & 0,00 \\
\hline Cart 18 & 0,34 & 0,33 & 0,00 & 0,92 & 1,54 & 0,00 \\
\hline Cart 19 & 0,50 & 0,50 & 0,00 & 0,82 & 1,36 & 0,00 \\
\hline Cart 20 & 0,59 & 0,59 & 0,02 & 0,05 & 1,83 & 0,00 \\
\hline
\end{tabular}

Tabela 42 - Resultado das Regressões: $R^{2}, R^{2}$ Ajustado, Coeficientes e P-Valor por Carteira para o Modelo CAPM

\begin{tabular}{|l|cc|c|}
\hline Média & Variação $\mathbf{R}^{2}$ & $\begin{array}{c}\text { Variação } \\
\mathbf{R}^{2} \text { Ajustado }\end{array}$ & $\begin{array}{c}\text { Variação } \beta_{2} \text { (CAPM) - } \\
\boldsymbol{\beta}_{6 \text { Resíduo lbovespa }}\end{array}$ \\
\hline Mínimos Quadrados Ordinários & $-0,02$ & $-0,01$ & 0,05 \\
\hline
\end{tabular}

Tabela 43 - Comparação dos Modelos CAPM e APT Unificado ao CAPM ${ }^{10}$

Assim como no modelo APT unificado ao CAPM, encontrou-se autocorrelação nos resíduos das regressões para quatro carteiras, sendo 3 autorelações positivas e uma negativa (Tabela 44).

A hipótese do teste é:

\footnotetext{
${ }^{10}$ Tabela compela no anexo.
} 
- $\mathrm{H}_{0}$ : Não existe autocorrelação

- $\mathrm{H}_{\mathrm{a}}$ : Autocorrelação positiva

- $\mathrm{H}_{0}^{*}$ : Não existe autocorrelação

- $\mathrm{H}_{\mathrm{a}}^{*}$ : Autocorrelação negativa

\begin{tabular}{|lccc|}
\hline Cstatística & DW & $\begin{array}{c}\text { No } \\
\text { Observações }\end{array}$ & Resultado \\
\hline Cart1 & - & - & - \\
\hline Cart2 & 2,16 & 214 & Não tem Autocorrelação \\
\hline Cart3 & 2,16 & 213 & Não tem Autocorrelação \\
\hline Cart4 & - & - & - \\
\hline Cart5 & 1,74 & 213 & Autocorrelação Positiva \\
\hline Cart6 & 2,16 & 214 & Não tem Autocorrelação \\
\hline Cart7 & 1,71 & 213 & Autocorrelação Positiva \\
\hline Cart8 & 2,219 & 214 & Não tem Autocorrelação \\
\hline Cart9 & 1,64 & 214 & Autocorrelação Positiva \\
\hline Cart10 & 2,10 & 213 & Não tem Autocorrelação \\
\hline Cart11 & 1,91 & 213 & Não tem Autocorrelação \\
\hline Cart12 & 2,00 & 214 & Não tem Autocorrelação \\
\hline Cart13 & 2,02 & 213 & Não tem Autocorrelação \\
\hline Cart14 & 1,81 & 213 & Não tem Autocorrelação \\
\hline Cart15 & 2,23 & 214 & Inconclusivo \\
\hline Cart16 & 1,84 & 213 & Não tem Autocorrelação \\
\hline Cart17 & 2,34 & 169 & Autocorrelação Negativa \\
\hline Cart18 & - & - & Não tem Autocorrelação \\
\hline Cart19 & 2,04 & 80 & Não tem Autocorrelação \\
\hline Cart20 & 1,96 & 87 &
\end{tabular}

Tabela 44 - Teste Durbin Watson para o Modelo CAPM

O teste Jarque-Bera indicou que apenas 2 regressões (das 20) apresentam distribuição normal ao nível de 5\%, como pode ser visto na Tabela 45. Ressalta-se que o teste serve para amostras grandes, não sendo possível garantir que as observações das amostras são suficientemente grande.

A hipótese do teste é:

- $\mathrm{H}_{\mathrm{o}}$ : Distribuição normal

- $\mathrm{H}_{\mathrm{a}}$ : Não segue distribuição normal

\begin{tabular}{|lccc|} 
& & & \\
\hline Cart 1 & 270,2 & 0,00 & 197 \\
\hline Cart 2 & 4,4 & 0,11 & 216 \\
\hline Cart 3 & 6,5 & 0,04 & 215 \\
\hline Cart 4 & 6,5 & 0,04 & 213 \\
\hline Cart 5 & 118,8 & 0,00 & 215 \\
\hline Cart 6 & 75,1 & 0,00 & 216 \\
\hline Cart 7 & 4,4 & 0,11 & 215 \\
\hline
\end{tabular}




\begin{tabular}{|lcll|}
\hline Cart 8 & $18.982,9$ & 0,00 & 216 \\
\hline Cart 9 & 17,2 & 0,00 & 216 \\
\hline Cart 10 & 172,5 & 0,00 & 215 \\
\hline Cart 11 & 295,8 & 0,00 & 215 \\
\hline Cart 12 & 135,6 & 0,00 & 216 \\
\hline Cart 13 & 119,5 & 0,00 & 215 \\
\hline Cart 14 & 36,6 & 0,00 & 215 \\
\hline Cart 15 & 23,9 & 0,00 & 216 \\
\hline Cart 16 & $2.184,4$ & 0,00 & 215 \\
\hline Cart 17 & $1.589,4$ & 0,00 & 171 \\
\hline Cart 18 & 878,3 & 0,00 & 178 \\
\hline Cart 19 & 32,2 & 0,00 & 82 \\
\hline Cart 20 & 20,5 & 0,00 & 89 \\
\hline
\end{tabular}

Tabela 45 - Teste Jarque-Bera para Modelo CAPM

O Teste White indicou que os resíduos são homocedásticos para 7 regressões, ao nível de $5 \%$, com as estatísticas de teste e a probabilidade destas estatísticas excederem o valor da tabela (caso em que se rejeitaria a hipótese nula) estão apresentados na Tabela 46. O teste serve para amostras grandes, não sendo possível garantir que as observações das amostras são suficientemente grande.

A hipótese do teste é:

- $\mathrm{H}_{0}$ : Homocedasticidade

- $\mathrm{H}_{\mathrm{a}}$ : Heterocedasticidade

\begin{tabular}{|lccc|}
\hline & White & Probabilidade & № Observações \\
\hline Cart 1 & 36,3 & 0,00 & 197 \\
\hline Cart 2 & 16,6 & 0,00 & 216 \\
\hline Cart 3 & 9,9 & 0,01 & 215 \\
\hline Cart 4 & 1,1 & 0,59 & 213 \\
\hline Cart 5 & 3,5 & 0,18 & 215 \\
\hline Cart 6 & 6,8 & 0,03 & 216 \\
\hline Cart 7 & 15,2 & 0,00 & 215 \\
\hline Cart 8 & 0,4 & 0,83 & 216 \\
\hline Cart 9 & 1,8 & 0,40 & 216 \\
\hline Cart 10 & 25,7 & 0,00 & 215 \\
\hline Cart 11 & 10,4 & 0,01 & 215 \\
\hline Cart 12 & 1,7 & 0,44 & 216 \\
\hline Cart 13 & 1,9 & 0,39 & 215 \\
\hline Cart 14 & 37,0 & 0,00 & 215 \\
\hline Cart 15 & 25,2 & 0,00 & 216 \\
\hline Cart 16 & 13,4 & 0,00 & 215 \\
\hline Cart 17 & 19,9 & 0,00 & 171 \\
\hline
\end{tabular}




\begin{tabular}{|lccc|} 
Cart 18 & 26,6 & 0,00 & 178 \\
\hline Cart 19 & 1,3 & 0,53 & 82 \\
\hline Cart 20 & 18,2 & 0,00 & 89 \\
\hline
\end{tabular}

Tabela 46 - Teste White para Modelo CAPM 


\section{5 \\ Conclusões e Sugestões para Estudos Futuros}

A intenção do presente estudo era analisar o desempenho do mercado acionário brasileiro, no período pós-estabilização econômica, através da utilização de diferentes modelos financeiros a fim de verificar qual deles seria capaz de melhor retratar o desempenho das ações.

Inicialmente foi dado um breve embasamento teórico a respeito de cada um dos modelos para seu o posterior desenvolvimento.

A controvérsia sobre o Capital Asset Pricing Model (CAPM) no meio acadêmico em contra partida a sua vasta utilização pelos agentes do mercado gera grande interesse para avaliar a capacidade de explicação do desempenho das ações.

O Arbitrage Pricing Theory (APT), por outro lado, se propõe explicar mais precisamente o retorno das ações, sendo contudo, pouquíssimo usado pelos agentes de mercado. A baixa utilização do APT deve-se não apenas a dificuldade de se definir o número de fatores explicativos necessários, mas também a complexidade para determinação de quais seriam os fatores capazes de explicar o retorno das ações.

Visando comparar o CAPM a dois modelos APT distintos foram desenvolvidos: um modelo com base em fatores ligados aos ativos, o Modelo de Três Fatores de Fama e French; e um modelo ligado a fatores macroeconômicos juntamente com o fator de mercado.

O prêmio de risco, ou fator de mercado, mostrou ter grande relevância para o poder explicativo do retorno das ações ao longo de todo o estudo.

No desenvolvimento do Modelo de Três Fatores, os dados apresentaram uma anomalia em relação à teoria prevista. No mercado brasileiro, a média de retorno das empresas de pequeno porte foi inferior à média de retorno das empresas de grande porte, o que não se mostra condizente com a teoria de risco-retorno. Apesar desta anomalia encontrada o modelo foi desenvolvido conforme proposto.

Quando comparado o Modelo de Três Fatores ao CAPM o primeiro mostrou ter maior poder explicativo do retorno das ações. Particularmente, os retornos das carteiras representadas pelas empresas de pequeno porte tiveram 
um ganho significativo do seu poder explicativo quando comparado ao modelo CAPM. O fator relativo ao indicador valor patrimonial / valor mercado também se mostrou relevante para explicar o retorno das ações, com o coeficiente aumentando juntamente com o aumento do indicador.

O APT de Três Fatores desenvolvido por Fama e French não apresenta elevado grau de complexidade para implementação, se mostrando como uma alternativa viável de utilização pelos agentes de mercado.

Todavia, para o mercado brasileiro a utilização deste modelo pressupõe que as ações de pequeno porte continuarão a apresentar retornos inferiores as ações das empresas grandes no futuro. Não parece uma alternativa prudente acreditar que essa anomalia irá perdurar, assim como se mostra impraticável avaliar quando poderá haver uma mudança estrutural do desempenho destas empresas.

O modelo APT Unificado ao CAPM com base em fatores macroeconômicos apresentou coeficientes consistentes e relevantes, tendo os fatores macroeconômicos indicados variações condizentes com o previsto pela teoria. Não obstante, não foi possível afirmar que existe um prêmio de risco diferente de zero para todas as variáveis do modelo simultaneamente.

Além disso, o ganho do poder explicativo do modelo APT Unificado ao CAPM foi baixo quando comparada ao CAPM tradicional.

Portanto, a complexidade em determinar fatores macroeconômicos relevantes e que apresentam resultados significativamente melhores que 0 CAPM me leva a concluir que sua utilização não se mostra viável para os agentes de mercado.

Como sugestão para estudos futuros coloca-se uma avaliação do retorno das empresas de pequeno porte no mercado brasileiro buscando entender quais fatores impactam seu desempenho quando comparado as grandes empresas. Um melhor entendimento dos fatores que impactam o retorno destas ações poderá levar ao desenvolvimento de um modelo APT baseado em fatores ligados aos ativos que melhor caracteriza o mercado brasileiro.

Outra linha de pesquisa interessante é buscar avaliar os modelos CAPM e APT considerando que os fatores estimados nos modelos não são estáticos no tempo. Mudanças estruturais na economia são capaz de gerar impactos no mercado acionário refletindo mudanças estruturais também na relação de risco retorno dos ativos. Os fatores a serem estimadas podem ser condicionados a outras váriaveis observadas em períodos anteriores ou considerados como um processo estocástico. Estudos já realizados utilizando esta abordagem mostram 
que os modelos condicionais tendem a apresentar melhores resultados que os modelos estáticos. Todavia os resultados variam muito de acordo com a amostra utilizada e a metodologia empregada. 
6

\section{Referências Bibliográficas}

\subsection{Citadas}

BANZ, R.W. The Relationship Between Return and Market Value of Common Stocks. 1981. Journal of Financial Economics, Vol. 9, p. 3-18.

BASU, S. The Relationship Between Earnings Yield, Market Value, and Return for NYSE Common Stocks: Further Evidence. 1983. Jounal of Financial Economics, Vol 12, p.129-156.

BHANDARI, L.C. Debt/Equity Ratio and Expected Common Stock Returns: Empirical Evidence. 1988. The Journal of Finance, Vol. 43, p. 507528.

DHRYMES, P.J.; FRIEND, I.; GULTEKIN, B. A Critical Reexamination of the Empirical Evidence on the Arbitrage Pricing Theory.1982. Working paper No. 12-82 - The Warton School, Universtiy of Pennsylvania.

FAMA, E. F.; FRENCH, K. R. The Cross Section of Expected Stock Returns. 1992. Journal of Finance, Vol. 47, No. 2, p. 427-465.

. Common Risk Factors in the Returns on Stocks and Bonds. 1993. Journal of Financial Economics, Vol. 33, p.3-56.

GUJARATI, D. N. Basic Econometrics. 4. ed. Nova lorque: McGrawHill/Irwin, 2003.

JUNIOR, H. S. L. Um Estudo das Anomalias no Apreçamento de Ações no Mercado Brasileiro Utilizando o Modelo de Quatro Fatores. Dissertação de Mestrado - Departamento de Engenharia Industrial, Pontifícia Universidade Católica do Rio de Janeiro, 2003.

MÁLAGA, F.K.; SECURATO, J.R. Aplicação do Modelo de Três Fatores de Fama e French no Mercado Acionário Brasileiro - Um Estudo Empírico do Período 1995-2003. Encontro Anual da Associação Nacional dos Programas de Pós-Graduação em Administração. 2004. Curitiba.

MARKOWITZ, H. Portfolio Selection.1952. The Journal of Finance, Vol. 7, No. 1, pp. 77-91. 
MELLO, L.M. Determinação e Análise de Desempenho do Modelo APT. 1999. Dissertação de Mestrado - Departamento de Engenharia Industrial, Pontifícia Universidade Católica do Rio de Janeiro, 1999.

MUSSA, A. A Adição do Fator de Risco Momento ao Modelo de Precificação de Ativos dos Três Fatores de Fama \& French Aplicado ao Mercado Acionário Brasileiro. Dissertação de Mestrado - Administração, Pontifícia Universidade Católica de São Paulo, 2007.

ROLL, R.; ROSS, S. A. An Empirical Investigation of the Arbitrage Pricing Theory. 1980. The Journal of Finance, Vol. 35, No. 5, p. 1073-1103.

ROSENBERG, B.; KENNETH, R.;Lanstein, r. Persuasive Evidence of Market Inefficiency. 1985. Journal of Portfolio Management, Vol. 9, p. 9-17.

ROSS, S. A. The Arbitrage Theory of Capital Asset Pricing.1976. Journal of Economic Theory 13, 341-360.

SCHOR, A.; BONOMO, M.A.; PEREIRA, P.L.V. Arbitrage Pricing Theory (APT) e Variáveis Macroeconômicas: Um estudo empírico sobre o mercado acionário brasileiro. 1998. Texto para discussão № 391 - Departamento de Economia, Pontifícia Universidade Católica do Rio de Janeiro, 1998.

SHARPE, W.F. Capital Asset Prices: A Theory of Market Equilibrium under Conditions of Risk. 1964. The Journal of Finance, Vol. 19, No. 3, p. 425442.

STATTMAN, D. Book Values and Stock Returns. 1980. A Journal of Selected Papers, Vol. 4, p. 25-45.

TOBIN, J. Liquidity Preference as Behavior Towards Risk. 1958. The Review of Economic Studies, Vol. 25, No. 2, p. 65-86.

WEI, K. C. J. An Asset-Pricing Theory Unifying the CAPM and APT. 1988. The Journal of Finance, Vol. 43, No. 4, p. 881-892.

\subsection{Não Citadas}

ABHYANKAR, A.; HO, K. Y.; ZHAO, H. International Value Versus Growth: Evidence From Stochastic Dominance Analysis. 2009. International Journal of Finance \& Economics, Vol. 14, p. 222-232.

ATHANASSAKOS, G. Value versus Growth Stock Returns and the Value Premium: The Canadian Experience 1985-2005. 2009. Canadian Journal of Administrative Sciences, Vol. 26, p.109-121. 
CALDEIRA, J. F.; MOURA, G. V.; SANTOS, A. A. P. Seleção de Carteiras Utilizando o Modelo Fama-French-Carhart. 2013. Revista Brasileira de Economia vol.67 no.1 Rio de Janeiro.

CARVAlHO, A. G.; TOlENTINO, R. A. Efeitos da Estabilizaçao de Preços em IPOs Sobre a Liquidez de Longo Prazo. 2010. Revista Brasileira de Finanças, Vol.8, No.3, p. 307-328.

CHAN, K. et al. Share Repurchases as a Potential Tool to Mislead Investors. 2010. Journal of Corporate Finance, Vol.16, p.137-158.

DA RÓS, S. Estudos Empíricos no Mercado Acionário Brasileiro Utilizando o Arbitrage Pricing Theory - Apt com Fatores Fundamentalistas Pré-Determinados. 1999. Dissertação de Mestrado - Departamento de Engenharia Industrial, Pontifícia Universidade Católica do Rio de Janeiro, 1999.

DECHOW, P. M.; SLOAN, R. G. Returns to Contrarian Investment Strategies: Tests of Naive Expectations Hypotheses. 1997. Journal of Financial Economics 43, p. 3-27.

FAMA, E. F. Market Effciency, Long-Term Returns, and Behavioral Finance. 1998. Journal of Financial Economics, Vol. 49, p.283-306.

FAMA, E. F.; FRENCH, K. R. Size and Book-to-Market Factors in Earnings and Returns. 1995. The Journal of Finance, Vol. 50, No. 1, p. 131155.

Multifactor Explanations of Asset Pricing Anomalies. 1996. Journal of Finance, Vol.51, No.1, p. 55-84.

The CAPM is Wanted, Dead or Alive. 1996. The Journal of Finance, Vol. 51, No. 5, p. 1947-1958.

Value Versus Growth: The International Evidence. 1998. The Journal of Finance, Vol. 53, No. 6.

. The Capital Asset Pricing Model: Theory and Evidence. 2004. Journal of Economic Perspectives, Vol.18, No.3, p.25-46

The Anatomy of Value and Growth Stock Returns. 2007. Financial Analysts Journal, Vol.63, No. 6, CFA Institute.

Average Returns, B/M, and Share Issues. 2008. The Journal of Finance, Vol. 63, No. 6.

IKENBERRY, D.; Lakonishok, J.; Vermaelen, T. Market Underreaction to Open Market Share Repurchases. 1995. Journal of Financial Economics Vol. 39, p.181-208.

JOHNSTON, J.; DINARDO, J. Econometric Methods. 4를 ed. Nova lorque: McGraw-Hill, 1997. 
LA PORTA, R. Expectations and the Cross-Section of Stock Returns. 1996. The Journal of Finance, Vol. 51, No. 5, p. 1715-1742

LA PORTA, R. et al. Good News for Value Stocks Further Evidence on Market Efficiency. 1997. The Journal of Finance, Vol. 52, No. 2.

LAKONISHOK, J.; Shleifer, A.; VISHNY. R. W. Contrarian Investment, Extrapolation, and Risk. 1994. The Journal of Finance, Vol. 49, No. 5, p. 1541 1578.

LEVY, H.; SARNAT, M. Portfolio and Investment Selection: Theory and Practice. 1.ed. Estados Unidos da América: Prentice-Hall Internacional, Inc. 1984.

LINTNER, J. The Valuation of Risk Assets and the Selection of Risky Investments in Stock Portfolios and Capital Budgets. 1965.The Review of Economics and Statistics, Vol. 47, No. 1, p. 13-37.

MONTGOMERY, D.C.; RUNGER, G.C. Estatística Aplicada e Probabilidade Para Engenheiros. $4^{\mathrm{a}}$ ed. Rio de Janeiro: Livros Técnicos e Científicos Editora Ltda., 2009.

OBERUC, R.E. Dynamic Portfolio Theory and Management: Using Active Asset Allocation to Improve Profits and Reduce Risk. 2. ed. Estados Unidos da América: Richard E. Oberuc. 2011.

PETKOVA, R.; Zhang, L. Is value riskier than growth? 2005. Journal of Financial Economics 78, p. 187-202.

SAMANEZ, C.P. Gestão de Investimentos e Geração de Valor. $1^{\text {a }}$ Ed. São Paulo: Pearson Education do Brasil, 2010.

SECURATO, J.R.; ROGERS, P. Estudo comparativo no Mercado Brasileiro do Capital Asset Pricing Model (CAPM), modelo 3-Fatores de Fama e French e Reward Beta Approach. 2009. RAC-Eletrônica, Curitiba, Vol. 3, No. 1, art.9, p. 159-179. 


\section{Anexos}

\begin{tabular}{|lrrrrrrr|}
\hline & Low / & Low / & Medium & Medium & High / & High / & Total \\
Small & Big & / Small & / Big & Small & Big & Amostra \\
\hline Jun-95 & 20 & 46 & 42 & 46 & 48 & 18 & 220 \\
\hline Dec-95 & 21 & 42 & 38 & 46 & 46 & 17 & 210 \\
\hline Jun-96 & 11 & 56 & 50 & 41 & 52 & 16 & 226 \\
\hline Dec-96 & 11 & 58 & 50 & 40 & 53 & 16 & 228 \\
\hline Jun-97 & 15 & 58 & 52 & 47 & 57 & 17 & 246 \\
\hline Dec-97 & 10 & 51 & 41 & 41 & 51 & 10 & 204 \\
\hline Jun-98 & 11 & 47 & 37 & 41 & 49 & 8 & 193 \\
\hline Dec-98 & 22 & 34 & 33 & 44 & 39 & 15 & 187 \\
\hline Jun-99 & 25 & 43 & 41 & 52 & 50 & 19 & 230 \\
\hline Dec-99 & 15 & 59 & 59 & 39 & 50 & 24 & 246 \\
\hline Jun-00 & 18 & 64 & 63 & 47 & 57 & 26 & 275 \\
\hline Dec-00 & 18 & 57 & 56 & 43 & 51 & 24 & 249 \\
\hline Jun-01 & 21 & 46 & 40 & 48 & 50 & 17 & 222 \\
\hline Dec-01 & 21 & 45 & 44 & 44 & 45 & 21 & 220 \\
\hline Jun-02 & 23 & 41 & 39 & 48 & 45 & 18 & 214 \\
\hline Dec-02 & 22 & 42 & 39 & 45 & 45 & 19 & 212 \\
\hline Jun-03 & 18 & 45 & 41 & 44 & 47 & 16 & 211 \\
\hline Dec-03 & 21 & 47 & 38 & 53 & 55 & 13 & 227 \\
\hline Jun-04 & 17 & 50 & 44 & 47 & 53 & 13 & 224 \\
\hline Dec-04 & 14 & 57 & 45 & 49 & 59 & 11 & 235 \\
\hline Jun-05 & 14 & 56 & 43 & 51 & 60 & 10 & 234 \\
\hline Dec-05 & 16 & 50 & 37 & 49 & 56 & 10 & 218 \\
\hline Jun-06 & 20 & 44 & 34 & 50 & 52 & 12 & 212 \\
\hline Dec-06 & 25 & 47 & 42 & 53 & 52 & 19 & 238 \\
\hline Jun-07 & 26 & 55 & 45 & 62 & 64 & 17 & 269 \\
\hline Dec-07 & 25 & 66 & 63 & 59 & 65 & 27 & 305 \\
\hline Jun-08 & 33 & 61 & 60 & 64 & 63 & 31 & 312 \\
\hline Dec-08 & 27 & 62 & 52 & 65 & 69 & 20 & 295 \\
\hline Jun-09 & 26 & 61 & 50 & 64 & 68 & 19 & 288 \\
\hline Dec-09 & 25 & 62 & 48 & 66 & 71 & 16 & 288 \\
\hline Jun-10 & 27 & 59 & 45 & 69 & 71 & 15 & 286 \\
\hline Dec-10 & 29 & 60 & 57 & 61 & 62 & 26 & 295 \\
\hline Jun-11 & 55 & 53 & 68 & 62 & 26 & 299 \\
\hline Dec-11 & 54 & 52 & 67 & 62 & 28 & 299 \\
\hline
\end{tabular}




\begin{tabular}{|llllllll|}
\hline Jun-12 & 34 & 50 & 42 & 70 & 64 & 20 & 280 \\
\hline Dec-12 & 31 & 54 & 45 & 67 & 65 & 20 & 282 \\
\hline Média & $\mathbf{2 2}$ & $\mathbf{5 2}$ & $\mathbf{4 6}$ & $\mathbf{5 3}$ & $\mathbf{5 6}$ & $\mathbf{1 8}$ & $\mathbf{2 4 7}$ \\
\hline
\end{tabular}

Tabela 47 - Número de Empresas por Carteira entre 1995-2012

\begin{tabular}{|c|c|c|c|c|c|c|c|}
\hline & $\begin{array}{l}\text { Low / } \\
\text { Small }\end{array}$ & $\begin{array}{r}\text { Low / } \\
\text { Big }\end{array}$ & $\begin{array}{l}\text { Medium } \\
\text { / Small }\end{array}$ & $\begin{array}{r}\text { Medium } \\
\text { / Big }\end{array}$ & $\begin{array}{l}\text { High / } \\
\text { Small }\end{array}$ & $\begin{array}{r}\text { High / } \\
\text { Big }\end{array}$ & Mercado \\
\hline Jun-95 & 2,0 & 49,5 & 1,9 & 71,7 & 1,7 & 42,6 & 169,5 \\
\hline Dec-95 & 1,8 & 52,0 & 2,1 & 80,7 & 1,4 & 43,8 & 181,8 \\
\hline Jun-96 & 0,8 & 92,1 & 4,6 & 100,0 & 2,0 & 45,9 & 245,4 \\
\hline Dec-96 & 1,3 & 95,7 & 4,8 & 135,9 & 2,4 & 53,8 & 293,9 \\
\hline Jun-97 & 2,0 & 139,1 & 6,0 & 231,6 & 3,1 & 95,1 & 476,8 \\
\hline Dec-97 & 1,0 & 235,0 & 4,4 & 141,9 & 3,0 & 5,2 & 390,5 \\
\hline Jun-98 & 1,0 & 203,2 & 4,6 & 95,6 & 3,4 & 4,4 & 312,2 \\
\hline Dec-98 & 2,3 & 72,6 & 3,4 & 46,1 & 2,5 & 30,8 & 157,7 \\
\hline Jun-99 & 3,8 & 110,6 & 5,7 & 174,0 & 5,0 & 53,3 & 352,3 \\
\hline Dec-99 & 3,0 & 354,4 & 10,7 & 76,9 & 6,6 & 85,2 & 536,7 \\
\hline Jun-00 & 4,4 & 362,1 & 12,0 & 111,3 & 4,6 & 65,6 & 560,1 \\
\hline Dec-00 & 4,4 & 366,3 & 9,2 & 84,5 & 5,5 & 68,0 & 537,9 \\
\hline Jun-01 & 4,1 & 352,4 & 10,0 & 148,1 & 6,7 & 52,7 & 574,1 \\
\hline Dec-01 & 6,8 & 306,5 & 7,3 & 145,8 & 5,8 & 55,5 & 527,7 \\
\hline Jun-02 & 7,0 & 312,4 & 9,0 & 147,4 & 5,1 & 52,2 & 533,2 \\
\hline Dec-02 & 7,4 & 325,0 & 10,4 & 167,7 & 7,3 & 44,9 & 562,9 \\
\hline Jun-03 & 6,2 & 335,5 & 9,8 & 175,4 & 10,0 & 47,9 & 584,7 \\
\hline Dec-03 & 8,5 & 587,5 & 13,2 & 227,1 & 13,9 & 83,1 & 933,4 \\
\hline Jun-04 & 6,7 & 619,7 & 17,5 & 181,2 & 14,4 & 59,1 & 898,6 \\
\hline Dec-04 & 7,7 & 843,5 & 18,6 & 255,8 & 14,7 & 63,3 & $1.203,7$ \\
\hline Jun-05 & 6,4 & 551,8 & 16,6 & 474,5 & 13,0 & 62,5 & $1.124,9$ \\
\hline Dec-05 & 11,2 & 638,3 & 20,1 & 696,6 & 20,9 & 75,6 & $1.462,6$ \\
\hline Jun-06 & 18,1 & $1.044,5$ & 26,4 & 435,9 & 17,0 & 93,4 & $1.635,4$ \\
\hline Dec-06 & 20,1 & 800,1 & 33,5 & 955,8 & 23,4 & 148,3 & $1.981,1$ \\
\hline Jun-07 & 29,3 & $1.067,4$ & 37,3 & $1.119,6$ & 37,5 & 172,1 & $2.463,2$ \\
\hline Dec-07 & 22,4 & $1.190,3$ & 46,6 & $1.444,8$ & 30,7 & 253,2 & $2.988,0$ \\
\hline Jun-08 & 20,5 & $1.969,4$ & 38,4 & 707,3 & 23,8 & 295,2 & $3.054,5$ \\
\hline Dec-08 & 7,4 & $1.234,4$ & 18,0 & 321,6 & 17,1 & 138,4 & $1.736,9$ \\
\hline Jun-09 & 9,1 & $1.291,1$ & 24,1 & 782,0 & 24,0 & 111,1 & $2.241,5$ \\
\hline Dec-09 & 18,3 & $1.546,8$ & 32,0 & $1.087,2$ & 35,2 & 163,6 & $2.883,2$ \\
\hline Jun-10 & 21,6 & 771,5 & 32,0 & $1.534,0$ & 27,8 & 159,4 & $2.546,3$ \\
\hline Dec-10 & 22,1 & 881,6 & 49,3 & $1.949,9$ & 31,1 & 253,0 & $3.187,1$ \\
\hline Jun-11 & 31,1 & 775,3 & 41,0 & $1.876,7$ & 27,9 & 289,1 & $3.041,1$ \\
\hline Dec-11 & 27,0 & 840,2 & 36,8 & $1.637,8$ & 27,7 & 257,8 & $2.827,4$ \\
\hline Jun-12 & 32,8 & 973,9 & 30,0 & $1.087,2$ & 30,0 & 663,5 & $2.817,5$ \\
\hline Dec-12 & 32,9 & $1.111,9$ & 39,1 & $1.123,2$ & 36,4 & 680,3 & $3.023,8$ \\
\hline Média & 11,5 & 625,1 & 19,1 & 556,5 & 15,1 & 135,3 & $1.362,4$ \\
\hline $\begin{array}{l}\text { Valor por } \\
\text { Empresa }\end{array}$ & 0,5 & 11,9 & 0,4 & 10,6 & 0,3 & 7,4 & 5,7 \\
\hline
\end{tabular}

Tabela 48 - Valor de Mercado das Carteiras (R\$ bilhões) entre 1995-2012 


\begin{tabular}{|c|c|c|c|c|c|c|}
\hline & $\begin{array}{l}\text { Low / } \\
\text { Small }\end{array}$ & Low / Big & $\begin{array}{r}\text { Medium / } \\
\text { Small }\end{array}$ & $\begin{array}{r}\text { Medium / } \\
\text { Big }\end{array}$ & $\begin{array}{l}\text { High / } \\
\text { Small }\end{array}$ & $\begin{array}{r}\text { High / } \\
\text { Big }\end{array}$ \\
\hline Jun-95 & $1,2 \%$ & $29,2 \%$ & $1,1 \%$ & $42,3 \%$ & $1,0 \%$ & $25,1 \%$ \\
\hline Dec-95 & $1,0 \%$ & $28,6 \%$ & $1,1 \%$ & $44,4 \%$ & $0,8 \%$ & $24,1 \%$ \\
\hline Jun-96 & $0,3 \%$ & $37,5 \%$ & $1,9 \%$ & $40,7 \%$ & $0,8 \%$ & $18,7 \%$ \\
\hline Dec-96 & $0,4 \%$ & $32,6 \%$ & $1,6 \%$ & $46,2 \%$ & $0,8 \%$ & $18,3 \%$ \\
\hline Jun-97 & $0,4 \%$ & $29,2 \%$ & $1,3 \%$ & $48,6 \%$ & $0,6 \%$ & $19,9 \%$ \\
\hline Dec-97 & $0,3 \%$ & $60,2 \%$ & $1,1 \%$ & $36,3 \%$ & $0,8 \%$ & $1,3 \%$ \\
\hline Jun-98 & $0,3 \%$ & $65,1 \%$ & $1,5 \%$ & $30,6 \%$ & $1,1 \%$ & $1,4 \%$ \\
\hline Dec-98 & $1,5 \%$ & $46,0 \%$ & $2,2 \%$ & $29,2 \%$ & $1,6 \%$ & $19,5 \%$ \\
\hline Jun-99 & $1,1 \%$ & $31,4 \%$ & $1,6 \%$ & $49,4 \%$ & $1,4 \%$ & $15,1 \%$ \\
\hline Dec-99 & $0,6 \%$ & $66,0 \%$ & $2,0 \%$ & $14,3 \%$ & $1,2 \%$ & $15,9 \%$ \\
\hline Jun-00 & $0,8 \%$ & $64,7 \%$ & $2,1 \%$ & $19,9 \%$ & $0,8 \%$ & $11,7 \%$ \\
\hline Dec-00 & $0,8 \%$ & $68,1 \%$ & $1,7 \%$ & $15,7 \%$ & $1,0 \%$ & $12,6 \%$ \\
\hline Jun-01 & $0,7 \%$ & $61,4 \%$ & $1,7 \%$ & $25,8 \%$ & $1,2 \%$ & $9,2 \%$ \\
\hline Dec-01 & $1,3 \%$ & $58,1 \%$ & $1,4 \%$ & $27,6 \%$ & $1,1 \%$ & $10,5 \%$ \\
\hline Jun-02 & $1,3 \%$ & $58,6 \%$ & $1,7 \%$ & $27,6 \%$ & $1,0 \%$ & $9,8 \%$ \\
\hline Dec-02 & $1,3 \%$ & $57,7 \%$ & $1,9 \%$ & $29,8 \%$ & $1,3 \%$ & $8,0 \%$ \\
\hline Jun-03 & $1,1 \%$ & $57,4 \%$ & $1,7 \%$ & $30,0 \%$ & $1,7 \%$ & $8,2 \%$ \\
\hline Dec-03 & $0,9 \%$ & $62,9 \%$ & $1,4 \%$ & $24,3 \%$ & $1,5 \%$ & $8,9 \%$ \\
\hline Jun-04 & $0,7 \%$ & $69,0 \%$ & $1,9 \%$ & $20,2 \%$ & $1,6 \%$ & $6,6 \%$ \\
\hline Dec-04 & $0,6 \%$ & $70,1 \%$ & $1,5 \%$ & $21,3 \%$ & $1,2 \%$ & $5,3 \%$ \\
\hline Jun-05 & $0,6 \%$ & $49,1 \%$ & $1,5 \%$ & $42,2 \%$ & $1,2 \%$ & $5,6 \%$ \\
\hline Dec-05 & $0,8 \%$ & $43,6 \%$ & $1,4 \%$ & $47,6 \%$ & $1,4 \%$ & $5,2 \%$ \\
\hline Jun-06 & $1,1 \%$ & $63,9 \%$ & $1,6 \%$ & $26,7 \%$ & $1,0 \%$ & $5,7 \%$ \\
\hline Dec-06 & $1,0 \%$ & $40,4 \%$ & $1,7 \%$ & $48,2 \%$ & $1,2 \%$ & $7,5 \%$ \\
\hline Jun-07 & $1,2 \%$ & $43,3 \%$ & $1,5 \%$ & $45,5 \%$ & $1,5 \%$ & $7,0 \%$ \\
\hline Dec-07 & $0,7 \%$ & $39,8 \%$ & $1,6 \%$ & $48,4 \%$ & $1,0 \%$ & $8,5 \%$ \\
\hline Jun-08 & $0,7 \%$ & $64,5 \%$ & $1,3 \%$ & $23,2 \%$ & $0,8 \%$ & $9,7 \%$ \\
\hline Dec-08 & $0,4 \%$ & $71,1 \%$ & $1,0 \%$ & $18,5 \%$ & $1,0 \%$ & $8,0 \%$ \\
\hline Jun-09 & $0,4 \%$ & $57,6 \%$ & $1,1 \%$ & $34,9 \%$ & $1,1 \%$ & $5,0 \%$ \\
\hline Dec-09 & $0,6 \%$ & $53,6 \%$ & $1,1 \%$ & $37,7 \%$ & $1,2 \%$ & $5,7 \%$ \\
\hline Jun-10 & $0,8 \%$ & $30,3 \%$ & $1,3 \%$ & $60,2 \%$ & $1,1 \%$ & $6,3 \%$ \\
\hline Dec-10 & $0,7 \%$ & $27,7 \%$ & $1,5 \%$ & $61,2 \%$ & $1,0 \%$ & $7,9 \%$ \\
\hline Jun-11 & $1,0 \%$ & $25,5 \%$ & $1,3 \%$ & $61,7 \%$ & $0,9 \%$ & $9,5 \%$ \\
\hline Dec-11 & $1,0 \%$ & $29,7 \%$ & $1,3 \%$ & $57,9 \%$ & $1,0 \%$ & $9,1 \%$ \\
\hline Jun-12 & $1,2 \%$ & $34,6 \%$ & $1,1 \%$ & $38,6 \%$ & $1,1 \%$ & $23,6 \%$ \\
\hline Dec-12 & $1,1 \%$ & $36,8 \%$ & $1,3 \%$ & $37,1 \%$ & $1,2 \%$ & $22,5 \%$ \\
\hline Média & $0,8 \%$ & $49,0 \%$ & $1,5 \%$ & $36,5 \%$ & $1,1 \%$ & $11,0 \%$ \\
\hline
\end{tabular}

Tabela 49 - Participação de Mercado por Carteira entre 1995-2012 


\begin{tabular}{|c|c|c|c|c|c|c|c|c|}
\hline & $\begin{array}{l}\text { Low / } \\
\text { Small }\end{array}$ & $\begin{array}{c}\text { Low / } \\
\text { Big }\end{array}$ & $\begin{array}{r}\text { Mediu } \\
m / \\
\text { Small }\end{array}$ & $\begin{array}{l}\text { Mediu } \\
\text { m / Big }\end{array}$ & $\begin{array}{l}\text { High / } \\
\text { Small }\end{array}$ & $\begin{array}{r}\text { High / } \\
\text { Big }\end{array}$ & $\begin{array}{r}\text { Merca } \\
\text { do }\end{array}$ & $\begin{array}{r}\text { Poupa } \\
\text { nça }\end{array}$ \\
\hline Jun-95 & $-8,7 \%$ & $-2,3 \%$ & $-6,3 \%$ & $-3,6 \%$ & $0,1 \%$ & $-3,0 \%$ & $-3,1 \%$ & $3,3 \%$ \\
\hline Dec-95 & $-5,1 \%$ & $0,1 \%$ & $-6,8 \%$ & $3,1 \%$ & $-1,5 \%$ & $0,5 \%$ & $1,4 \%$ & $2,4 \%$ \\
\hline Jun-96 & $2,0 \%$ & $5,1 \%$ & $1,6 \%$ & $7,9 \%$ & $3,5 \%$ & $3,8 \%$ & $5,9 \%$ & $1,3 \%$ \\
\hline Dec-96 & $-1,6 \%$ & $2,0 \%$ & $1,5 \%$ & $3,2 \%$ & $3,1 \%$ & $5,1 \%$ & $3,1 \%$ & $1,2 \%$ \\
\hline Jun-97 & $3,0 \%$ & $7,6 \%$ & $6,7 \%$ & $10,5 \%$ & $5,0 \%$ & $10,8 \%$ & $9,6 \%$ & $1,2 \%$ \\
\hline Dec-97 & $-8,0 \%$ & $-4,3 \%$ & $-4,7 \%$ & $-2,8 \%$ & $-3,8 \%$ & $-1,3 \%$ & $-3,7 \%$ & $1,4 \%$ \\
\hline Jun-98 & $1,1 \%$ & $-1,6 \%$ & $0,7 \%$ & $-3,8 \%$ & $2,2 \%$ & $1,5 \%$ & $-2,1 \%$ & $1,1 \%$ \\
\hline Dec-98 & $-5,2 \%$ & $-7,3 \%$ & $-4,4 \%$ & $-4,7 \%$ & $-1,1 \%$ & $-7,2 \%$ & $-6,4 \%$ & $1,2 \%$ \\
\hline Jun-99 & $2,0 \%$ & $9,2 \%$ & $1,4 \%$ & $11,7 \%$ & $9,9 \%$ & $9,9 \%$ & $10,3 \%$ & $1,1 \%$ \\
\hline Dec-99 & $2,3 \%$ & $9,1 \%$ & $7,1 \%$ & $7,6 \%$ & $10,7 \%$ & $4,5 \%$ & $8,1 \%$ & $0,8 \%$ \\
\hline Jun-00 & $-0,5 \%$ & $1,9 \%$ & $1,2 \%$ & $0,7 \%$ & $1,0 \%$ & $1,3 \%$ & $1,5 \%$ & $0,7 \%$ \\
\hline Dec-00 & $-1,3 \%$ & $0,1 \%$ & $-0,1 \%$ & $1,4 \%$ & $1,1 \%$ & $0,2 \%$ & $0,3 \%$ & $0,6 \%$ \\
\hline Jun-01 & $-1,6 \%$ & $2,3 \%$ & $-0,6 \%$ & $2,2 \%$ & $4,4 \%$ & $-1,8 \%$ & $1,8 \%$ & $0,6 \%$ \\
\hline Dec-01 & $-4,3 \%$ & $-1,2 \%$ & $1,2 \%$ & $0,4 \%$ & $1,4 \%$ & $7,1 \%$ & $0,1 \%$ & $0,7 \%$ \\
\hline Jun-02 & $-4,4 \%$ & $1,2 \%$ & $-0,2 \%$ & $-0,4 \%$ & $0,0 \%$ & $0,3 \%$ & $0,6 \%$ & $0,7 \%$ \\
\hline Dec-02 & $-0,3 \%$ & $2,0 \%$ & $0,9 \%$ & $0,8 \%$ & $5,7 \%$ & $-0,6 \%$ & $1,4 \%$ & $0,8 \%$ \\
\hline Jun-03 & $3,3 \%$ & $0,5 \%$ & $1,0 \%$ & $3,5 \%$ & $2,2 \%$ & $2,2 \%$ & $1,6 \%$ & $0,9 \%$ \\
\hline Dec-03 & $3,7 \%$ & $8,3 \%$ & $6,7 \%$ & $8,9 \%$ & $8,5 \%$ & $12,8 \%$ & $8,8 \%$ & $0,8 \%$ \\
\hline Jun-04 & $5,2 \%$ & $0,6 \%$ & $0,2 \%$ & $-0,1 \%$ & $0,0 \%$ & $-3,6 \%$ & $0,2 \%$ & $0,6 \%$ \\
\hline Dec-04 & $7,9 \%$ & $5,2 \%$ & $7,0 \%$ & $6,5 \%$ & $6,2 \%$ & $3,5 \%$ & $5,5 \%$ & $0,7 \%$ \\
\hline Jun-05 & $-1,0 \%$ & $-1,8 \%$ & $0,4 \%$ & $1,0 \%$ & $-0,6 \%$ & $-0,3 \%$ & $-0,5 \%$ & $0,7 \%$ \\
\hline Dec-05 & $1,5 \%$ & $5,1 \%$ & $2,7 \%$ & $5,1 \%$ & $5,0 \%$ & $4,3 \%$ & $5,0 \%$ & $0,7 \%$ \\
\hline Jun-06 & $-0,1 \%$ & $2,4 \%$ & $2,5 \%$ & $2,5 \%$ & $5,7 \%$ & $3,4 \%$ & $2,5 \%$ & $0,7 \%$ \\
\hline Dec-06 & $3,8 \%$ & $3,9 \%$ & $3,6 \%$ & $3,3 \%$ & $4,2 \%$ & $3,1 \%$ & $3,5 \%$ & $0,7 \%$ \\
\hline Jun-07 & $4,5 \%$ & $5,0 \%$ & $6,3 \%$ & $3,3 \%$ & $8,8 \%$ & $4,9 \%$ & $4,3 \%$ & $0,6 \%$ \\
\hline Dec-07 & $-1,6 \%$ & $2,5 \%$ & $-0,7 \%$ & $6,4 \%$ & $1,0 \%$ & $0,8 \%$ & $4,1 \%$ & $0,6 \%$ \\
\hline Jun-08 & $-4,5 \%$ & $0,1 \%$ & $-3,1 \%$ & $2,4 \%$ & $-0,9 \%$ & $2,4 \%$ & $0,8 \%$ & $0,6 \%$ \\
\hline Dec-08 & $-12,6 \%$ & $-8,5 \%$ & $-10,7 \%$ & $-5,1 \%$ & $-9,0 \%$ & $-3,4 \%$ & $-7,5 \%$ & $0,7 \%$ \\
\hline Jun-09 & $5,0 \%$ & $5,4 \%$ & $5,3 \%$ & $4,6 \%$ & $7,0 \%$ & $4,9 \%$ & $5,1 \%$ & $0,6 \%$ \\
\hline Dec-09 & $6,8 \%$ & $3,8 \%$ & $7,0 \%$ & $6,1 \%$ & $7,0 \%$ & $5,4 \%$ & $4,8 \%$ & $0,5 \%$ \\
\hline Jun-10 & $-1,5 \%$ & $0,0 \%$ & $-1,5 \%$ & $-2,6 \%$ & $-1,1 \%$ & $-1,3 \%$ & $-1,7 \%$ & $0,5 \%$ \\
\hline Dec-10 & $2,5 \%$ & $4,1 \%$ & $4,2 \%$ & $2,0 \%$ & $4,4 \%$ & $1,9 \%$ & $2,6 \%$ & $0,6 \%$ \\
\hline Jun-11 & $-2,0 \%$ & $-0,1 \%$ & $-1,2 \%$ & $-1,1 \%$ & $2,8 \%$ & $1,1 \%$ & $-0,6 \%$ & $0,6 \%$ \\
\hline Dec-11 & $-3,2 \%$ & $2,3 \%$ & $-1,2 \%$ & $-1,3 \%$ & $-2,9 \%$ & $-1,0 \%$ & $-0,3 \%$ & $0,6 \%$ \\
\hline Jun-12 & $2,0 \%$ & $2,6 \%$ & $0,2 \%$ & $1,5 \%$ & $0,0 \%$ & $-1,9 \%$ & $1,1 \%$ & $0,5 \%$ \\
\hline Dec-12 & $2,1 \%$ & $2,8 \%$ & $1,6 \%$ & $1,6 \%$ & $2,8 \%$ & $1,2 \%$ & $2,0 \%$ & $0,4 \%$ \\
\hline Média & $-0,2 \%$ & $1,9 \%$ & $0,8 \%$ & $2,3 \%$ & $2,6 \%$ & $2,0 \%$ & $2,0 \%$ & $0,9 \%$ \\
\hline $\begin{array}{l}\text { Desvio } \\
\text { Padrão }\end{array}$ & $4,5 \%$ & $4,0 \%$ & $4,1 \%$ & $4,1 \%$ & $4,1 \%$ & $4,1 \%$ & $4,0 \%$ & $0,6 \%$ \\
\hline $\begin{array}{l}\text { Estatís } \\
\text { tica t }\end{array}$ & $-0,32$ & 2,86 & 1,19 & 3,33 & 3,76 & 2,89 & 2,93 & 9,61 \\
\hline $\begin{array}{l}\text { t crítico } \\
5 \%\end{array}$ & 2,03 & - & - & 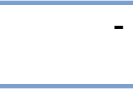 & - & - & 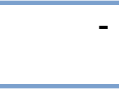 & - \\
\hline $\begin{array}{l}\text { t crítico } \\
10 \%\end{array}$ & 1,69 & - & - & - & - & & & \\
\hline
\end{tabular}

Tabela 50 - Retorno Médio Mensal por Carteira entre 1995-2012 


\begin{tabular}{|c|c|c|c|}
\hline & $\mathbf{R}_{\mathrm{m}}-\mathbf{R}_{\mathrm{f}}$ & SMB & HML \\
\hline Jun-95 & $-6,4 \%$ & $-2,0 \%$ & $4,1 \%$ \\
\hline Dec-95 & $-1,0 \%$ & $-5,7 \%$ & $2,0 \%$ \\
\hline Jun-96 & $4,6 \%$ & $-3,2 \%$ & $0,1 \%$ \\
\hline Dec-96 & $1,9 \%$ & $-2,4 \%$ & $3,9 \%$ \\
\hline Jun-97 & $8,4 \%$ & $-4,7 \%$ & $2,6 \%$ \\
\hline Dec-97 & $-5,1 \%$ & $-2,7 \%$ & $3,6 \%$ \\
\hline Jun-98 & $-3,2 \%$ & $2,6 \%$ & $2,1 \%$ \\
\hline Dec-98 & $-7,5 \%$ & $2,9 \%$ & $2,1 \%$ \\
\hline Jun-99 & $9,2 \%$ & $-5,8 \%$ & $4,3 \%$ \\
\hline Dec-99 & $7,4 \%$ & $-0,4 \%$ & $1,9 \%$ \\
\hline Jun-00 & $0,8 \%$ & $-0,7 \%$ & $0,5 \%$ \\
\hline Dec-00 & $-0,3 \%$ & $-0,7 \%$ & $1,2 \%$ \\
\hline Jun-01 & $1,2 \%$ & $-0,2 \%$ & $0,9 \%$ \\
\hline Dec-01 & $-0,6 \%$ & $-2,7 \%$ & $7,0 \%$ \\
\hline Jun-02 & $-0,1 \%$ & $-1,9 \%$ & $1,8 \%$ \\
\hline Dec-02 & $0,6 \%$ & $1,4 \%$ & $1,7 \%$ \\
\hline Jun-03 & $0,6 \%$ & $0,1 \%$ & $0,3 \%$ \\
\hline Dec-03 & $8,0 \%$ & $-3,7 \%$ & $4,6 \%$ \\
\hline Jun-04 & $-0,4 \%$ & $2,8 \%$ & $-4,7 \%$ \\
\hline Dec-04 & $4,8 \%$ & $2,0 \%$ & $-1,7 \%$ \\
\hline Jun-05 & $-1,2 \%$ & $0,0 \%$ & $0,9 \%$ \\
\hline Dec-05 & $4,3 \%$ & $-1,8 \%$ & $1,3 \%$ \\
\hline Jun-06 & $1,8 \%$ & $-0,1 \%$ & $3,4 \%$ \\
\hline Dec-06 & $2,9 \%$ & $0,4 \%$ & $-0,1 \%$ \\
\hline Jun-07 & $3,7 \%$ & $2,1 \%$ & $2,1 \%$ \\
\hline Dec-07 & $3,5 \%$ & $-3,6 \%$ & $0,4 \%$ \\
\hline Jun-08 & $0,2 \%$ & $-4,5 \%$ & $2,9 \%$ \\
\hline Dec-08 & $-8,2 \%$ & $-5,1 \%$ & $4,3 \%$ \\
\hline Jun-09 & $4,5 \%$ & $0,8 \%$ & $0,8 \%$ \\
\hline Dec-09 & $4,3 \%$ & $1,8 \%$ & $0,9 \%$ \\
\hline Jun-10 & $-2,2 \%$ & $-0,1 \%$ & $-0,4 \%$ \\
\hline Dec-10 & $2,1 \%$ & $1,1 \%$ & $-0,1 \%$ \\
\hline Jun-11 & $-1,2 \%$ & $-0,1 \%$ & $3,0 \%$ \\
\hline Dec-11 & $-0,9 \%$ & $-2,4 \%$ & $-1,6 \%$ \\
\hline Jun-12 & $0,5 \%$ & $0,0 \%$ & $-3,2 \%$ \\
\hline Dec-12 & $1,6 \%$ & $0,3 \%$ & $-0,4 \%$ \\
\hline Média & $1,1 \%$ & $-1,0 \%$ & $1,5 \%$ \\
\hline Desvio Padrão & $4,1 \%$ & $2,5 \%$ & $2,3 \%$ \\
\hline Estatística t & 1,56 & $-2,45$ & 3,81 \\
\hline t crítico 5\% & 2,03 & - & - \\
\hline t crítico $10 \%$ & 1,69 & - & - \\
\hline
\end{tabular}

Tabela 51 - Retorno Médio Mensal de cada Fator 


\begin{tabular}{|lcccccccccc|}
\hline & Cart & Cart & Cart & Cart & Cart & Cart & Cart & Cart & Cart & Cart \\
\hline 1995 & 1 & 2 & 3 & 4 & 5 & 6 & 7 & 8 & 9 & 10 \\
\hline 1996 & 0 & 2 & 1 & 1 & 2 & 3 & 2 & 4 & 3 & 2 \\
\hline 1997 & 1 & 2 & 1 & 2 & 3 & 3 & 2 & 4 & 4 & 2 \\
\hline 1998 & 1 & 2 & 1 & 3 & 4 & 3 & 2 & 4 & 4 & 3 \\
\hline 1999 & 3 & 2 & 2 & 3 & 4 & 3 & 2 & 4 & 4 & 3 \\
\hline 2000 & 5 & 3 & 2 & 3 & 4 & 3 & 2 & 5 & 4 & 3 \\
\hline 2001 & 4 & 3 & 2 & 3 & 4 & 3 & 2 & 5 & 4 & 3 \\
\hline 2002 & 4 & 3 & 2 & 3 & 4 & 3 & 2 & 5 & 4 & 3 \\
\hline 2003 & 4 & 3 & 2 & 3 & 4 & 3 & 3 & 5 & 4 & 3 \\
\hline 2004 & 5 & 3 & 3 & 3 & 4 & 3 & 3 & 5 & 4 & 3 \\
\hline 2005 & 6 & 3 & 4 & 5 & 4 & 3 & 3 & 6 & 4 & 4 \\
\hline 2006 & 6 & 5 & 5 & 5 & 5 & 4 & 3 & 7 & 5 & 4 \\
\hline 2007 & 6 & 6 & 6 & 6 & 6 & 7 & 6 & 7 & 6 & 5 \\
\hline 2008 & 7 & 7 & 7 & 7 & 7 & 7 & 7 & 7 & 7 & 7 \\
\hline 2009 & 7 & 7 & 7 & 7 & 7 & 7 & 7 & 7 & 7 & 7 \\
\hline 2010 & 7 & 7 & 7 & 7 & 7 & 7 & 7 & 7 & 7 & 7 \\
\hline 2011 & 7 & 7 & 7 & 7 & 7 & 7 & 7 & 7 & 7 & 7 \\
\hline 2012 & 7 & 7 & 7 & 7 & 7 & 7 & 7 & 7 & 7 & 7 \\
\hline Média & 4 & 4 & 4 & 4 & 5 & 4 & 4 & 6 & 5 & 4 \\
\hline Geral & & & & & & & & & & \\
\hline
\end{tabular}

Tabela 52 - Número Médio de Empresas por Ano por Carteira 1 a 10 


\begin{tabular}{|lcccccccccc|}
\hline & Cart & Cart & Cart & Cart & Cart & Cart & Cart & Cart & Cart & Cart \\
\hline 1995 & 3 & 1 & 1 & 3 & 1 & 2 & - & - & - & - \\
\hline 1996 & 3 & 1 & 1 & 3 & 1 & 2 & - & 0 & - & - \\
\hline 1997 & 3 & 1 & 1 & 3 & 1 & 2 & - & 1 & - & - \\
\hline 1998 & 4 & 1 & 1 & 3 & 1 & 2 & 0 & 0 & - & - \\
\hline 1999 & 4 & 1 & 1 & 3 & 1 & 2 & 1 & 1 & - & - \\
\hline 2000 & 4 & 1 & 1 & 3 & 1 & 2 & 1 & 1 & - & - \\
\hline 2001 & 4 & 1 & 1 & 4 & 2 & 2 & 1 & 1 & - & - \\
\hline 2002 & 4 & 1 & 1 & 4 & 2 & 2 & 1 & 1 & - & - \\
\hline 2003 & 4 & 1 & 1 & 4 & 2 & 2 & 1 & 1 & - & - \\
\hline 2004 & 4 & 1 & 1 & 4 & 3 & 2 & 1 & 1 & - & - \\
\hline 2005 & 4 & 1 & 1 & 4 & 3 & 2 & 2 & 1 & - & 0 \\
\hline 2006 & 5 & 1 & 1 & 4 & 4 & 2 & 3 & 1 & 1 & 2 \\
\hline 2007 & 6 & 3 & 4 & 6 & 5 & 5 & 5 & 3 & 5 & 5 \\
\hline 2008 & 7 & 6 & 7 & 7 & 7 & 7 & 7 & 6 & 7 & 8 \\
\hline 2009 & 7 & 7 & 7 & 7 & 7 & 7 & 7 & 7 & 7 & 9 \\
\hline 2010 & 7 & 7 & 7 & 7 & 7 & 7 & 7 & 7 & 7 & 9 \\
\hline 2011 & 7 & 7 & 7 & 6 & 7 & 7 & 7 & 7 & 7 & 9 \\
\hline 2012 & 7 & 7 & 7 & 7 & 7 & 7 & 7 & 7 & 7 & 9 \\
\hline Média & $\mathbf{5}$ & $\mathbf{3}$ & $\mathbf{3}$ & $\mathbf{4}$ & $\mathbf{3}$ & $\mathbf{4}$ & $\mathbf{3}$ & $\mathbf{3}$ & $\mathbf{2}$ & $\mathbf{3}$ \\
\hline Geral & & & & & & & & & & \\
\hline
\end{tabular}

Tabela 53 - Número Médio de Empresas por Ano por Carteira 11 a 20 


\begin{tabular}{|lcccccccccc|}
\hline & Cart 1 & Cart 2 & Cart 3 & Cart 4 & Cart 5 & Cart 6 & Cart 7 & Cart 8 & Cart 9 & Cart \\
\hline 1995 & $2,2 \%$ & $-3,6 \%$ & $4,6 \%$ & $0,8 \%$ & $0,1 \%$ & $-0,4 \%$ & $-0,4 \%$ & $1,7 \%$ & $-4,0 \%$ & $-1,9 \%$ \\
\hline 1996 & $3,1 \%$ & $2,2 \%$ & $3,4 \%$ & $4,5 \%$ & $2,7 \%$ & $1,1 \%$ & $1,0 \%$ & $4,5 \%$ & $1,8 \%$ & $5,5 \%$ \\
\hline 1997 & $2,6 \%$ & $2,2 \%$ & $2,8 \%$ & $-0,1 \%$ & $-1,7 \%$ & $2,5 \%$ & $-2,1 \%$ & $3,6 \%$ & $1,7 \%$ & $3,4 \%$ \\
\hline 1998 & $0,4 \%$ & $-1,4 \%$ & $-2,7 \%$ & $-0,2 \%$ & $-3,3 \%$ & $-3,7 \%$ & $0,0 \%$ & $-4,2 \%$ & $-2,2 \%$ & $-2,1 \%$ \\
\hline 1999 & $5,2 \%$ & $4,3 \%$ & $6,5 \%$ & $6,5 \%$ & $9,5 \%$ & $11,2 \%$ & $11,3 \%$ & $7,2 \%$ & $12,7 \%$ & $7,5 \%$ \\
\hline 2000 & $3,0 \%$ & $-2,7 \%$ & $2,1 \%$ & $1,1 \%$ & $2,7 \%$ & $1,4 \%$ & $2,4 \%$ & $0,4 \%$ & $0,5 \%$ & $-1,1 \%$ \\
\hline 2001 & $3,2 \%$ & $4,8 \%$ & $1,8 \%$ & $0,2 \%$ & $0,9 \%$ & $0,2 \%$ & $2,8 \%$ & $3,0 \%$ & $1,8 \%$ & $-1,1 \%$ \\
\hline 2002 & $0,6 \%$ & $4,4 \%$ & $0,4 \%$ & $2,1 \%$ & $0,4 \%$ & $0,3 \%$ & $-2,6 \%$ & $-1,6 \%$ & $4,0 \%$ & $0,9 \%$ \\
\hline 2003 & $3,7 \%$ & $2,1 \%$ & $3,6 \%$ & $2,9 \%$ & $8,4 \%$ & $8,5 \%$ & $6,8 \%$ & $7,9 \%$ & $5,7 \%$ & $6,0 \%$ \\
\hline 2004 & $6,2 \%$ & $1,3 \%$ & $2,0 \%$ & $3,7 \%$ & $3,7 \%$ & $4,5 \%$ & $5,8 \%$ & $7,2 \%$ & $5,4 \%$ & $1,8 \%$ \\
\hline 2005 & $1,9 \%$ & $0,5 \%$ & $1,0 \%$ & $0,8 \%$ & $2,1 \%$ & $2,3 \%$ & $1,1 \%$ & $3,2 \%$ & $2,0 \%$ & $3,2 \%$ \\
\hline 2006 & $2,3 \%$ & $4,4 \%$ & $2,3 \%$ & $1,2 \%$ & $1,6 \%$ & $1,6 \%$ & $2,8 \%$ & $2,4 \%$ & $3,0 \%$ & $4,1 \%$ \\
\hline 2007 & $2,1 \%$ & $2,5 \%$ & $0,4 \%$ & $2,6 \%$ & $1,9 \%$ & $1,6 \%$ & $3,3 \%$ & $11,2 \%$ & $3,2 \%$ & $2,0 \%$ \\
\hline 2008 & $-1,2 \%$ & $-1,6 \%$ & $-2,0 \%$ & $-2,5 \%$ & $-2,8 \%$ & $-4,1 \%$ & $-5,5 \%$ & $-1,2 \%$ & $-5,2 \%$ & $-3,8 \%$ \\
\hline 2009 & $3,9 \%$ & $3,5 \%$ & $6,3 \%$ & $5,7 \%$ & $4,6 \%$ & $6,2 \%$ & $5,8 \%$ & $6,0 \%$ & $7,6 \%$ & $5,9 \%$ \\
\hline 2010 & $2,5 \%$ & $1,8 \%$ & $2,0 \%$ & $1,6 \%$ & $1,7 \%$ & $1,9 \%$ & $-0,2 \%$ & $2,4 \%$ & $0,8 \%$ & $1,1 \%$ \\
\hline 2011 & $2,0 \%$ & $0,9 \%$ & $1,0 \%$ & $-1,0 \%$ & $-0,3 \%$ & $-0,7 \%$ & $-1,5 \%$ & $0,7 \%$ & $-4,5 \%$ & $-1,3 \%$ \\
\hline 2012 & $1,8 \%$ & $0,9 \%$ & $4,0 \%$ & $0,9 \%$ & $3,4 \%$ & $2,8 \%$ & $0,6 \%$ & $-0,8 \%$ & $0,9 \%$ & $-0,3 \%$ \\
\hline Média & $\mathbf{2 , 5 \%}$ & $\mathbf{1 , 5} \%$ & $\mathbf{2 , 2} \%$ & $\mathbf{1 , 7} \%$ & $\mathbf{2 , 0} \%$ & $\mathbf{2 , 1} \%$ & $\mathbf{1 , 7} \%$ & $\mathbf{3 , 0} \%$ & $\mathbf{2 , 0} \%$ & $\mathbf{1 , 7 \%}$ \\
\hline Desvio & $\mathbf{7 , 1 \%}$ & $\mathbf{7 , 8 \%}$ & $\mathbf{8 , 0 \%}$ & $\mathbf{8 , 2 \%}$ & $\mathbf{8 , 5 \%}$ & $\mathbf{8 , 7 \%}$ & $\mathbf{9 , 8} \%$ & $\mathbf{1 4 , 0 \%}$ & $\mathbf{9 , 8 \%}$ & $\mathbf{1 0 , 0 \%}$ \\
\hline Padrão & & & & & & & & & & \\
\hline
\end{tabular}

Tabela 54 - Retorno Médio Mensal por Ano por Carteira 1 a 10 


\begin{tabular}{|c|c|c|c|c|c|c|c|c|c|c|}
\hline & $\begin{array}{r}\text { Cart } \\
11\end{array}$ & $\begin{array}{r}\text { Cart } \\
12\end{array}$ & $\begin{array}{r}\text { Cart } \\
13\end{array}$ & $\begin{array}{r}\text { Cart } \\
14\end{array}$ & $\begin{array}{r}\text { Cart } \\
15\end{array}$ & $\begin{array}{r}\text { Cart } \\
16\end{array}$ & $\begin{array}{r}\text { Cart } \\
17\end{array}$ & $\begin{array}{r}\text { Cart } \\
18\end{array}$ & $\begin{array}{r}\text { Cart } \\
19\end{array}$ & $\begin{array}{r}\text { Cart } \\
20\end{array}$ \\
\hline 1995 & $-1,4 \%$ & $0,3 \%$ & $0,7 \%$ & $-1,2 \%$ & $-0,9 \%$ & $-5,5 \%$ & - & - & - & - \\
\hline 1996 & $4,7 \%$ & $3,6 \%$ & $3,3 \%$ & $2,7 \%$ & $6,2 \%$ & $7,4 \%$ & - & $-10,3 \%$ & - & - \\
\hline 1997 & $2,3 \%$ & $4,4 \%$ & $4,5 \%$ & $-1,6 \%$ & $5,3 \%$ & $5,1 \%$ & - & $-3,0 \%$ & - & - \\
\hline 1998 & $-2,1 \%$ & $-3,4 \%$ & $-3,9 \%$ & $-0,9 \%$ & $-2,6 \%$ & $-2,8 \%$ & $23,1 \%$ & $-4,0 \%$ & - & - \\
\hline 1999 & $5,3 \%$ & $5,8 \%$ & $6,0 \%$ & $11,4 \%$ & $11,5 \%$ & $17,6 \%$ & $13,2 \%$ & $36,1 \%$ & - & - \\
\hline 2000 & $-2,1 \%$ & $-0,8 \%$ & $0,0 \%$ & $1,7 \%$ & $1,3 \%$ & $0,4 \%$ & $2,5 \%$ & $-2,1 \%$ & - & - \\
\hline 2001 & $0,5 \%$ & $-0,4 \%$ & $0,0 \%$ & $0,7 \%$ & $-0,3 \%$ & $2,1 \%$ & $-1,3 \%$ & $-6,2 \%$ & - & - \\
\hline 2002 & $-1,9 \%$ & $-1,0 \%$ & $-1,1 \%$ & $0,5 \%$ & $-0,9 \%$ & $3,0 \%$ & $-3,0 \%$ & $-16,2 \%$ & - & - \\
\hline 2003 & $3,9 \%$ & $6,6 \%$ & $7,6 \%$ & $9,6 \%$ & $6,2 \%$ & $6,4 \%$ & $5,4 \%$ & $10,0 \%$ & - & - \\
\hline 2004 & $5,1 \%$ & $-0,2 \%$ & $-0,5 \%$ & $3,4 \%$ & $3,5 \%$ & $3,7 \%$ & $2,8 \%$ & $-2,3 \%$ & - & - \\
\hline 2005 & $-0,9 \%$ & $0,8 \%$ & $0,7 \%$ & $3,0 \%$ & $4,3 \%$ & $3,8 \%$ & $7,3 \%$ & $8,9 \%$ & - & $30,9 \%$ \\
\hline 2006 & $4,3 \%$ & $2,2 \%$ & $3,3 \%$ & $5,4 \%$ & $3,4 \%$ & $3,1 \%$ & $6,5 \%$ & $3,7 \%$ & $2,9 \%$ & $2,0 \%$ \\
\hline 2007 & $3,2 \%$ & $-1,4 \%$ & $1,9 \%$ & $5,0 \%$ & $3,6 \%$ & $1,2 \%$ & $0,5 \%$ & $1,3 \%$ & $-0,6 \%$ & $4,8 \%$ \\
\hline 2008 & $-2,4 \%$ & $-4,7 \%$ & $-7,1 \%$ & $-7,2 \%$ & $-8,0 \%$ & $-4,3 \%$ & $-7,6 \%$ & $-9,4 \%$ & $-10,0 \%$ & $-7,6 \%$ \\
\hline 2009 & $6,3 \%$ & $7,9 \%$ & $8,4 \%$ & $8,9 \%$ & $8,3 \%$ & $7,2 \%$ & $9,0 \%$ & $9,3 \%$ & $11,5 \%$ & $14,4 \%$ \\
\hline 2010 & $1,8 \%$ & $1,3 \%$ & $3,7 \%$ & $2,0 \%$ & $1,2 \%$ & $-0,5 \%$ & $1,4 \%$ & $1,2 \%$ & $-0,6 \%$ & $1,4 \%$ \\
\hline 2011 & $-0,3 \%$ & $-2,2 \%$ & $-1,4 \%$ & $-1,7 \%$ & $-2,9 \%$ & $-1,0 \%$ & $-1,6 \%$ & $-0,1 \%$ & $-1,9 \%$ & $-3,1 \%$ \\
\hline 2012 & $2,5 \%$ & $2,6 \%$ & $1,8 \%$ & $1,5 \%$ & $1,9 \%$ & $1,0 \%$ & $1,6 \%$ & $1,4 \%$ & $2,4 \%$ & $-0,9 \%$ \\
\hline Média & $1,6 \%$ & $1,2 \%$ & $1,5 \%$ & $2,4 \%$ & $2,3 \%$ & $2,7 \%$ & $3,0 \%$ & $1,3 \%$ & $0,5 \%$ & $3,2 \%$ \\
\hline $\begin{array}{l}\text { Desvio } \\
\text { Padrão }\end{array}$ & $10,8 \%$ & $12,7 \%$ & $13,6 \%$ & $11,9 \%$ & $11,7 \%$ & $12,5 \%$ & $16,7 \%$ & $21,2 \%$ & $12,6 \%$ & $15,9 \%$ \\
\hline
\end{tabular}

Tabela 55 - Retorno Médio Mensal por Ano por Carteira 11 a 20 


\begin{tabular}{|lcccccc|}
\hline & Câmbio & Selic & PIM & IGP-M & Ibovespa & Poupança \\
\hline 1995 & $1,1 \%$ & $-1,5 \%$ & $-0,7 \%$ & $1,2 \%$ & $0,6 \%$ & $2,8 \%$ \\
\hline 1996 & $0,6 \%$ & $-1,2 \%$ & $0,5 \%$ & $0,7 \%$ & $4,3 \%$ & $1,3 \%$ \\
\hline 1997 & $0,6 \%$ & $1,5 \%$ & $-0,3 \%$ & $0,6 \%$ & $3,9 \%$ & $1,3 \%$ \\
\hline 1998 & $0,7 \%$ & $-0,8 \%$ & $-0,2 \%$ & $0,1 \%$ & $-1,8 \%$ & $1,1 \%$ \\
\hline 1999 & $4,1 \%$ & $-1,0 \%$ & $0,7 \%$ & $1,5 \%$ & $8,5 \%$ & $1,0 \%$ \\
\hline 2000 & $0,5 \%$ & $-0,5 \%$ & $0,8 \%$ & $0,8 \%$ & $-0,6 \%$ & $0,7 \%$ \\
\hline 2001 & $1,6 \%$ & $0,2 \%$ & $-0,5 \%$ & $0,8 \%$ & $-0,5 \%$ & $0,7 \%$ \\
\hline 2002 & $3,8 \%$ & $0,4 \%$ & $0,5 \%$ & $1,9 \%$ & $-1,0 \%$ & $0,7 \%$ \\
\hline 2003 & $-1,7 \%$ & $-0,4 \%$ & $0,3 \%$ & $0,7 \%$ & $6,0 \%$ & $0,9 \%$ \\
\hline 2004 & $-0,6 \%$ & $0,1 \%$ & $0,6 \%$ & $1,0 \%$ & $1,5 \%$ & $0,7 \%$ \\
\hline 2005 & $-1,4 \%$ & $0,0 \%$ & $0,3 \%$ & $0,1 \%$ & $2,3 \%$ & $0,7 \%$ \\
\hline 2006 & $-0,5 \%$ & $-0,6 \%$ & $0,2 \%$ & $0,3 \%$ & $2,6 \%$ & $0,7 \%$ \\
\hline 2007 & $-1,5 \%$ & $-0,2 \%$ & $0,5 \%$ & $0,6 \%$ & $3,1 \%$ & $0,6 \%$ \\
\hline 2008 & $2,7 \%$ & $0,3 \%$ & $-1,4 \%$ & $0,8 \%$ & $-3,8 \%$ & $0,6 \%$ \\
\hline 2009 & $-2,5 \%$ & $-0,4 \%$ & $1,5 \%$ & $-0,1 \%$ & $5,3 \%$ & $0,6 \%$ \\
\hline 2010 & $-0,3 \%$ & $0,2 \%$ & $0,3 \%$ & $0,9 \%$ & $0,2 \%$ & $0,6 \%$ \\
\hline 2011 & $0,7 \%$ & $0,0 \%$ & $0,0 \%$ & $0,4 \%$ & $-1,5 \%$ & $0,6 \%$ \\
\hline 2012 & $1,1 \%$ & $-0,4 \%$ & $-0,1 \%$ & $0,6 \%$ & $0,8 \%$ & $0,5 \%$ \\
\hline Média & $\mathbf{0 , 5} \%$ & $-\mathbf{0 , 2} \%$ & $\mathbf{0 , 1} \%$ & $\mathbf{0 , 7} \%$ & $\mathbf{1 , 7} \%$ & $\mathbf{0 , 9} \%$ \\
\hline Desvio & $\mathbf{4 , 3} \%$ & $\mathbf{3 , 5} \%$ & $\mathbf{2 , 1} \%$ & $\mathbf{6 , 7} \%$ & $\mathbf{9 , 1} \%$ & $\mathbf{0 , 6} \%$ \\
\hline Padrão & & & & & & \\
\hline
\end{tabular}

Tabela 56 - Variação Mensal Média das Variáveis Explicativas por Ano 


\section{Estatística JB}

\section{Cart 1}

Cart 2

Cart 3

Cart 4

Cart 5

Cart 6

Cart 7

Cart 8

Cart 9

Cart 10

Cart 11

Cart 12

Cart 13

Cart 14

Cart 15

Cart 16

Cart 17

Cart 18

Cart 19

Cart 20
Probabilidade

0,00

0,00

0,00

0,00

0,00

0,00

0,00

0,00

0,00

0,00

0,00

0,00

0,00

0,00

0,00

0,00

0,00

0,00

0,00

0,00
№ Observações

195

214

213

211

213

214

213

214

214

213

213

214

213

213

214

213

169

176

80

87

Tabela 57 - Teste Jarque-Bera para Modelo APT Unificado ao CAPM pelo Método dos Mínimos Quadrados Ponderado 


\begin{tabular}{|c|c|c|c|}
\hline & White & Probabilidade & № Observações \\
\hline Cart 1 & 177,2 & 0,00 & 195 \\
\hline Cart 2 & 145,4 & 0,00 & 214 \\
\hline Cart 3 & 179,9 & 0,00 & 213 \\
\hline Cart 4 & 106,2 & 0,00 & 211 \\
\hline Cart 5 & 114,0 & 0,00 & 213 \\
\hline Cart 6 & 132,4 & 0,00 & 214 \\
\hline Cart 7 & 185,7 & 0,00 & 213 \\
\hline Cart 8 & 19,4 & 0,56 & 214 \\
\hline Cart 9 & 151,3 & 0,00 & 214 \\
\hline Cart 10 & 154,3 & 0,00 & 213 \\
\hline Cart 11 & 109,8 & 0,00 & 213 \\
\hline Cart 12 & 173,6 & 0,00 & 214 \\
\hline Cart 13 & 173,2 & 0,00 & 213 \\
\hline Cart 14 & 174,8 & 0,00 & 213 \\
\hline Cart 15 & 182,9 & 0,00 & 214 \\
\hline Cart 16 & 145,3 & 0,00 & 213 \\
\hline Cart 17 & 156,3 & 0,00 & 169 \\
\hline Cart 18 & 163,6 & 0,00 & 176 \\
\hline Cart 19 & 59,3 & 0,00 & 80 \\
\hline Cart 20 & 71,3 & 0,00 & 87 \\
\hline
\end{tabular}

Tabela 58 - Teste White para Modelo APT Unificado ao CAPM pelo Método dos Mínimos Quadrados Ponderado 


\begin{tabular}{|l|c|c|c|}
\hline Variação $\mathbf{R}^{2}$ & $\begin{array}{c}\text { Variação } \mathbf{R}^{2} \\
\text { Ajustado }\end{array}$ & $\begin{array}{c}\text { Variação } \boldsymbol{\beta}_{2} \text { (CAPM) - } \boldsymbol{\beta}_{6} \\
\text { Residuo lbovespa }\end{array}$ \\
\hline Cart 1 & $-0,09$ & $-0,08$ & 0,08 \\
\hline Cart 2 & $-0,02$ & $-0,01$ & $-0,03$ \\
\hline Cart 3 & $-0,02$ & $-0,01$ & $-0,02$ \\
\hline Cart 4 & $-0,01$ & 0,00 & 0,02 \\
\hline Cart 5 & $-0,04$ & $-0,03$ & $-0,04$ \\
\hline Cart 6 & 0,00 & 0,01 & $-0,03$ \\
\hline Cart 7 & $-0,02$ & $-0,02$ & 0,09 \\
\hline Cart 8 & 0,00 & 0,01 & 0,02 \\
\hline Cart 9 & $-0,01$ & 0,00 & $-0,01$ \\
\hline Cart 10 & $-0,04$ & $-0,03$ & 0,11 \\
\hline Cart 11 & $-0,02$ & $-0,01$ & 0,03 \\
\hline Cart 12 & $-0,02$ & $-0,01$ & 0,06 \\
\hline Cart 13 & $-0,03$ & $-0,02$ & 0,04 \\
\hline Cart 14 & $-0,02$ & $-0,02$ & 0,08 \\
\hline Cart 15 & $-0,03$ & $-0,02$ & 0,11 \\
\hline Cart 16 & $-0,03$ & $-0,02$ & 0,08 \\
\hline Cart 17 & $-0,01$ & 0,00 & $-0,04$ \\
\hline Cart 18 & $-0,01$ & 0,00 & 0,04 \\
\hline Cart 19 & $-0,04$ & $-0,01$ & 0,12 \\
\hline Cart 20 & $-0,03$ & $-0,02$ & 0,23 \\
\hline Média & $-\mathbf{0 , 0 2}$ & $-\mathbf{0 , 0 1}$ & $\mathbf{0 , 0 5}$ \\
\hline
\end{tabular}

Tabela 59 - Comparação dos Modelos CAPM e APT Unificado ao CAPM 